UNIVERSIDADE DE SÃO PAULO

CAROLINE PEREIRA KATSUMATA

Degradação de fármacos em meio aquoso por meio de fotólise e peroxidação fotoassistida 
CAROLINE PEREIRA KATSUMATA

DEGRADAÇÃO DE FÁRMACOS EM MEIO AQUOSO POR MEIO DE FOTÓLISE E PEROXIDAÇÃO FOTOASSISTIDA

Dissertação apresentada à Escola Politécnica da Universidade de São Paulo para obtenção do

Título de Mestre em Engenharia 
CAROLINE PEREIRA KATSUMATA

\section{DEGRADAÇÃO DE FÁRMACOS EM MEIO AQUOSO POR MEIO DE FOTÓLISE E PEROXIDAÇÃO FOTOASSISTIDA}

Dissertação apresentada à Escola Politécnica da Universidade de São Paulo para obtenção do

Título de Mestre em Engenharia

Área de concentração: Engenharia Química

Orientador: Prof. Dr. Antonio Carlos Silva Costa Teixeira 
Autorizo a reprodução e divulgação total ou parcial deste trabalho, por qualquer meio convencional ou eletrônico, para fins de estudo e pesquisa, desde que citada a fonte.

Este exemplar foi revisado e corrigido em relação à versão original, sob responsabilidade única do autor e com a anuência de seu orientador.

São Paulo, de setembro de 2014.

Assinatura do autor

Assinatura do orientador

Ficha Catalográfica

Katsumata, Caroline Pereira

Degradação de fármacos em meio aquoso por meio de foto-

lise e peroxidação fotoassistida / C.P. Katsumata. -- versão corr.

-- São Paulo, 2014.

$116 \mathrm{p}$.

Dissertação (Mestrado) - Escola Politécnica da Universidade de São Paulo. Departamento de Engenharia Química.

1.Fármacos 2.Fotólise 3.UV/H2O2 4.Micropoluentes emergentes I.Universidade de São Paulo. Escola Politécnica. Departamento de Engenharia Química II.t. 
Dedico esse trabalho a Deus que me deu o dom da vida, aos meus pais Genival e Terezinha pelo amor, incentivo e carinho, ao meu marido Felipe pela paciência, compreensão e companheirismo, ao meu irmão Rafael pela imensa saudade. 


\section{AGRADECIMENTOS}

Agradeço a Deus que me proporciona grandes oportunidades na vida e por estar sempre ao meu lado.

Agradeço a Santa Rita de Cássia que sempre intercede por mim.

Ao meu orientador Antonio Carlos, por sempre me ensinar e pela sua dedicação para realização desse trabalho. Obrigada por todas as reuniões, aprendizados e pela oportunidade em realizar esse mestrado, sem você esse trabalho não seria o mesmo.

Aos meus pais, Genival e Terezinha, sem vocês eu nada seria, obrigada pela educação, incentivo e apoio em todos os momentos. Amo vocês.

Ao meu querido esposo Felipe, pelo seu amor. Obrigada por tudo.

Ao meu irmão Rafael (in memoriam), por todos os momentos que passamos juntos.

À minha grande amiga que conheci ao ingresso desse mestrado, Marcela, obrigada pelas ajudas e por sua amizade.

À Christiane também grande amiga obrigada por sua amizade e por todos os almoços e cafés.

À Dr. Ana Paula Batista pela grande ajuda nesse trabalho, obrigada por todos os ensinamentos e pela amizade.

À Katia e o Paulo pela contribuição intelectual e aos técnicos de laboratório Rodrigo e Joel.

A todos os amigos do bem que me ajudaram e torceram pela finalização desse trabalho.

Ao Luiz Franco, pela ajuda na matéria de Fundamentos a Engenharia Química.

Ao Laboratório de Fotodinâmica Molecular (Instituto de Química da USP), pela realização dos espectros de fosforescência, em especial ao Volnir.

À Vanessa e Mainah pela ajuda com análises de Microtox.

À Escola Politécnica - USP- Engenharia Química pela oportunidade.

$\mathrm{E}$ ao $\mathrm{CNPq}$ pela bolsa concedida.

Obrigada a todos. 
"A vida é como andar de bicicleta, para ter equilíbrio você tem que se manter em movimento" Albert Einstein 


\section{RESUMO}

Estudou-se a degradação dos fármacos acetaminofeno (ACT), atenolol (ATL), bezafibrato (BZF), diclofenaco (DIC) e ibuprofeno (IBU) em solução aquosa através de fotólise e peroxidação fotoassistida. As soluções foram caracterizadas antes e após os processos de fotólise e UV/ $\mathrm{H}_{2} \mathrm{O}_{2}$ quanto à degradação dos fármacos e à remoção de carbono orgânico total. Também foi avaliada a degradação por fotólise dos fármacos em uma matriz real (efluente de estação de tratamento de esgoto, ETE). Os experimentos foram realizados em um reator anular com lâmpada de vapor de mercúrio de baixa pressão de 36 ou $75 \mathrm{~W}$ e concentrações iniciais de 5 ou $20 \mathrm{mg} \mathrm{L}^{-1}$ de cada fármaco, em mistura e individualmente, no caso dos estudos de fotólise UV. Os resultados mostraram absorção de radiação UV $(254 \mathrm{~nm})$ pelo ACT superior à dos demais fármacos $\left(\varepsilon=8990 \mathrm{~L} \mathrm{~mol}^{-1} \mathrm{~cm}^{-1}\right)$, e comparativamente inferior para o ATL e IBU ( $\varepsilon=725$ e $1080 \mathrm{~L} \mathrm{~mol}^{-1} \mathrm{~cm}^{-1}$, respectivamente). Não houve degradação por hidrólise após $24 \mathrm{~h}$ em qualquer $\mathrm{pH}$. O DIC e o BZF degradaram-se mais rapidamente, independentemente do processo fotoassistido. As concentrações de DIC nos experimentos realizados com $[\mathrm{DIC}]_{0}=5 \mathrm{mg} \mathrm{L}^{-1}$ ficaram abaixo do limite de detecção após 20 minutos de irradiação. Na presença de $\mathrm{H}_{2} \mathrm{O}_{2}$ as concentrações dos contaminantes ficaram abaixo do limite de detecção após 50 minutos para concentrações iniciais de 20 $\mathrm{mg} \mathrm{L}^{-1}$. Os resultados dos ensaios de toxicidade nos experimentos realizados com a mistura de fármacos mostraram valores de $\mathrm{CE}_{50}$ inferiores aos valores obtidos nos experimentos com a solução dos fármacos individuais. Os valores de TOC apresentaram redução de até $13 \%$ ao final de 120 minutos, o que comprova a persistência dos produtos de degradação. A degradação por fotólise UV do ATL e do ACT ocorreu mesmo em efluente de ETE, sendo a eficiência desse processo semelhante à obtida usando-se água como matriz. Esses resultados são úteis para compreensão da remediação de águas e efluentes contendo esses contaminantes emergentes por meio de processos foto-oxidativos.

Palavras-Chaves: Fotólise. Peroxidação fotoassistida. Processo Oxidativos Avançados. 


\begin{abstract}
This work aimed at studying the degradation of the following pharmaceutical compounds in aqueous solution by means of photolysis and photoassisted peroxidation: acetaminophen (ACT), atenolol (ATL), bezafibrate (BZF), diclofenac (DIC), and ibuprofen (IBU). Solutions were characterized before and after photolysis and $\mathrm{UV} / \mathrm{H}_{2} \mathrm{O}_{2}$ processes regarding drug degradation and total organic carbon removal. In addition, the photolysis of the pharmaceutical compounds was investigated in a real wastewater matrix (effluent from a sewage treatment plant, STP). The experiments were carried out in an annular photochemical reactor equipped with a low pressure mercury lamp (36 or $75 \mathrm{~W}$ ) and initial solution concentrations of 5 and $20 \mathrm{mg} \mathrm{L}^{-1}$ of each drug, for the mixture and individual compounds, in the case of UV photolysis studies. The results revealed higher absorption of UV radiation $(254 \mathrm{~nm}$ ) by ACT than that shown by the other pharmaceutical compounds $\left(\varepsilon=8990 \mathrm{~L} \mathrm{~mol}^{-1} \mathrm{~cm}^{-1}\right)$, and comparatively lower for ATL and IBU $\left(\varepsilon=725\right.$ and $1080 \mathrm{~L} \mathrm{~mol}^{-1} \mathrm{~cm}^{-1}$, respectively). No hydrolysis was observed after 24 hours at any $\mathrm{pH}$. The degradation of DIC and BZF was faster, regardless the photoassisted process. DIC concentrations in the experiments carried out with $[D I C]_{0}=5$ $\mathrm{mg} \mathrm{L}^{-1}$ were below the detection limit after 20 minutes of irradiation. In the presence of $\mathrm{H}_{2} \mathrm{O}_{2}$, contaminant concentrations were below the detection limit after 50 minutes of irradiation for initial concentrations of $20 \mathrm{mg} \mathrm{L}^{-1}$. The results of the toxicity assays for the experiments carried out with the mixture of pharmaceutical compounds showed $C_{50}$ values lower than those obtained with the compounds individually. TOC removals up to $13 \%$ after 120 minutes were obtained, therefore confirming the formation of persistent degradation products. In the case of ATL and ACT, UV degradation occurred even in STP wastewater and the efficiency of the process was similar to that obtained with pure water. The results obtained in this study are useful to understand the treatment of water and wastewater contaminated with this class of emerging pollutants by means of photooxidative process.
\end{abstract}

Keywords: Photolysis. Peroxidation photo-assisted. Degradation. Advanced Oxidation Process. 


\section{LISTA DE TABELAS}

Tabela 1 - Principais classes de poluentes orgânicos emergentes. .............................22

Tabela 2 - Fármacos identificados na Represa Billings..........................................24

Tabela 3 - Concentrações médias de fármacos detectados em ambientes aquáticos ...25

Tabela 4 - Principais tipos de processos oxidativos avançados..................................31

Tabela 5 - Subprodutos de degradação do ibuprofeno por fotólise. Adaptado de Szabó

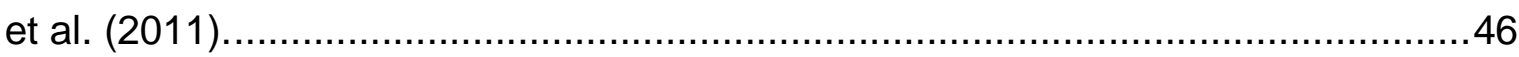

Tabela 6 - Número CAS, pureza, massa molar, fórmulas molecular e estrutural dos

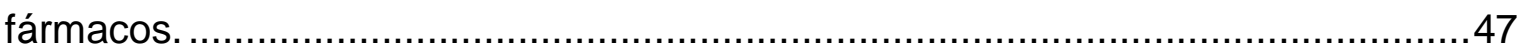

Tabela 7 - Gradiente de eluição para a fase móvel água-metanol empregado na

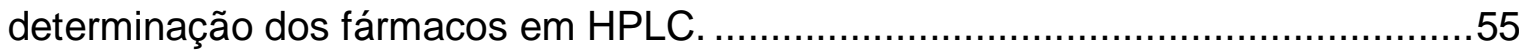

Tabela 8 - Tempo de retenção e comprimento de onda mais indicado para análise. ....55

Tabela 9 - Equações das curvas analíticas, coeficientes de determinação $\left(R^{2}\right)$, limite de detecção (LD) e de quantificação (LQ) para os contaminantes estudados. .............56

Tabela 10 - Resultados das medidas de pka para os fármacos estudados. .................63

Tabela 11: Modelos de decaimento da concentração dos fármacos conforme a Figura 27 (mistura dos fármacos), coeficiente de determinação $\left(R^{2}\right)$, constante de velocidade $(k)$, tempo de meia vida (t 1/2) e porcentagem de remoção em 120 min dos experimentos: (A) $5 \mathrm{mg} \mathrm{L}^{-1}$ e $36 \mathrm{~W}$; (B) $20 \mathrm{mg} \mathrm{L}^{-1}$ e $36 \mathrm{~W}$; (C) $5 \mathrm{mg} \mathrm{L}^{-1}$ e $75 \mathrm{~W}$; (D) $20 \mathrm{mg} \mathrm{L}^{-1}$ e $75 \mathrm{~W}$.

Tabela 12: Modelos de decaimento da concentração dos fármacos conforme a Figura 28 (fármacos isoladamente), coeficiente de determinação $\left(R^{2}\right)$, constante de velocidade $(\mathrm{k})$, tempo de meia vida (t 1/2) e porcentagem de remoção em $120 \mathrm{~min}$ dos experimentos: (A) $5 \mathrm{mg} \mathrm{L}^{-1}$ e $75 \mathrm{~W}$; (B) $20 \mathrm{mg} \mathrm{L}^{-1}$ e $75 \mathrm{~W}$.

Tabela 13 - Valores de CE50 (\%) nos tempos de 0, 15, 45 e 120 min de degradação por fotólise da solução de mistura de fármacos. ${ }^{a}$

Tabela 14 - Valores de $\mathrm{CE}_{50}$ (\%) no tempo inicial e tempo final de degradação por fotólise (60 min para diclofenaco e 120 para os demais) da solução de fármacos individualmente. ${ }^{a}$ 


\section{LISTA DE FIGURAS}

Figura 1 - Diagrama esquemático das rotas de fármacos. Adaptado de Lapworth et al. (2012). 29

Figura 2 - Fórmula estrutural do acetaminofeno (ACT) ……...................................34

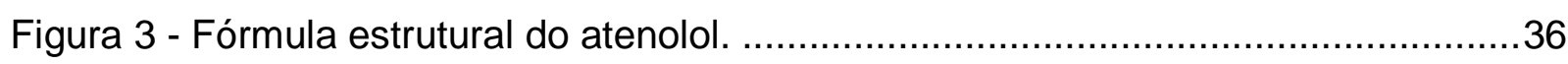

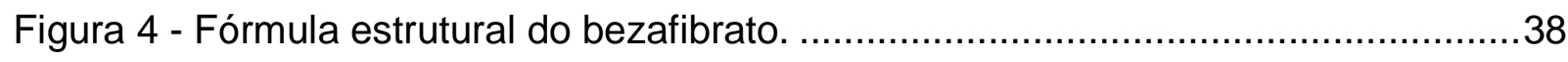

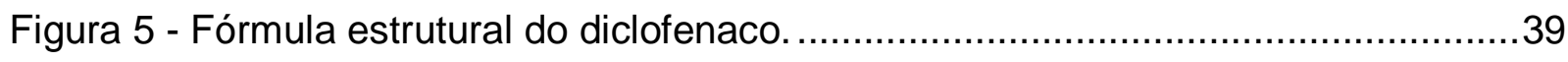

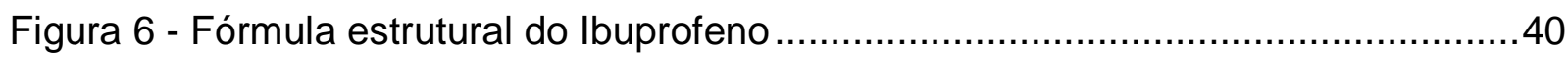

Figura 7 - Degradação do ACT com a formação de 1-(2-amino-5-hidroxifenil)-etanona

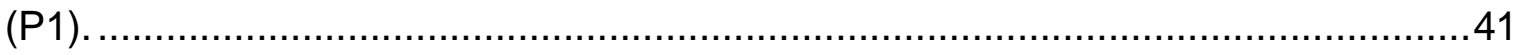

Figura 8 - Via de mecanismo da fotólise do ATL. Fonte: Andrisano et al. (1999)...........42

Figura 9 - Via de degradação do BZF por processo UV/H2O2. Adaptado de Yuan et al. (2012). 43

Figura 10 - Mecanismo inicial de degradação do diclofenaco via fotólise. Fonte: Pinto (2003). 44

Figura 11 - Via de formação de dímero proposto. Adaptado de Keen et al. (2013). ......45 Figura 12 - Espectro da lâmpada de mercúrio de baixa pressão (LP). Fonte: fabricante.

Figura 13 - Foto do equipamento experimental utilizado no trabalho. 49

Figura 14 - Esquema do equipamento experimental empregado no trabalho. Adaptado de BASTOS (2012).

Figura 15 - Resultado do experimento actinométrico empregando ferrioxalato de potássio $0,15 \mathrm{~mol} \mathrm{~L}^{-1}$ no reator irradiado com lâmpada $\mathrm{LP} \mathrm{Hg}$ de $75 \mathrm{~W}$. 59

Figura 16 - Resultado do experimento actinométrico empregando ferrioxalato de potássio $0,15 \mathrm{~mol} \mathrm{~L}^{-1}$ no reator irradiado com lâmpada LP Hg de $36 \mathrm{~W}$ 59

Figura 17 - Resultados dos experimentos de hidrólise dos fármacos estudados. (a) Hidrólise da mistura dos fármacos em pH 3. (b) Hidrólise dos fármacos individuais em pH 3. (c) Hidrólise da mistura dos fármacos em pH 7. (d) Hidrólise dos fármacos individuais em pH 7. (e) Hidrólise da mistura dos fármacos em pH 9. (f) Hidrólise dos fármacos individuais em pH 9. A concentração indicada refere-se à 
concentração inicial nominal de $5 \mathrm{mg} \mathrm{L}^{-1}$ de cada fármaco na solução aquosa.

$(\rightarrow \mathrm{ATL} \rightarrow \mathrm{ACT} \rightarrow \mathrm{BZF} \rightarrow \mathrm{DIC}=\mathrm{IBU}$

Figura 18 - Fórmulas estruturais das formas neutra e desprotonada e distribuição das

formas em equilíbrio em função do $\mathrm{pH}$ para o acetaminofeno (ACT).

.64

Figura 19 - Fórmulas estruturais das formas neutra, protonada e desprotonada e

distribuição das formas em equilíbrio em função do $\mathrm{pH}$ para o atenolol (ATL)

Figura 20 - Fórmulas estruturais das formas neutra, protonada e desprotonada e

distribuição das formas em equilíbrio em função do pH para o bezafibrato (BZF). .66

Figura 21 - Fórmulas estruturais das formas neutra, protonada e desprotonada e

distribuição das formas em equilíbrio em função do $\mathrm{pH}$ para o diclofenaco (DIC)...67

Figura 22 - Fórmulas estruturais das formas neutra, protonada e desprotonada e

distribuição das formas em equilíbrio em função do pH para o ibuprofeno (IBU). ...68

Figura 23 - Coeficiente de absorção molar dos fármacos estudados em função do

comprimento de onda em pH 2, 5 e 12. ( - pH $2-\mathrm{pH} 5-\mathrm{pH}$ 12) ...................70

Figura 24 - Coeficientes de absorção molar dos fármacos estudados em $254 \mathrm{~nm}$ a

diferentes $\mathrm{pH} . \quad( \pm \mathrm{pH} 2 \approx \mathrm{pH} 5=\mathrm{pH} 12)$. .72

Figura 25 - Espectros de excitação (absorção) e de emissão (fluorescência) dos

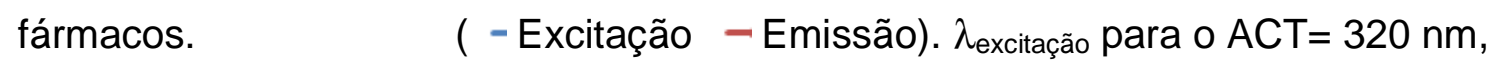

$\lambda_{\text {excitação }}$ para $\circ \mathrm{ATL}=300 \mathrm{~nm}, \lambda_{\text {excitação }}$ para $\circ \mathrm{BZF}=305 \mathrm{~nm}, \lambda_{\text {excitação }}$ para $\circ \mathrm{DIC}=$

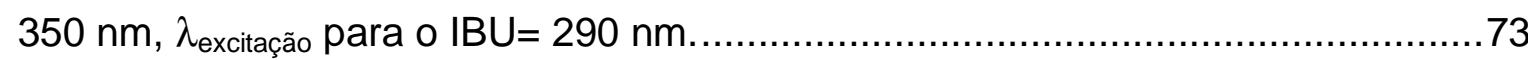

Figura 25 (cont.) - Espectros de excitação (absorção) e de emissão (fluorescência) dos

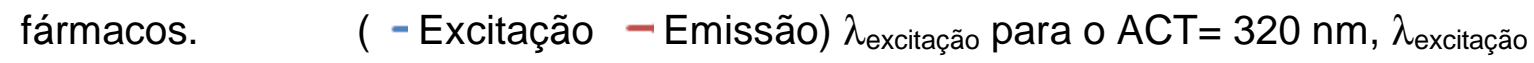

para $\circ \mathrm{ATL}=300 \mathrm{~nm}, \lambda_{\text {excitação }}$ para $\circ \mathrm{BZF}=305 \mathrm{~nm}, \lambda_{\text {excitaçăo }}$ para $\circ \mathrm{DIC}=350 \mathrm{~nm}$,

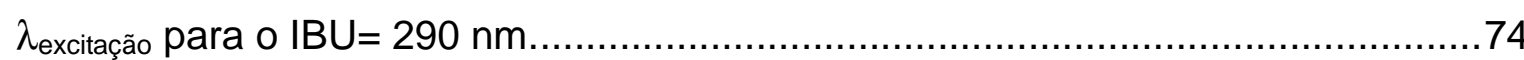

Figura 25 (cont.) - Espectros de excitação (absorção) e de emissão (fluorescência) dos

fármacos. ( - Excitação - Emissão) $\lambda_{\text {excitação }}$ para o $A C T=320 \mathrm{~nm}, \lambda_{\text {excitação }}$

para o $A T L=300 \mathrm{~nm}, \lambda_{\text {excitação }}$ para o $B Z F=305 \mathrm{~nm}, \lambda_{\text {excitação }}$ para o $\mathrm{DIC}=350 \mathrm{~nm}$,

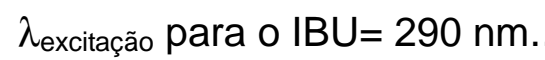

Figura 25 (cont.) - Espectros de excitação (absorção) e de emissão (fluorescência) dos fármacos. ( - Excitação - Emissão) $\lambda_{\text {excitação }}$ para o $A C T=320 \mathrm{~nm}, \lambda_{\text {excitação }}$ 
para o $A T L=300 \mathrm{~nm}, \lambda_{\text {excitação }}$ para o $B Z F=305 \mathrm{~nm}, \lambda_{\text {excitação }}$ para o $\mathrm{DIC}=350 \mathrm{~nm}$,

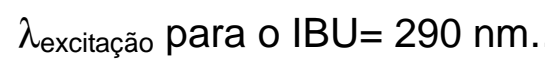

Figura 27 - Resultados dos experimentos de fotólise dos fármacos estudados. (a) $5 \mathrm{mg}$ $\mathrm{L}^{-1}$ e $36 \mathrm{~W}$; (b) $20 \mathrm{mg} \mathrm{L}^{-1}$ e $36 \mathrm{~W}$; (c) $5 \mathrm{mg} \mathrm{L}^{-1}$ e $75 \mathrm{~W}$; (d) $20 \mathrm{mg} \mathrm{L}^{-1}$ e $75 \mathrm{~W}$. A concentração indicada refere-se à concentração inicial nominal de cada fármaco na solução aquosa em pH 2 e $25^{\circ} \mathrm{C}$.

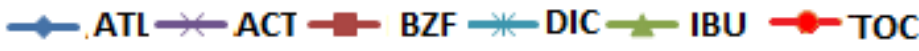

Figura 28 - Resultados dos experimentos de fotólise dos fármacos individualmente. (a) $5 \mathrm{mg} \mathrm{L}^{-1}$ e $75 \mathrm{~W}$; (b) $20 \mathrm{mg} \mathrm{L}^{-1}$ e $75 \mathrm{~W}$. A concentração indicada refere-se à concentração inicial nominal de cada fármaco na solução aquosa em pH 2 e 25 C.

$(\multimap \mathrm{ATL} \leftarrow \mathrm{ACT} \rightarrow \mathrm{BZF} \leadsto \mathrm{DIC} \longleftarrow \mathrm{IBU}$ 85

Figura 29 - Resultados de TOC (normalizado) dos experimentos de fotólise dos fármacos individualmente. Experimentos realizados com lâmpada de $75 \mathrm{~W}$. ( $\square \mathrm{mg}$ $\left.\mathrm{L}^{-1} \bullet 20 \mathrm{mg} \mathrm{L}^{-1}\right)$

Figura 30 - Espectros de absorção UV-visível dos fármacos em função do tempo, à concentração nominal inicial de $5 \mathrm{mg} \mathrm{L}^{-1}$ e potência da lâmpada $75 \mathrm{~W}$ em pH 2 e 25 C. ( $-0 \mathrm{~min}-5 \mathrm{~min}-10 \mathrm{~min}-15 \mathrm{~min}-20 \mathrm{~min}-30 \mathrm{~min}-15 \mathrm{~min}-60$ $\min -90 \min -120 \min )$ 89

Figura 31 - Espectros de absorção UV-visível em função do tempo, para a mistura dos fármacos. (a) $5 \mathrm{mg} \mathrm{L}^{-1}$ de cada fármaco e $75 \mathrm{~W}$. (b) $20 \mathrm{mg} \mathrm{L}^{-1}$ de cada fármaco e 75 $\mathrm{W}$ em pH 2 e $25^{\circ} \mathrm{C}$. ( $-0 \mathrm{~min}-5 \mathrm{~min}-10 \mathrm{~min}-15 \mathrm{~min}-20 \mathrm{~min}-30 \mathrm{~min}$ -45 min - 60 min - $90 \mathrm{~min}-120 \mathrm{~min})$. (1:4 - diluição de 1 parte de solução para 3 partes de água para leitura no espectrofotometro) .93

Figura 32 - Resultados dos experimentos de fotólise, fotólise com supressão de oxigênio dissolvido, fotólise com supressor de oxigênio singlete e supressor de radicais hidroxila para experimentos realizados com os fármacos individualmente com concentração nominal inicial de $20 \mathrm{mg} \mathrm{L}^{-1}$ e $75 \mathrm{~W}$ em pH 2 e $25^{\circ} \mathrm{C}$. A concentração indicada refere-se à concentração inicial nominal de cada fármaco na solução aquosa. $\quad(\bullet$ Fotólise na presença de oxigênio dissolvido 
Supressão de oxigênio singlete $\rightarrow$ Condições anóxicas $\rightarrow$ - Supressão de radicais hidroxila)

Figura 33 - Resultado do experimento $\mathrm{UV} / \mathrm{H}_{2} \mathrm{O}_{2}$ realizados com a mistura dos fármacos com concentração inicial nominal de $5 \mathrm{mg} \mathrm{L}^{-1}$ e $75 \mathrm{~W}$ em pH 2, $25^{\circ} \mathrm{C}$ e concentração inicial de $\mathrm{H}_{2} \mathrm{O}_{2}$ de $3,6 \mathrm{mmol} \mathrm{L}^{-1}$. ( - ATL - ACT - BZF

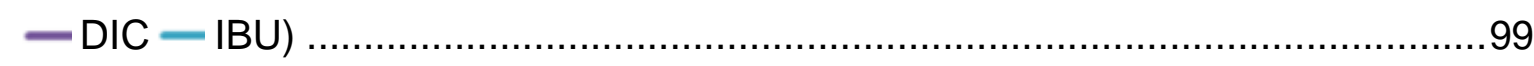

Figura 34 - Resultado do experimento $\mathrm{UV} / \mathrm{H}_{2} \mathrm{O}_{2}$ realizados com a mistura dos fármacos com concentração inicial nominal de $20 \mathrm{mg} \mathrm{L}^{-1}$ e $75 \mathrm{~W}$ em pH 2, $25^{\circ} \mathrm{C}$ e concentração inicial de $\mathrm{H}_{2} \mathrm{O}_{2}$ de $14,45 \mathrm{mmol} \mathrm{L}^{-1}$. $\quad$ ( - ATL — ACT - BZF — DIC - IBU) 100

Figura 35 - Consumo de peróxido de hidrogênio durante a irradiação nos experimentos $\mathrm{UV} / \mathrm{H}_{2} \mathrm{O}_{2}$. Experimento I - experimentos $\mathrm{UV} / \mathrm{H}_{2} \mathrm{O}_{2}$ realizados com a mistura dos fármacos com concentração inicial nominal de $5 \mathrm{mg} \mathrm{L}^{-1}$ e $75 \mathrm{~W}$ e concentração inicial de $\mathrm{H}_{2} \mathrm{O}_{2}$ de 3,6 mmol L $\mathrm{L}^{-1}$. Experimento II - experimentos $\mathrm{UV} / \mathrm{H}_{2} \mathrm{O}_{2}$ realizados com a mistura dos fármacos com concentração inicial nominal de $20 \mathrm{mg} \mathrm{L}^{-1} \mathrm{e} 75 \mathrm{~W}$ e concentração inicial de $\mathrm{H}_{2} \mathrm{O}_{2}$ de $14,45 \mathrm{mmol} \mathrm{L}^{-1}$. (- Experimento I - Experimento II) 101

Figura 36 - Resultados para o fármaco ATL nos experimentos de fotólise realizados com água de osmose inversa e efluente de $\mathrm{ETE}$, com a mistura dos fármacos com concentração nominal inicial de $5 \mathrm{mg} \mathrm{L}^{-1}$ e $75 \mathrm{~W}$ em pH 2 e 25 C. ( - -Água efluente de ETE).

Figura 37 - Resultados para o fármaco ATL nos experimentos de fotólise realizados com água de osmose inversa e efluente de ETE, com a mistura dos fármacos com concentração nominal inicial de $20 \mathrm{mg} \mathrm{L}^{-1}$ e $75 \mathrm{~W}$ em pH 2 e 25 C. ( - - Água $\multimap$ efluente de ETE). 103

Figura 38 - Resultados para o fármaco ACT nos experimentos de fotólise realizados com água de osmose inversa e efluente de $\mathrm{ETE}$, com a mistura dos fármacos com concentração nominal inicial de $5 \mathrm{mg} \mathrm{L}^{-1}$ e $75 \mathrm{~W}$ em pH 2 e 25 C. ( - -Água efluente de ETE) 104

Figura 39 - Resultados para o fármaco ACT nos experimentos de fotólise realizados com água de osmose inversa e efluente de $\mathrm{ETE}$, com a mistura dos fármacos com 
concentração nominal inicial de $20 \mathrm{mg} \mathrm{L}^{-1}$ e $75 \mathrm{~W}$ em pH 2 e $25^{\circ} \mathrm{C}$. ( - - Água efluente de ETE) 104 


\section{LISTA DE ABREVIATURAS E SIGLAS}

\begin{tabular}{ll} 
ACT & Acetaminofeno \\
ATL & Atenolol \\
BZF & Bezafibrato \\
CE $_{50}$ & Concentração efetiva do agente tóxico que causa 50\% de \\
CI & mortandade do organismo-teste \\
CT & Carbono Inorgânico \\
DIC & Carbono Total \\
DP & Diclofenaco \\
ETE & Difenidramina \\
HPLC & Estação de Tratamento de Esgoto \\
IBU & Cromatografia Líquida de Alta Eficiência \\
LD & lbuprofeno \\
LQ & Limite de Detecção \\
POA & Limite de Quantificação \\
TOC & Processos Oxidativos Avançados \\
UV & Carbono Orgânico Total \\
PHT & Radiação Ultravioleta \\
PZ & Fenitoína \\
\hline
\end{tabular}




\section{LISTA DE SÍMBOLOS}

A Absorbância

A Área irradiada

c Concentração molar

c Velocidade da luz no vácuo

$C_{\text {az }}$ Concentração da azida de sódio

$C_{\mathrm{i}}$ Concentração do fármaco

E Energia do fóton

$E_{p, 0} \quad$ Fluxo fotônico incidente

h Constante de Planck

I Caminho óptico

$\mathrm{N}_{\mathrm{a}}$ Constante de Avogadro

Log da constante de equilíbrio ácidobase

$\checkmark \quad$ Volume irradiado

$\varepsilon \quad$ Coeficiente de absorção molar

$\Phi_{M} \quad$ Rendimento quântico da fotólise de M

$\lambda$ Comprimento de onda da radiação $\mathrm{m}^{2}$

$\mathrm{mol} \mathrm{L}^{-1}$

$\mathrm{m} \mathrm{s}^{-1}$

$\mathrm{mol} \mathrm{L}^{-1}$

$\mathrm{mol} \mathrm{L}^{-1}$

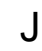

$\mathrm{mol} \mathrm{cm} \mathrm{s}^{-2} \mathrm{~s}^{-1}$

$\mathrm{J} s$ fóton ${ }^{-1}$

$\mathrm{cm}$

espécies $\mathrm{mol}^{-1}$

$$
\begin{gathered}
\mathrm{m}^{3} \\
\mathrm{~L} \mathrm{~mol}^{-1} \mathrm{~cm}^{-1} \\
\text { espécies fótons } \\
\mathrm{nm} \text { ou } \mathrm{m}
\end{gathered}
$$




\section{SUMÁRIO}

1. INTRODUÇÃO

2. OBJETIVOS

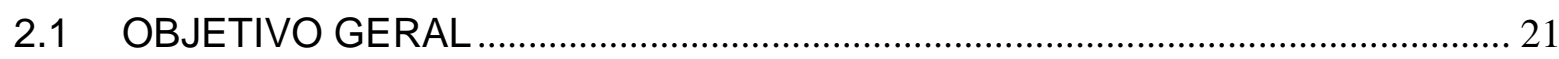

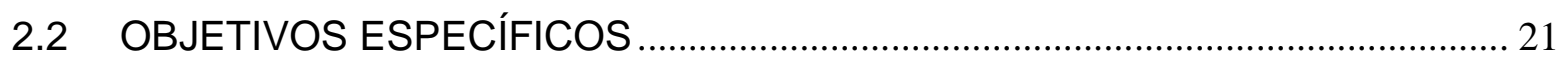

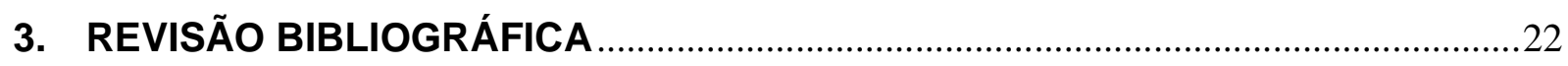

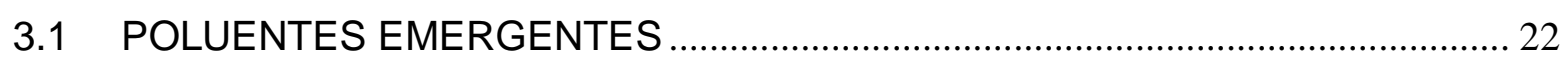

3.2 INTRODUÇÃO DE FÁRMACOS NO MEIO AQUÁTICO........................................ 24

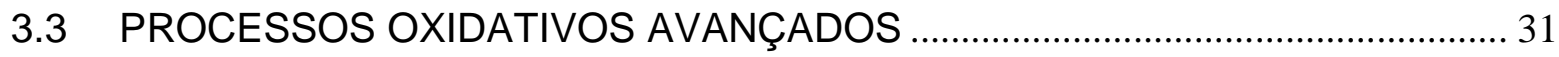

3.3.1 Fotólise ......................................................................................................... 31

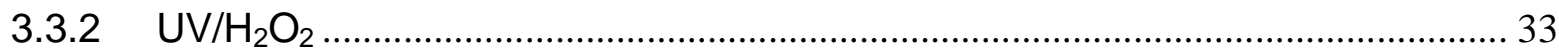

3.4 FÁRMACOS EM ESTUDO E APLICAÇÃO DOS PROCESSOS OXIDATIVOS

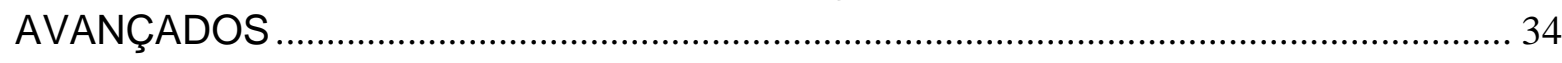

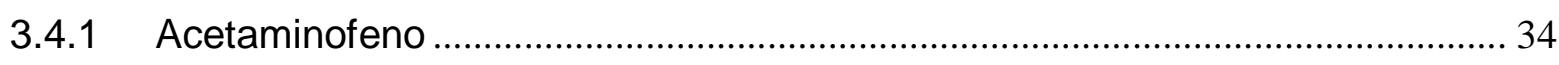

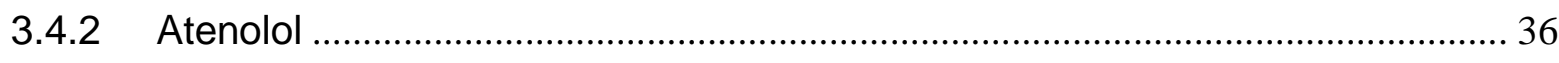

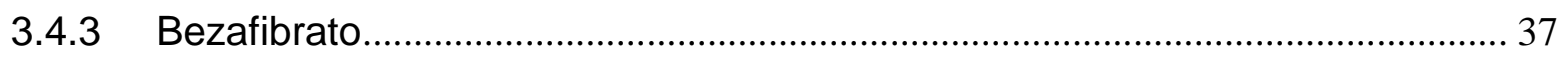

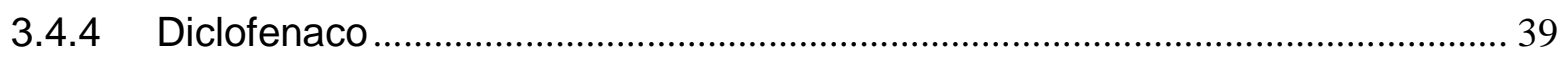

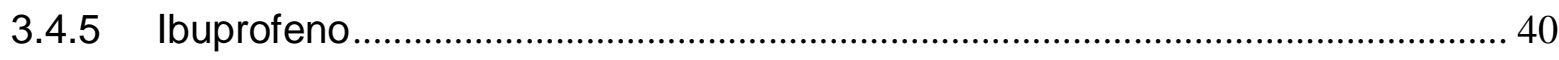

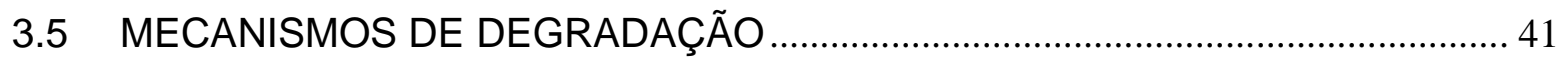

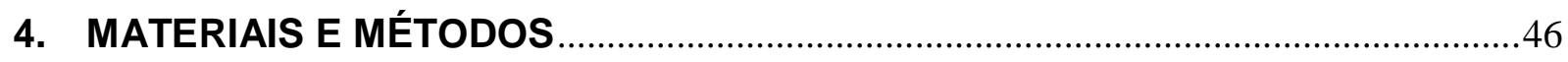

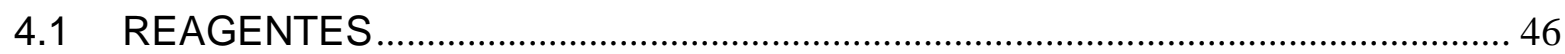

4.2 EQUIPAMENTO EXPERIMENTAL E PROCEDIMENTOS …….......................... 48

4.2.1 Equipamento Experimental ............................................................................... 48

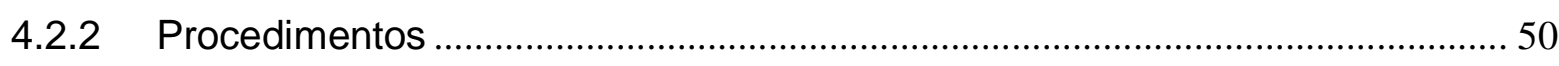

4.2.2.1 Determinação dos valores de $\mathrm{pK}_{\mathrm{a}}$ dos fármacos .............................................5 50

4.2.2.2 Determinação dos coeficientes de absorção molar dos fármacos ................ 51

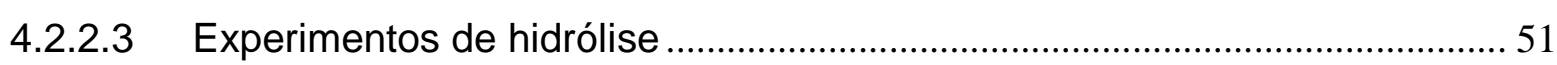


4.2.2.4 Experimentos de degradação por fotólise

4.2.2.4.1 Experimentos de fotólise usando efluente de estação de tratamento de esgotos (ETE).

4.2.2.4.2 Experimentos de degradação por peroxidação fotoassistida $\left(\mathrm{UV} / \mathrm{H}_{2} \mathrm{O}_{2}\right) .53$

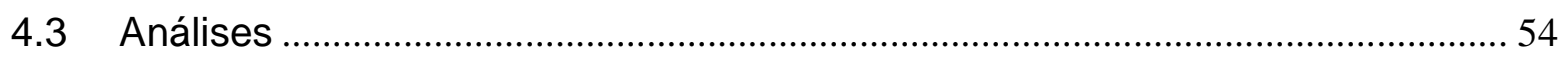

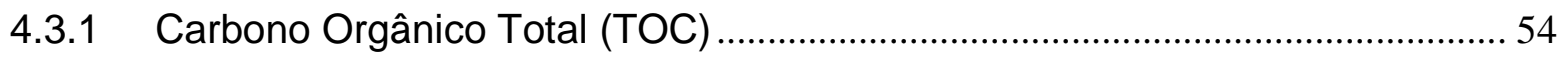

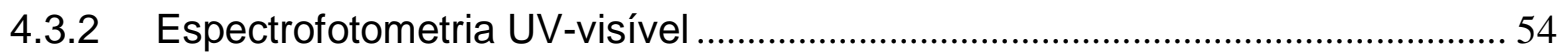

4.3.3 Cromatografia Líquida de Alta Eficiência …………………………………….... 54

4.3.4 Análise de Peróxido de Hidrogênio Residual..................................................... 56

4.3.5 Análise por Fluorescência e Fosforescência ………………………………..... 57

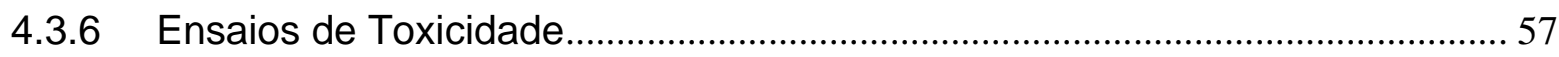

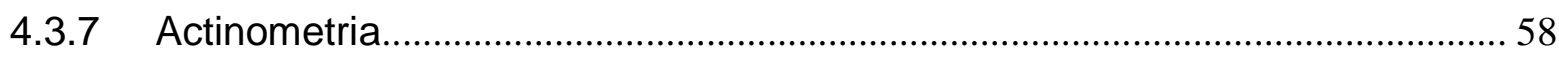

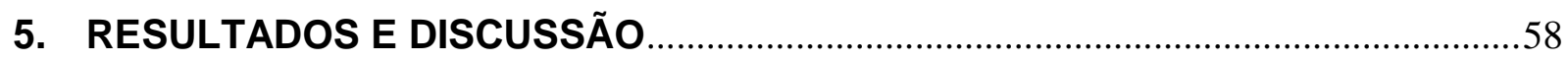

5.1 CARACTERIZAÇÃO ACTINOMÉTRICA DO REATOR FOTOQUÍMICO............58

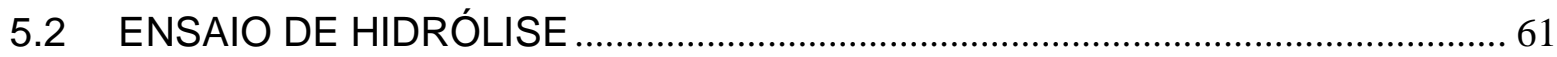

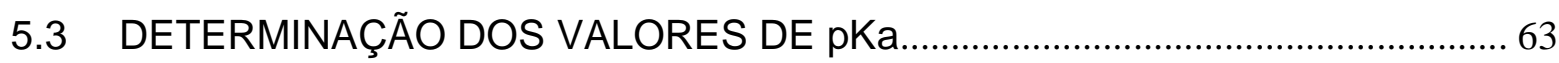

5.4 DETERMINAÇÕES DOS COEFICIENTES DE ABSORÇÃO MOLAR ………..... 69

5.5 DETERMINAÇÃO DOS ESPECTROS DE FLUORESCÊNCIA E

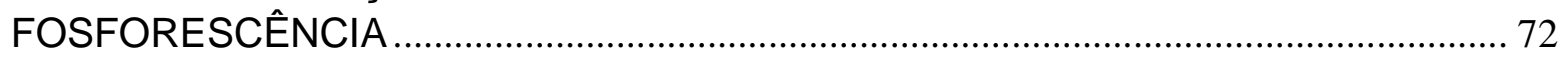

5.6 ESTUDO DA DEGRADAÇÃO DOS FÁRMACOS POR FOTÓLISE ………........78

5.6.1 Degradação dos fármacos por fotólise na mistura ………………………….... 78

5.6.2 Degradação dos fármacos isolados por fotólise ............................................. 84

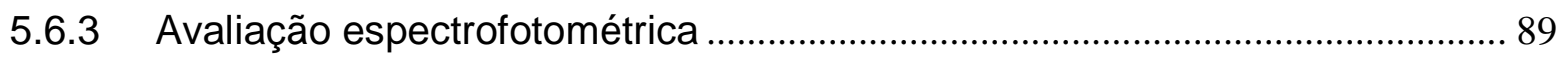

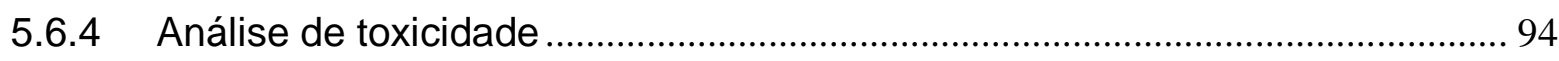

5.6.4.1 Avaliação da toxicidade da mistura dos fármacos ........................................ 94

5.6.4.2 Avaliação da toxicidade dos fármacos individualmente ............................... 95

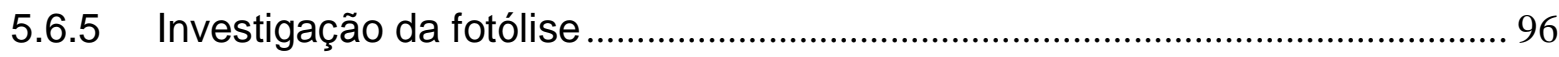

5.7 ESTUDO DA DEGRADAÇÃO DOS FÁRMACOS POR UV/ $\mathrm{H}_{2} \mathrm{O}_{2} \ldots \ldots \ldots \ldots \ldots \ldots \ldots . . . . . . . . . .99$

5.7.1 Análise de Peróxido de Hidrogênio Residual....................................................... 101

5.8 ESTUDO DA DEGRADAÇÃO DOS FÁRMACOS EM EFLUENTE DE ESTAÇÃO DE TRATAMENTO DE ESGOTO …………………………………........ 102 


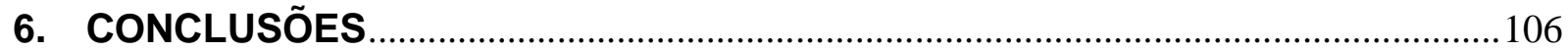

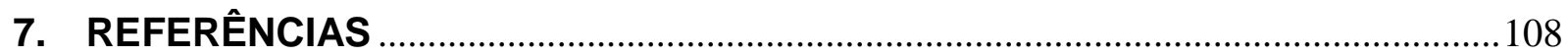




\section{INTRODUÇÃO}

Os insumos necessários para produção de bens de consumo e alimentos são retirados do meio ambiente, porém uma enorme quantidade de resíduos é gerada, algumas vezes tratada e despejada no meio. Os lançamentos indevidos desses resíduos ocasionam alterações no meio ambiente (SOUZA, 2011), causando poluição ambiental e esgotamento dos recursos naturais.

Um dos recursos que sofre com este impacto é a água. A qualidade das águas tem sido amplamente discutida, tendo em vista que se trata de um recurso natural imprescindível às atividades humanas. Diante disso, temas como reuso, minimização e tratamento de resíduos vêm ganhando cada vez mais importância (MELO et al., 2009).

Poluentes emergentes podem ser definidos como quaisquer substâncias químicas naturais ou sintéticas que não eram monitoradas até pouco tempo e nem consideradas como poluentes, mas que mesmo em baixas concentrações podem causar riscos à saúde humana e ao meio ambiente (BILA e DEZOTTI, 2006).

Estudos relataram que tem sido detectada grande variedade de fármacos e metabólitos em corpos d'água (SIRÉS et al., 2006). Estes micropoluentes começaram a chamar a atenção da comunidade científica, pois as mais modernas estações de tratamento de água e efluentes, salvo em alguns casos, não apresentam processos de tratamento adequados para degradá-los, eliminá-los ou removê-los completamente da matriz aquosa (SILVA e COLLINS, 2011).

Os processos de oxidação avançada (POA), fotoquímicos ou não fotoquímicos, são uma alternativa para a degradação desses poluentes emergentes. Nesses processos há geração de radicais hidroxila $\left({ }^{\circ} \mathrm{OH}\right)$, espécies de forte caráter oxidante, que reagem com a maioria dos compostos orgânicos, com baixa seletividade e reações de segunda ordem (constantes cinéticas da ordem de $10^{8}-10^{10} \mathrm{~L} \mathrm{~mol}^{-1} \mathrm{~s}^{-1}$. (OPPENLÄNDER, 2003).

Almeida e Weber (2005) identificaram alguns fármacos no Reservatório Billings, tais como: acetominofeno, atenolol, bezafibrato, buformin, cafeína, diazepam, diclofenaco e ibuprofeno. Neste trabalho, foi estudada a degradação de alguns desses fármacos, entre eles: acetaminofeno (ACT), atenolol (ATL), bezafibrato (BZF), 
diclofenaco (DIC) e ibuprofeno (IBU), cuja escolha baseou-se em aspectos como presença no Reservatório Billings e disponibilidade para aquisição. Optou-se por realizar o estudo da mistura dos fármacos selecionados, pois é dessa forma que eles se encontram em água e efluentes aquosos, ou seja, os fármacos não são encontrados isoladamente, mas sim em uma mistura deles, de seus metabólitos e produtos transformados (KOLPIN et al., 2002); para comparação, foi realizado também o estudo da degradação dos fármacos individualmente. A degradação dos fármacos foi realizada por meio dos processos de fotólise UV e peroxidação fotoassistida $\left(U V / \mathrm{H}_{2} \mathrm{O}_{2}\right)$, caracterizando as soluções aquosas antes e após o tratamento quanto à degradação do fármaco, à remoção de carbono orgânico total e à toxicidade, a fim de avaliar o desempenho eficiência dos processos estudados. Como complemento do trabalho, também foi avaliada a degradação por fotólise dos fármacos estudados em uma matriz real (efluente de estação de tratamento de esgoto). 


\section{OBJETIVOS}

\subsection{OBJETIVO GERAL}

O objetivo geral deste trabalho é avaliar a degradação de poluentes emergentes (fármacos de diferentes classes), identificados em importante reservatório de água da Região Metropolitana de São Paulo, por meio dos processos de fotólise UV e peroxidação fotoassistida $\left(\mathrm{UV} / \mathrm{H}_{2} \mathrm{O}_{2}\right)$, em solução aquosa.

\subsection{OBJETIVOS ESPECÍFICOS}

- Analisar a degradação dos fármacos acetaminofeno (antipirético), atenolol (betabloqueador/anti-hipertensivo), bezafibrato (regulador de lipídios), diclofenaco (analgésico/anti-inflamatório) e ibuprofeno (analgésico/antiinflamatório/antipirético), em solução aquosa, por meio dos processos de fotólise UV e peroxidação fotoassistida por radiação UV $\left(U V / \mathrm{H}_{2} \mathrm{O}_{2}\right)$ e em efluente de estação de tratamento de esgoto (ETE) por meio de fotólise UV;

- Caracterizar as soluções aquosas antes e após o tratamento quanto à degradação dos fármacos, à remoção de carbono orgânico total e à toxicidade, a fim de avaliar o desempenho dos processos estudados;

- Discutir os resultados obtidos com base nas propriedades físico-químicas e químicas dos fármacos em estudo, avaliando os efeitos das variáveis. 


\section{REVISÃO BIBLIOGRÁFICA}

\subsection{POLUENTES EMERGENTES}

Nos últimos anos, inúmeros compostos orgânicos sintéticos vêm sendo encontrados em águas superficiais, como a consequência da atividade humana. Esses compostos são denominados poluentes emergentes por terem sido recentemente detectados, embora seus efeitos potenciais sobre a saúde humana e sobre os ecossistemas naturais ainda não sejam completamente conhecidos. Entre as substâncias que podem ser consideradas neste grupo estão os compostos perfluorados, pesticidas, fármacos, hormônios, desreguladores endócrinos, protetores solares, toxinas de algas e dioxinas, entre outros (BERNABEU et al., 2012). Uma de suas características é de que não precisam persistir no ambiente para causar efeitos deletérios, uma vez que as taxas de transformação/remoção, se não forem baixas, podem ser compensadas pela sua introdução contínua no ambiente (BARCELÓ, 2003).

$\mathrm{Na}$ Tabela 1, estão apresentadas as principais classes de poluentes orgânicos emergentes, segundo Silva e Collins, 2011.

Tabela 1 - Principais classes de poluentes orgânicos emergentes.

\begin{tabular}{ll}
\hline \multicolumn{1}{c}{ Classe } & \multicolumn{1}{c}{ Exemplos } \\
\hline $\begin{array}{l}\text { Produtos Farmacêuticos } \\
\text { Antibióticos (uso humano ou } \\
\text { veterinário) }\end{array}$ & $\begin{array}{l}\text { clorotetraciclina, eritromicina, sulfametoxazol, lincomicina, } \\
\text { trimetoprim } \\
\text { diclofenaco, paracetamol, cetoprofeno, acetaminofeno, } \\
\text { ibuprofeno } \\
\text { Analgésicos e anti-inflamatórios }\end{array}$ \\
$\begin{array}{l}\text { Drogas de uso psiquiátrico } \\
\text { Reguladores lipídicos e seus } \\
\text { metabólitos }\end{array}$ & $\begin{array}{l}\text { benzafibrato, ácido clofíbrico, ácido fenofíbrico } \\
\beta-B l o q u e a d o r e s\end{array}$ \\
$\begin{array}{l}\text { Meio de contrastes de raios-X } \\
\text { Contraceptivos }\end{array}$ & $\begin{array}{l}\text { atenolol, propranolol, metoprolol, betaxolol } \\
\text { iopamidol, diatrizoato, lopromida,lomeprol }\end{array}$ \\
\hline
\end{tabular}
Fonte: SILVA e COLLINS, 2011. 
Tabela 1 (cont) - Principais classes de poluentes orgânicos emergentes.

Classe Exemplos

\section{Produtos de higiene pessoal}

Fragrâncias

Protetores solares

almíscares nitrados, policíclicos e macrocíclicos

Repelentes de insetos

benzofenonas, parabenos

Antissépticos

$\mathrm{N}, \mathrm{N}$-dietiltoluamida

triclosano, clorofeno

\section{Interferentes endócrinos}

Retardantes de chama

Aditivos industriais

Surfactantes

Aditivos de gasolina

Inibidores de corrosão

Hormônios naturais

Agrotóxicos

Hidrocarbonetos

poliaromáticos (PAH)

difenil éteres polibromados

ácido etilenodiaminotetra-acético, ácido nitriloacético

alquilfenóis lineares, carboxilados e etoxilados,compostos

perfluorados

metil-t-butil éter

benzotriazois, benzotiazois

$17 \beta$-estradiol, progesterona, testosterona, estrona

atrazina, clordano, dieldrin,hexaclorobenzeno

benzo[a]pireno, fluoranteno, antraceno, naftaleno

Bifenilas policloradas (PCB)

Ftalatos

3,3',4,4'- tetraclorobifenil ,3,4,4',5-tetraclorobifenil

dietilftalato, dibutilftalato

Dioxinas e Furanos

2,3,7,8-tetracloro-p-dioxina

Drogas de abuso

anfetaminas, cocaína,tetra-hidrocanabinol, 3,4- metilenodioximetanfetamina 


\subsection{INTRODUÇÃO DE FÁRMACOS NO MEIO AQUÁTICO}

Uma grande quantidade de fármacos é produzida diariamente para consumo humano e animal. Na literatura, são encontrados diversos artigos sobre a presença de tais compostos no meio ambiente, por serem considerados poluentes emergentes, entre os quais os estudos realizados por Kummerer et al. (2009), Rivera-Utrilla et al. (2013), Daughton (2004), entre outros. Aproximadamente 150 compostos farmacêuticos já foram monitorados no meio ambiente, principalmente em amostras aquosas (Rivera-Utrilla et al., 2013).

Segundo Almeida e Weber (2005), foram identificados alguns fármacos no Reservatório Billings, tais como: acetaminofeno, atenolol, bezafibrato, buformin, cafeína, diazepam, diclofenaco e ibuprofeno. As concentrações médias detectadas, bem como as funções de cada um, estão apresentadas na Tabela 2.

Tabela 2 - Fármacos identificados na Represa Billings.

\begin{tabular}{ccc}
\hline Composto & Função & Concentrações médias $\mathbf{( n g ~ \mathbf { ~ L } ^ { - 1 } \mathbf { ) }}$ \\
\hline Acetaminofeno & Antipirético & $0,3-10,3$ \\
Atenolol & Betabloqueador/anti-hipertensivo & $0,9-16,4$ \\
Bezafibrato & Regulador de lipídios & $1,2-3,7$ \\
Buformin & Síntese da insulina/antidiabético & $2,6-18,4$ \\
Cafeína & Antipirético/analgésico/estimulante & $0,35-28,3$ \\
Diazepam & Ansiolítico/uso psiquiátrico & $0,2-4,8$ \\
Diclofenaco & Analgésico/anti-inflamatório & $8,1-394,5$ \\
Ibuprofeno & Antiinflamatório/Analgésico/antipirético & $10,0-78,2$ \\
\hline
\end{tabular}

Fonte: ALMEIDA e WEBER, 2005.

O reservatório Billings fica localizado na região do planalto, abrange áreas dos municípios de São Paulo, Santo André, São Bernardo do Campo, Diadema, Ribeirão Pires e Rio Grande da Serra. Possui cerca de 1,1 bilhão de $\mathrm{m}^{3}$ de água. As águas desse reservatório são utilizadas para geração de energia elétrica, abastecimento público, através da reversão do Braço Taquacetuba para o Reservatório do Guarapiranga, saneamento, controle de cheias e lazer, entre outros (RESERVATÓRIO BILLINGS, 2013). 
MELO et al. (2009) mencionam fármacos de diversas classes terapêuticas, como antibióticos, hormônios, anti-lipêmicos, anti-inflamatórios, analgésicos, entre outros, detectados em esgoto doméstico, águas superficiais e subterrâneas em várias partes do mundo, em concentrações na faixa de $\mathrm{ng} \mathrm{L}^{-1}$ a $\mu \mathrm{L} \mathrm{L}^{-1}$ (Tabela 3).

Tabela 3 - Concentrações médias de fármacos detectados em ambientes aquáticos.

\begin{tabular}{|c|c|c|c|}
\hline $\begin{array}{c}\text { Fármaco } \\
\text { (classe terapêutica) }\end{array}$ & $\begin{array}{l}\text { Concentração } \\
\text { média }\left(\mu \mathrm{g} \mathrm{L}^{-1}\right)\end{array}$ & Matriz & Referência \\
\hline $\begin{array}{l}\text { Amoxicilina } \\
\text { (antibiótico) }\end{array}$ & 0,013 & Esgoto bruto/Itália & Castiglioni et al. (2006) \\
\hline \multirow{5}{*}{$\begin{array}{c}\text { Atenolol } \\
\text { ( } \beta \text {-bloqueador) }\end{array}$} & 0,49 & Esgoto bruto/Itália & Castiglioni et al. (2006) \\
\hline & 0,28 & Efluente de ETE/Itália & Castiglioni et al. (2006) \\
\hline & 0,05 & Água superficial/ Itália & Calamari et al. (2003) \\
\hline & 0,30 & Esgoto bruto/Suécia & Bendz et al. (2005) \\
\hline & 0,16 & Efluente de ETE/Suécia & Bendz et al. (2005) \\
\hline \multirow{8}{*}{$\begin{array}{l}\text { Bezafibrato } \\
\text { (antilipêmico) }\end{array}$} & 0,54 & Efluente de ETE/França & Andreozzi et al. (2003b) \\
\hline & 0,30 & Efluente de ETE/Itália & Andreozzi et al. (2003b) \\
\hline & 0,07 & Efluente de ETE/Canadá & Gagné et al. (2006) \\
\hline & 0,42 & Esgoto bruto/Finlândia & Lindqvist et al. (2005) \\
\hline & 1,20 & Esgoto bruto/Brasil & Stumpf et al. (1999) \\
\hline & 0,18 & Água superficial/ Brasil & Stumpf et al. (1999) \\
\hline & 2,20 & Efluente de ETE/Alemanha & Ternes (1998) \\
\hline & 0,35 & Água superficial/Alemanha & Ternes (1998) \\
\hline \multirow{10}{*}{$\begin{array}{c}\text { Carbamazepina } \\
\text { (anticonvulsionante) }\end{array}$} & 1,7 & Esgoto bruto/Suécia & Bendz et al. (2005) \\
\hline & 1,2 & Efluente de ETE/Suécia & Bendz et al. (2005) \\
\hline & 1,0 & Efluente de ETE/França & Andreozzi et al. (2003b) \\
\hline & 1,0 & Efluente de ETE/Grécia & Andreozzi et al. (2003b) \\
\hline & 0,38 & Efluente de ETE/Itália & Andreozzi et al. (2003b) \\
\hline & 0,085 & Efluente de ETE/Canadá & Gagné et al.(2006) \\
\hline & 2,1 & Efluente de ETE/Alemanha & Ternes (1998) \\
\hline & 0,25 & Água superficial/Alemanha & Ternes (1998) \\
\hline & 0,5 & Esgoto bruto/Espanha & Santos et al. (2005) \\
\hline & 0,48 & Efluente de ETE/Espanha & Santos et al. (2005) \\
\hline
\end{tabular}

Fonte: Fonte: MELO et al. (2009). 
Tabela 3 (cont.) - Concentrações médias de fármacos detectados em ambientes aquáticos.

\begin{tabular}{|c|c|c|c|}
\hline $\begin{array}{c}\text { Fármaco } \\
\text { (classe terapêutica) }\end{array}$ & $\begin{array}{l}\text { Concentração } \\
\text { média }\left(\mu \mathrm{g} \mathrm{L}^{-1}\right)\end{array}$ & Matriz & Referência \\
\hline \multirow{9}{*}{$\begin{array}{c}\text { Cetoprofeno } \\
\text { (anti-inflamatório) }\end{array}$} & 0,94 & Esgoto bruto/Suécia & Bendz et al. (2005) \\
\hline & 0,33 & Efluente de ETE/Suécia & Bendz et al. (2005) \\
\hline & 0,81 & Efluente de ETE/França & Andreozzi et al. (2003b) \\
\hline & 2,0 & Esgoto bruto/Finlândia & Lindqvist et al. (2005) \\
\hline & 0,15 & Esgoto bruto/Brasil & Stumpf et al. (1999) \\
\hline & 0,22 & Água superficial/ Brasil & Stumpf et al. (1999) \\
\hline & 0,2 & Efluente de ETE/Alemanha & Ternes (1998) \\
\hline & 1,1 & Esgoto bruto/Espanha & Santos et al. (2005) \\
\hline & 0,98 & Efluente de ETE/Espanha & Santos et al. (2005) \\
\hline \multirow{7}{*}{$\begin{array}{l}\text { Ciprofloxacina } \\
\text { (antibiótico) }\end{array}$} & 0,26 & Esgoto bruto/ltália & Castiglioni et al. (2006) \\
\hline & 0,097 & Efluente de ETE/Itália & Castiglioni et al. (2006) \\
\hline & 0,06 & Efluente de ETE/França & Andreozzi et al. (2003b) \\
\hline & 0,07 & Efluente de ETE/Grécia & Andreozzi et al. (2003b) \\
\hline & 0,03 & Efluente de ETE/Suécia & Andreozzi et al. (2003b) \\
\hline & 0,37 & Efluente de ETE/Suíça & Golet et al. (2001) \\
\hline & 0,02 & Água superficial/EUA & Kolpin et al. (2002) \\
\hline \multirow{13}{*}{$\begin{array}{c}\text { Diclofenaco } \\
\text { (anti-inflamatório) }\end{array}$} & 0,16 & Esgoto bruto/Suécia & Bendz et al. (2005) \\
\hline & 0,12 & Efluente de ETE/Suécia & Bendz et al. (2005) \\
\hline & 0,33 & Efluente de ETE/França & Andreozzi et al. (2003b) \\
\hline & 0,84 & Efluente de ETE/Grécia & Andreozzi et al. (2003b) \\
\hline & 2,47 & Efluente de ETE/Itália & Andreozzi et al. (2003b) \\
\hline & 0,35 & Esgoto bruto/Finlândia & Lindqvist et al. (2005) \\
\hline & 0,4 & Esgoto bruto/Brasil & Stumpf et al. (1999) \\
\hline & 0,02 & Água superficial/Brasil & Stumpf et al. (1999) \\
\hline & 0,81 & Efluente de ETE/Alemanha & Ternes (1998) \\
\hline & 0,15 & Água superficial/Alemanha & Ternes (1998) \\
\hline & 2,9 & Esgoto bruto/Brasil & Ghisele (2006) \\
\hline & 1,8 & Efluente de ETE/Brasil & Ghisele (2006) \\
\hline & 4,0 & Água superficial/Brasil & Ghisele (2006) \\
\hline \multirow{3}{*}{$\begin{array}{c}\text { 17a-Etinilestradiol } \\
\text { (hormônio contraceptivo) }\end{array}$} & 0,073 & Água superficial/EUA & Kolpin et al. (2002) \\
\hline & 0,001 & Efluente de ETE/Alemanha & Ternes et al. (1999) \\
\hline & 0,009 & Efluente de ETE/Canadá & Ternes et al. (1999) \\
\hline
\end{tabular}

Fonte: Fonte: MELO et al. (2009). 
Tabela 3 (cont.) - Concentrações médias de fármacos detectados em ambientes aquáticos.

\begin{tabular}{|c|c|c|c|}
\hline $\begin{array}{c}\text { Fármaco } \\
\text { (classe terapêutica) }\end{array}$ & $\begin{array}{l}\text { Concentração } \\
\text { média }\left(\mu \mathrm{g} \mathrm{L}^{-1}\right)\end{array}$ & Matriz & Referência \\
\hline \multirow{5}{*}{$\begin{array}{l}\text { 17a-Etinilestradiol } \\
\text { (hormônio contraceptivo) }\end{array}$} & 0,005 & Esgoto bruto/Brasil & Ternes et al. (1999) \\
\hline & 5,8 & Esgoto bruto/Brasil & Ghisele (2006) \\
\hline & 5,0 & Efluente de ETE/Brasil & Ghisele (2006) \\
\hline & 2,4 & Água superficial/Brasil & Ghisele (2006) \\
\hline & 1,7 & Água potável/Brasil & Ghisele (2006) \\
\hline \multirow{8}{*}{$\begin{array}{c}\text { Genfibrozil } \\
\text { (antilipêmico) }\end{array}$} & 0,71 & Esgoto bruto/Suécia & Bendz et al. (2005) \\
\hline & 0,18 & Efluente de ETE/Suécia & Bendz et al. (2005) \\
\hline & 0,7 & Efluente de ETE/França & Andreozzi et al. (2003b) \\
\hline & 0,71 & Efluente de ETE/Grécia & Andreozzi et al. (2003b) \\
\hline & 2,14 & Efluente de ETE/Itália & Andreozzi et al. (2003b) \\
\hline & 0,071 & Efluente de ETE/Canadá & Gagné et al. (2006) \\
\hline & 0,4 & Esgoto bruto/Brasil & Stumpf et al. (1999) \\
\hline & 0,048 & Água superficial/EUA & Kolpin et al. (2002) \\
\hline \multirow{16}{*}{$\begin{array}{c}\text { Ibuprofeno } \\
\text { (anti-inflamatório) }\end{array}$} & 3,6 & Esgoto bruto/Suécia & Bendz et al. (2005) \\
\hline & 0,15 & Efluente de ETE/Suécia & Bendz et al. (2005) \\
\hline & 0,92 & Efluente de ETE/França & Andreozzi et al. (2003b) \\
\hline & 0,05 & Efluente de ETE/Grécia & Andreozzi et al. (2003b) \\
\hline & 0,07 & Efluente de ETE/Itália & Andreozzi et al. (2003b) \\
\hline & 0,79 & Efluente de ETE/Canadá & Gagné et al. (2006) \\
\hline & 13,1 & Esgoto bruto/Finlândia & Lindqvist et al. (2005) \\
\hline & 0,6 & Esgoto bruto/Brasil & Stumpf et al. (1999) \\
\hline & 0,19 & Água superficial/Brasil & Stumpf et al. (1999) \\
\hline & 0,37 & Efluente de ETE/Alemanha & Ternes (1998) \\
\hline & 0,07 & Água superficial/Alemanha & Ternes (1998) \\
\hline & 0,2 & Água superficial/EUA & Kolpin et al. (2002) \\
\hline & 54,2 & Esgoto bruto/Brasil & Ghisele (2006) \\
\hline & 48,4 & Efluente de ETE/Brasil & Ghisele (2006) \\
\hline & 3,7 & Esgoto bruto/Espanha & Carbala et al. (2004) \\
\hline & 1,3 & Efluente de ETE/Espanha & Carbala et al. (2004) \\
\hline \multirow{4}{*}{$\begin{array}{c}\text { Propranolol } \\
\text { ( } \beta \text {-bloqueador) }\end{array}$} & 0,05 & Esgoto bruto/Suécia & Bendz et al. (2005) \\
\hline & 0,03 & Efluente de ETE/Suécia & Bendz et al. (2005) \\
\hline & 0,03 & Efluente de ETE/França & Andreozzi et al. (2003b) \\
\hline & 0,01 & Efluente de ETE/Grécia & Andreozzi et al. (2003b) \\
\hline
\end{tabular}

Fonte: Melo et al. (2009). 
Tabela 3 (cont.) - Concentrações médias de fármacos detectados em ambientes aquáticos.

\begin{tabular}{|c|c|c|c|}
\hline $\begin{array}{c}\text { Fármaco } \\
\text { (classe terapêutica) }\end{array}$ & $\begin{array}{l}\text { Concentração } \\
\text { média }\left(\mu \mathrm{g} \mathrm{L}^{-1}\right)\end{array}$ & Matriz & Referência \\
\hline \multirow{3}{*}{$\begin{array}{c}\text { Propranolol } \\
\text { ( } \beta \text {-bloqueador) }\end{array}$} & 0,04 & Efluente de ETE/Itália & Andreozzi et al. (2003b) \\
\hline & 0,17 & Efluente de ETE/Alemanha & Ternes (1998) \\
\hline & 0,01 & Água superficial/Alemanha & Ternes (1998) \\
\hline \multirow{12}{*}{$\begin{array}{c}\text { Naproxeno } \\
\text { (anti-inflamatório) }\end{array}$} & 3,7 & Esgoto bruto/Suécia & Bendz et al. (2005) \\
\hline & 0,25 & Efluente de ETE/Suécia & Bendz et al. (2005) \\
\hline & 1,1 & Efluente de ETE/França & Andreozzi et al. (2003b) \\
\hline & 2,0 & Efluente de ETE/Itália & Andreozzi et al. (2003b) \\
\hline & 0,27 & Efluente de ETE/Canadá & Gagné et al. (2006) \\
\hline & 4,9 & Esgoto bruto/Finlândia & Lindqvist et al. (2005) \\
\hline & 0,6 & Esgoto bruto/Brasil & Stumpf et al. (1999) \\
\hline & 0,02 & Água superficial/Brasil & Stumpf et al. (1999) \\
\hline & 0,3 & Efluente de ETE/Alemanha & Ternes (1998) \\
\hline & 0,07 & Água superficial/Alemanha & Ternes (1998) \\
\hline & 4,7 & Esgoto bruto/Espanha & Santos et al. (2005) \\
\hline & 1,5 & Efluente de ETE/Espanha & Santos et al. (2005) \\
\hline \multirow{9}{*}{$\begin{array}{l}\text { Sulfametoxazol } \\
\text { (antibiótico) }\end{array}$} & 0,08 & Efluente de ETE/França & Andreozzi et al. (2003b) \\
\hline & 0,09 & Efluente de ETE/Grécia & Andreozzi et al. (2003b) \\
\hline & 0,01 & Efluente de ETE/Itália & Andreozzi et al. (2003b) \\
\hline & 0,02 & Efluente de ETE/Suécia & Andreozzi et al. (2003b) \\
\hline & 0,049 & Efluente de ETE/Canadá & Gagné et al. (2006) \\
\hline & 0,58 & Esgoto bruto/Espanha & Carbala et al. (2004) \\
\hline & 0,25 & Efluente de ETE/Espanha & Carbala et al. (2004) \\
\hline & 0,4 & Efluente de ETE/Alemanha & Hirsch et al. (1999) \\
\hline & 0,05 & Água superficial/EUA & Stackelberg et al. (2004) \\
\hline Tetraciclina & 0,01 & Água superficial//tália & Calamari et al. (2003) \\
\hline (antibiótico) & 0,11 & Água superficial/EUA & Kolpin et al. (2002) \\
\hline \multirow{7}{*}{$\begin{array}{l}\text { Trimetoprim } \\
\text { (antibiótico) }\end{array}$} & 0,08 & Esgoto bruto/Suécia & Bendz et al. (2005) \\
\hline & 0,04 & Efluente de ETE/Suécia & Bendz et al. (2005) \\
\hline & 0,03 & Efluente de ETE/França & Andreozzi et al. (2003b) \\
\hline & 0,08 & Efluente de ETE/Grécia & Andreozzi, et al. (2003b) \\
\hline & 0,065 & Efluente de ETE/Canadá & Gagné et al. (2006) \\
\hline & 0,15 & Água superficial/EUA & Kolpin et al. (2002) \\
\hline & 0,32 & Efluente de ETE/Alemanha & Hirsch et al (1999) \\
\hline
\end{tabular}

Fonte: MELO et al. (2009). 
Os fármacos são introduzidos no ambiente continuamente e prevalecem em pequenas concentrações e, segundo estudos de Yuan et al. (2009) e de Síres e Brillas (2012), podem afetar a qualidade da água e, potencialmente, afetar o abastecimento de água potável, o ecossistema e a saúde humana. No entanto, pouco se conhece sobre os efeitos dessas drogas no meio ambiente e também sobre a ingestão em longo prazo de misturas de compostos em baixas concentrações através da água potável.

De acordo com Rivera-Utrilla et al. (2013) após a ingestão terapêutica, os fármacos podem ser excretados sem serem transformados ou podem ser metabolizados por reações bioquímicas de duas formas: a primeira são reações de oxidação, redução, hidrólise e alquilação; a segunda forma consiste na formação de conjugados de glucoronídeos e sulfatos que são formados e excretados pela urina ou bile, na forma de derivados mais polares e hidrófilos, como um metabólito, ou como mistura de vários metabólitos.

Lapworth et al. (2012) afirmam que as principais rotas dos fármacos são provenientes de efluentes das estações de tratamento de águas residuais municipais; fossas sépticas; efluentes hospitalares; atividades pecuárias, incluindo lagoas de resíduos e aplicação de esterco para o solo; resíduos domésticos e industriais, bem como indiretamente, através do processo de água subterrâneas ou de superfície. $\mathrm{Na}$ Figura 1 estão ilustradas as principais fontes de poluição no ambiente, rotas e destino dos fármacos.

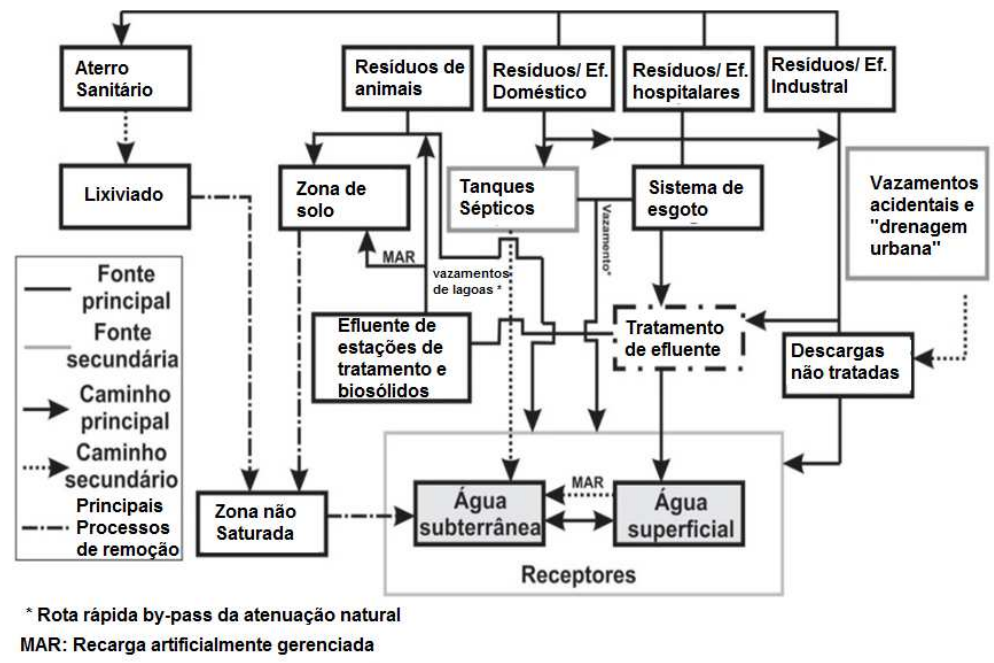

Figura 1 - Diagrama esquemático das rotas de fármacos. Adaptado de Lapworth et al. (2012). 
Fármacos ingeridos por animais são excretados pela urina e fezes no chão ou diretamente em águas de superfície, sem passar através de estações de tratamento de esgoto (ETE). Esse solo pode se tornar uma fonte de contaminação de águas superficiais e subterrâneas (Alder et al., 2010).

Halling-Sørensen et al. (1998) afirmam que em grandes criações de gado, produtos farmacêuticos podem indiretamente entrar no ambiente através da aplicação de esterco como fertilizante e podem eventualmente passar para os seres humanos através da cadeia alimentar.

Segundo Escher et al. (2012), outra fonte de entrada dos fármacos no ambiente aquático são os efluentes de ETE, devido à ineficiência dos processos para eliminação destes compostos que estão em concentrações baixas. Estudos mostraram que as estações de tratamento convencionais, baseados principalmente na utilização de microrganismos (tratamento biológico), são insuficientes para destruir efetivamente fármacos, devido à sua estrutura molecular complexa e baixa concentração na água. Em alguns casos, a porcentagem removida desses compostos pode ser menor do que 10\% (Rivera-Utrilla et al., 2013). Por outro lado, muitas vezes fármacos são adsorvidos no lodo biológico e sedimentos, sendo transferidos para o solo como resultado da disposição desses resíduos em aterros. Portanto, tratamentos ou pós-tratamentos mais eficazes e específicos são necessários para reduzir o impacto ambiental e potencial de efluentes contendo fármacos e seus derivados.

Indústrias farmacêuticas normalmente não eram consideradas fontes importantes de aporte no ambiente de águas residuais contendo drogas. No entanto, o estudo de Fick et al. (2009) sugere que a água residual da produção de drogas pode, potencialmente, ser uma fonte de concentrações muito elevadas em determinados locais, contribuindo para os níveis de poluição ambiental muito superiores aos anteriormente relatados (Fick et al., 2009).

As concentrações de fármacos em efluentes hospitalares são acima de $100 \mu \mathrm{g}$ $\mathrm{L}^{-1}$, segundo Ceron (2011). Este autor comenta também a falta de legislação específica e de protocolos para descarte correto de fármacos. Da mesma forma, Rodrigues (2009) propõem que haja leis mais específicas sobre os descartes final dessas drogas. 


\subsection{PROCESSOS OXIDATIVOS AVANÇADOS}

Uma das alternativas para tratamento de águas e efluentes contento poluentes emergentes são os processos oxidativos avançados (POA). Os POA são capazes de destruir quimicamente diversas classes de poluentes e são definidos como processos envolvendo a geração e uso de agentes oxidantes fortes, principalmente radicais hidroxila (TARR, 2003). A geração destes radicais é o passo fundamental para a eficiência dos POA. Quanto mais eficientemente estes radicais forem gerados, melhor o desempenho do processo de tratamento (DEZOTTI, 1998). Huang et al. (1993) apresentam os principais tipos de POA, descritos na Tabela 4.

Tabela 4 - Principais tipos de processos oxidativos avançados.

\section{Sistemas Homogêneos}

\begin{tabular}{cc}
\hline Com Irradiação & Sem Irradiação \\
$\mathrm{O}_{3} / \mathrm{UV}$ & $\mathrm{O}_{3} / \mathrm{H}_{2} \mathrm{O}_{2}$ \\
$\mathrm{H}_{2} \mathrm{O}_{2} / \mathrm{UV}$ & $\mathrm{O}_{3} / \mathrm{OH}^{-}$ \\
$\mathrm{UV} / \mathrm{H}_{2} \mathrm{O}_{2} / \mathrm{Fe}$ (II) (foto-Fenton) & $\mathrm{H}_{2} \mathrm{O}_{2} / \mathrm{Fe}(\mathrm{II})$ (Fenton) \\
\hline
\end{tabular}

Sistemas Heterogêneos

\begin{tabular}{cc}
\hline Com Irradiação & Sem Irradiação \\
$\mathrm{TiO}_{2} / \mathrm{O}_{2} / \mathrm{UV}$ & Eletro-Fenton \\
$\mathrm{TiO}_{2} / \mathrm{H}_{2} \mathrm{O}_{2} / \mathrm{UV}$ & \\
\hline
\end{tabular}

Fonte: adaptado de Huang et al. (1993).

\subsubsection{Fotólise}

A fotólise baseia-se na irradiação da matriz aquosa contendo os contaminantes por meio de radiação ultravioleta (UV), com comprimento de onda do espectro eletromagnético compreendido entre 200 e $400 \mathrm{~nm}$. A radiação UV situa-se em um intervalo de comprimentos de onda entre os raios- $X$ e a luz visível, podendo ser dividida em: UV-vácuo ou VUV (40 a 200 nm); UVC (200 a 280 nm); UVB (280 a 315 nm); UVA (315 a 400 nm) (WRIGHT e CAIRNS, 1998). Uma lâmpada de mercúrio de baixa pressão (LP) é um conversor eficiente de energia elétrica em energia radiante. 
Essas lâmpadas fornecem radiação UV praticamente monocromática em comprimento de onda de 253,7 nm (OPPENLÄNDER, 2003).

Para ocorrer a fotólise, o poluente deverá absorver a radiação incidente, resultando a degradação a partir do seu estado excitado (PARSONS, 2005). Assim, a partir da absorção da radiação UV (Equação 1), forma-se o estado eletrônico excitado $R X^{*}$, altamente energético, que pode retornar ao estado fundamental por processos físicos (radiativos, tais como fluorescência e fosforescência ou desativação nãoradiativa) ou sofrer reações químicas (PARSONS, 2005).

$$
\begin{aligned}
& \mathrm{RX}+h v \rightarrow \mathrm{RX}^{*} \\
& \mathrm{RX}^{*} \rightarrow\left(\mathrm{R}^{\bullet} \ldots \mathrm{X}_{\text {cage }} \rightarrow \mathrm{R}^{\bullet}+{ }^{\cdot X}\right. \\
& \left(\mathrm{R}^{\bullet} \ldots \mathrm{X}\right)_{\text {cage }} \rightarrow \mathrm{RX} \\
& \mathrm{RX}^{*} \rightarrow\left(\mathrm{R}^{+} \ldots \mathrm{X}\right)_{\text {cage }} \rightarrow \mathrm{R}^{+}+\mathrm{X}^{-} \\
& \mathrm{RX}^{*}+{ }^{3} \mathrm{O}_{2} \rightarrow \mathrm{RX}^{+\bullet}+\mathrm{O}_{2}^{-\bullet} \\
& \mathrm{RX}^{*}+{ }^{3} \mathrm{O}_{2} \rightarrow \mathrm{RX}+{ }^{1} \mathrm{O}_{2}
\end{aligned}
$$

A etapa de reação predominante é a cisão homolítica de ligação química (Equação 2) e ocorre com aprisionamento de espécies ativas por moléculas de solvente (solvente cage). Os poluentes orgânicos podem seguir diferentes mecanismos de reação, resultando em diferentes produtos de degradação na presença e na ausência de oxigênio dissolvido. A recombinação dos radicais primários, devido ao aprisionamento por solvente (Equação 3), ocorre com alta probabilidade, o que explica o baixo rendimento quântico da fotólise direta de moléculas orgânicas geralmente observado em meio condensado, se comparado ao que se observa em fase gasosa. Processos de transferência de energia e elétrons para o oxigênio, Equações 5 e 6, também podem ocorrer, mas requerem tempo de vida relativamente longo para o estado excitado, tal como o estado triplete. $O$ oxigênio dissolvido é a espécie que mais comumente interage com o composto orgânico no estado excitado, principalmente se a concentração em fase aquosa dos demais constituintes é baixa. Espécies altamente reativas, como o radical superóxido (Equação 5) e oxigênio singlete ${ }^{1} \mathrm{O}_{2}$ (Equação 6), 
podem ser geradas em conjunto com o cátion-radical do poluente orgânico (Equação 5), a partir da desativação do estado excitado (PARSONS, 2005).

\subsection{2 $\mathrm{UV} / \mathrm{H}_{2} \mathrm{O}_{2}$}

Um dos processos oxidativos avançado (POA) empregado com êxito na remoção de poluentes emergentes é o processo de peroxidação fotoassistida $\left(\mathrm{UV} / \mathrm{H}_{2} \mathrm{O}_{2}\right)$, considerado mais eficiente que os processos de fotólise e de peroxidação separados (TAMBOSI, 2008). Sob irradiação UV ocorre fotólise da molécula de peróxido de hidrogênio, gerando radicais hidroxila, que oxidam o poluente orgânico (HUANG et al., 1993). O efeito da radiação UV na decomposição de $\mathrm{H}_{2} \mathrm{O}_{2}$ pode ser explicado pelo mecanismo de Haber-Weiss, descrito pelas equações a seguir (OPPENLÄNDER, 2003):

Iniciação:

$$
\mathrm{H}_{2} \mathrm{O}_{2}+\mathrm{hv} \rightarrow 2^{\circ} \mathrm{OH}
$$

Propagação:

$$
\left(\begin{array}{l}
\mathrm{H}_{2} \mathrm{O}_{2}+\stackrel{\circ}{\circ} \mathrm{OH} \rightarrow \mathrm{H}_{2} \mathrm{O}+\mathrm{HO}_{2}^{\cdot} \\
\mathrm{HO}_{2}{ }^{\cdot}+\mathrm{H}_{2} \mathrm{O}_{2} \rightarrow \mathrm{H}_{2} \mathrm{O}+\mathrm{O}_{2}+{ }^{\circ} \mathrm{OH}
\end{array}\right)
$$

Reação global:

$$
2 \mathrm{H}_{2} \mathrm{O}_{2} \rightarrow 2 \mathrm{H}_{2} \mathrm{O}+\mathrm{O}_{2}
$$

Terminação:

$$
\begin{aligned}
& \mathrm{HO}^{\bullet}+{ }^{\bullet} \mathrm{OH} \rightarrow \mathrm{H}_{2} \mathrm{O}_{2} \\
& \mathrm{HO}^{\bullet}+\mathrm{HO}_{2}^{\cdot} \rightarrow \mathrm{H}_{2} \mathrm{O}+\mathrm{O}_{2} \\
& \mathrm{HO}_{2}^{\cdot}+\mathrm{HO}_{2}^{\cdot} \rightarrow \mathrm{H}_{2} \mathrm{O}_{2}+\mathrm{O}_{2}
\end{aligned}
$$

Quando a concentração de peróxido de hidrogênio é elevada, a eficiência do processo é comprometida, pois o peróxido atua como consumidor de radicais (radical scavenger), o que é indesejável ao processo. Para evitar o efeito inibidor e reações 
competitivas, que podem resultar em retardamento da degradação dos poluentes, é necessário avaliar as concentrações ótimas de $\mathrm{H}_{2} \mathrm{O}_{2}$ e de ${ }^{\bullet} \mathrm{OH}$ (TAMBOSI et al., 2010).

É preferível empregar pH baixos (entre 2 e 5), pois o efeito sequestrador de radicais hidroxila por espécies eventualmente presentes em solução, especialmente íons carbonato e bicarbonato, pode comprometer a degradação dos poluentes (GOGATE e PRANDIT, 2004).

\subsection{FÁRMACOS EM ESTUDO E APLICAÇÃO DOS PROCESSOS OXIDATIVOS AVANÇADOS}

\subsubsection{Acetaminofeno}

O acetaminofeno (ACT), também conhecido como paracetamol (Figura 2), é o principal componente ativo de vários antipiréticos e analgésicos, que podem ser adquiridos na maioria dos países sem prescrição médica. Quando ingerido, cerca de 60-70\% do composto original são excretados inalterados pelo organismo (MUIR et al., 1997) e devido a isso, é frequentemente detectado em ambientes aquáticos.

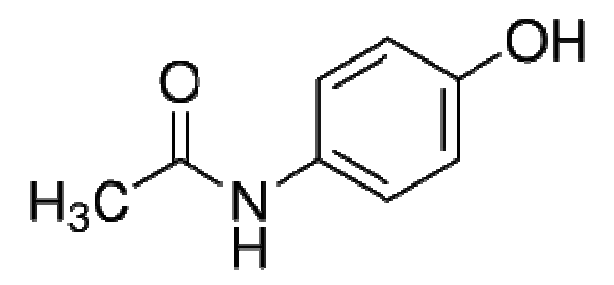

Figura 2 - Fórmula estrutural do acetaminofeno (ACT).

O ACT foi detectado em até $6 \mu \mathrm{g} \mathrm{L}^{-1} \mathrm{em}$ efluentes de ETE Europeias (TERNES, 1998) e a $380 \mathrm{ng} \mathrm{L}^{-1}$ em águas subterrâneas (BARBER et al., 2002). Foi também detectado na faixa de 11-70 $\mathrm{g} \mathrm{L} \mathrm{L}^{-1}$ (em efluente bruto) no rio Tyne no Reino Unido (ROBERTS e THOMAS, 2006) e $10 \mathrm{ng} \mathrm{L}^{-1}$ em córregos dos Estados Unidos (KOLPIN et al., 2002). 
Vários estudos avaliaram técnicas de oxidação para eliminar esse composto da água, entre os quais os trabalhos de Su et al. (2013), Rivas et al. (2011), Yamamoto et al. (2009) e Andreozzi et al. (2003a).

Su et al. (2013) investigaram a degradação do ACT utilizando um reator aerado por meio da reação Fenton. Os parâmetros operacionais estudados foram $\mathrm{pH}$, concentração de íons ferrosos $\left(\mathrm{Fe}^{2+}\right)$ e concentração de $\mathrm{H}_{2} \mathrm{O}_{2}$. As remoções obtidas de ACT e TOC foram de 99\% e 14\%, respectivamente, após 40 minutos.

Rivas et al. (2011) avaliaram a eficiência da fotólise sob radiação UVC aplicada a uma mistura de fármacos (ACT, cafeína, antipirina, doxiciclina e cetorolaco) em água ultrapura e em efluente obtido a partir de ETE. Para o composto ACT, eles obtiveram um valor alto de $\varepsilon$ (coeficiente de absorção molar) e não houve necessariamente alta degradação, indicando um valor de rendimento quântico baixo. Do mesmo modo, uma substância com um valor baixo de $\varepsilon$ pode ser facilmente degradada pela luz, se o valor do rendimento quântico for alto. Concluiu-se que no caso da fotólise da mistura dos fármacos existem alguns efeitos de interação competitiva entre eles (efeito sinérgico). Como regra geral, as taxas de degradação foram reduzidas se comparadas com as observadas por fotólises realizadas com os compostos individualmente. A presença de matéria orgânica natural nos efluentes reais afetou negativamente o processo fotolítico, diminuindo a degradação do fármaco, com a exceção da doxiciclina, cuja fotodegradação foi aumentada. A adição de peróxido de hidrogênio aumentou significativamente a fotodegradação de compostos que mostram valores baixos de degradação; mais uma vez, a exceção foi a doxiciclina.

Yamamoto et al. (2009) selecionaram oito fármacos com potencial relativamente alto de risco ecológico e de consumo elevado (ACT, ATL, carbamazepina, IBU, ifenprodil, indometacina, ácido mefenâmico e propranolol). Experimentos de fotólise com luz solar mostraram que os fármacos propranolol, indometacina, e ifenprodil foram facilmente fotodegradados (remoção de $50 \%$ em menos de $24 \mathrm{~h}$ ), enquanto que os outros cinco fármacos mostraram-se relativamente estáveis à luz solar.

Andreozzi et al. (2003a) estudaram a oxidação do ACT por processo de ozonização e $\mathrm{UV} / \mathrm{H}_{2} \mathrm{O}_{2}$. Ambos os sistemas de oxidação mostraram-se capazes de transformar o anel aromático do substrato com mineralização parcial do fármaco. Para 
as condições experimentais adotadas obtiveram-se até $30 \%$ e $40 \%$ de remoção com ozonização e $\mathrm{UV} / \mathrm{H}_{2} \mathrm{O}_{2}$, respectivamente.

\subsubsection{Atenolol}

O atenolol (ATL), (Figura 3), $\beta$-bloqueador, é prescrito para tratamento de doenças cardiovasculares (anti-hipertensivos ou antiarrítmicos) (ZENG, 2012).<smiles>CC(C)NCC(O)COc1ccc(CC(N)=O)cc1</smiles>

Figura 3 - Fórmula estrutural do atenolol.

Foi detectada a presença de ATL em afluentes e efluentes de estações de tratamento de esgoto e em águas superficiais, como é o caso dos estudos de Calamari et al. (2003), que detectaram concentrações no intervalo 3-241 ng L-1 em águas superficiais da Itália e Bendz et al. (2005) que detectaram $0,3 \mu \mathrm{g} \mathrm{L}^{-1}$ em esgoto bruto e 1,6 $\mathrm{g} \mathrm{L} \mathrm{L}^{-1}$ em efluentes das ETE da Suécia.

Segundo Pomati el al. (2006), o ATL pode inibir o crescimento de células embrionárias humanas e possui efeito tóxico em águas doces. Dessa forma, é importante o desenvolvimento de tecnologias avançadas para garantir a efetiva eliminação desse composto antes do lançamento em águas naturais.

O emprego de processos oxidativos avançados (POA) para mineralização do ATL foi estudado por Zhang et al. (2013), loannou et al. (2011), Salgado et al. (2013) e Rosario-Ortiz et al. (2010), entre outros.

loannou et al. (2011) estudaram a degradação de dois $\beta$-bloqueadores (ATL e propranolol) por meio de $\mathrm{TiO}_{2}$ utilizando luz solar. Através da fotodegradação (com ausência do catalisador) obteve-se remoção de menos de $15 \%$ após 120 min. Pode-se concluir que o desempenho do processo é afetado por vários fatores, incluindo o tipo de catalisador (em 120 min de degradação, a remoção variou de 64\% a 6\% de acordo 
com o tipo de catalisador, entre eles: Degussa P25, Hombicat UV100, Aldrich, Tronox AK-1, Tronox TRHP-2, Tronox TR); a concentração de substrato (quanto maior a concentração inicial menor a taxa de degradação após 120 min de fotocatálise); e a matriz aquosa (efeito prejudicial na remoção dos fármacos, devido à presença de matéria orgânica dissolvida).

Salgado et al. (2013) investigaram a fotólise UV do cetoprofeno, DIC e ATL, tendo determinado os coeficientes de absorção molar $(\varepsilon)$ e os rendimentos quânticos. O valor de $\varepsilon$ foi alto para o cetoprofeno $\left(37155 \mathrm{~L} \mathrm{~mol}^{-1} \mathrm{~cm}^{-1}\right)$ e DIC $\left(5929 \mathrm{~L} \mathrm{~mol}^{-1} \mathrm{~cm}^{-1}\right)$, e baixo para o ATL (527 L mol$\left.{ }^{-1} \mathrm{~cm}^{-1}\right)$, e o valor de rendimento quântico da degradação do cetoprofeno também foi mais elevado em relação aos outros fármacos, o que indica maior eficiência na fotodegradação do cetoprofeno e menor eficiência na fotodegradação do ATL. Os subprodutos da fotólise do cetoprofeno, DIC e ATL foram identificados e monitorados durante o tempo de irradiação. Isto permitiu propor vias de foto-transformação e a identificação dos produtos de transformação mais persistentes.

O estudo de ROSARIO-ORTIZ et al. (2010) consistiu em avaliar a oxidação dos fármacos meprobamato, carbamazepina, dilantina, ATL, primidona e trimetoprimem em três águas residuais por processo $\mathrm{UV} / \mathrm{H}_{2} \mathrm{O}_{2}$. Os resultados indicam que eficiência do processo $\mathrm{UV} / \mathrm{H}_{2} \mathrm{O}_{2}$ para a remoção dos compostos farmacêuticos. Em alguns casos, as remoções superaram 99\%.

\subsubsection{Bezafibrato}

O bezafibrato (BZF) (Figura 4) é uma droga hipolipemiante (fármacos usados no controle do colesterol), pertencente ao grupo dos fibratos. Fibratos ou derivados do ácido fíbrico, segundo Xavier (2013), são os medicamentos para tratamento da hipertrigliceridemia e têm papel significativo no controle das dislipidemias mistas. Os fibratos podem reduzir o risco de doença arterosclerótica coronariana (DAC) em pessoas com hipercolesterolemia e também em pacientes no pós-infarto do miocárdio com níveis de LDL-colesterol (LDL-C) pouco elevados, de HDL-colesterol (HDL-c) baixos e com discretos aumentos de triglicérides (TG). 


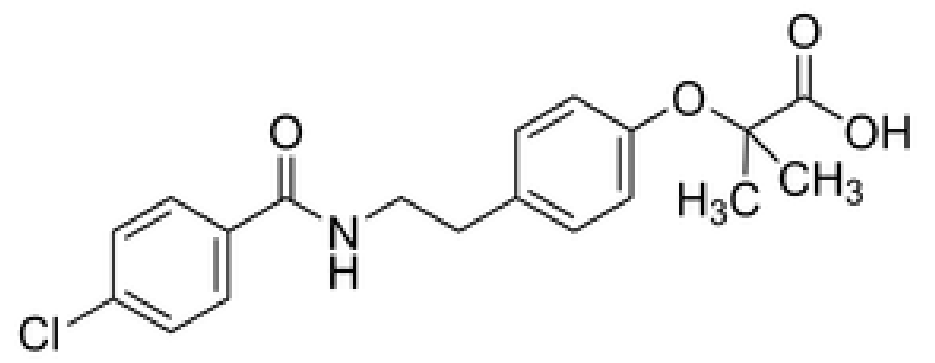

Figura 4 - Fórmula estrutural do bezafibrato.

Foram identificados e quantificados $0,54 \mu \mathrm{g} \mathrm{L}^{-1}$ de BZF em efluentes de ETE da França, 0,30 $\mu \mathrm{g} \mathrm{L}^{-1}$ na Itália e $0,070 \mu \mathrm{g} \mathrm{L}^{-1}$ no Canadá (ANDREOZZI et al., 2003b; GAGNÉ et al., 2006); em esgoto bruto na Finlândia $\left(0,42 \mu \mathrm{g} \mathrm{L}^{-1}\right)$ e no Brasil $\left(1,2 \mu \mathrm{g} \mathrm{L}^{-1}\right)$ (LINDQVIST et al., 2005; STUMPF et al., 1999, respectivamente) e também em águas superficiais na Alemanha $\left(0,35 \mu \mathrm{g} \mathrm{L}^{-1}\right)$ (TERNES, 1998).

Huber et al. (2003) investigaram a oxidação de fármacos (BZF, carbamazepina, diazepam, DIC, 17a-etinilestradiol, IBU, iopromida, sulfametoxazol e roxitromicina) durante a ozonização convencional e processos oxidativos avançados (POA) aplicados ao tratamento de água potável. Obtiveram constantes de velocidade de segunda ordem para as reações dos produtos farmacêuticos selecionados, com ozônio e radicais hidroxila ( $\mathrm{pH} 7$ e 20 学). Na segunda parte do estudo, a cinética da oxidação dos produtos farmacêuticos selecionados foi investigada em experimentos de ozonização em diferentes matrizes aquosas naturais. Em geral, pode-se concluir que ozonização e POA são processos promissores para uma eficiente remoção de fármacos em águas potáveis, permitindo, em média, 98\% de degradação do BZF em diferentes amostras de água superficial.

YUAN et al. (2012) investigaram a degradação do bezafibrato (BZF) em águas superficiais e efluentes de estações de tratamento de águas residuais pelo processo $\mathrm{UV} / \mathrm{H}_{2} \mathrm{O}_{2}$. Os resultados mostraram que o processo $\mathrm{UV} / \mathrm{H}_{2} \mathrm{O}_{2}$ é um método promissor para remover BZF em baixa concentração, geralmente em $\mu \mathrm{L} \mathrm{L}^{-1}$. Para concentrações iniciais de $100 \mu \mathrm{g} \mathrm{L}^{-1}$, em água deionizada, foram removidos mais de 99,8\% após 16 minutos de exposição à luz, empregando $0,1 \mathrm{mg} \mathrm{L}^{-1}$ de $\mathrm{H}_{2} \mathrm{O}_{2}$ e $\mathrm{pH}$ neutro. 


\subsubsection{Diclofenaco}

O diclofenaco (DIC) (Figura 5) é um anti-inflamatório não-esteroide, comumente utilizado para o tratamento de artrite, lesões dos tecidos moles, dismenorreia e menorragia (FEI, 2006). Segundo Zhang (2008) a quantidade de DIC consumida globalmente é estimada em 940 toneladas por ano. Esse valor é estimado de acordo com dados do IMS Health sobre as vendas em 2007 em 76 dos principais países, que representam $96 \%$ do mercado farmacêutico global.<smiles>NC(=O)Cc1ccccc1Nc1c(Cl)cccc1Cl</smiles>

Figura 5 - Fórmula estrutural do diclofenaco.

O DIC é um dos fármacos mais detectados em ambientes aquáticos. ANDREOZZl et al. (2003b) quantificaram em efluentes de ETE $0,33 \mu \mathrm{g} \mathrm{L}^{-1}$ da França, $0,84 \mu \mathrm{g} \mathrm{L}^{-1}$ da Grécia e 2,47 $\mu \mathrm{g} \mathrm{L}^{-1}$ da Itália. BENDZ et al. (2005) detectaram $0,16 \mu \mathrm{g} \mathrm{L}^{-1}$ em esgoto bruto na Suécia. GHISELLI (2006) encontrou no Brasil 2,9 $\mathrm{\mu g} \mathrm{L}^{-1}$ em esgoto bruto, $1,8 \mu \mathrm{g} \mathrm{L}^{-1}$ em efluentes de ETE e 4,0 $\mathrm{g} \mathrm{L}^{-1}$ em águas superficiais.

Mesmo sob concentrações baixas, foram observados efeitos tóxicos subletais sobre peixes, após a exposição ao DIC, revelando alterações dos rins e guelras (SCHWAIGER et al., 2004).

Vários processos oxidativos avançados vêm sendo utilizados para eliminação do diclofenaco (DIC) de matrizes aquosas, entre eles o foto-Fenton (RAVINA et al., 2002), UV e UV/ $\mathrm{H}_{2} \mathrm{O}_{2}$ (BAEZA et al., 2011) e por processos de ozonização e UV/ $\mathrm{H}_{2} \mathrm{O}_{2}$ (Vogna et al., 2004).

Ravina et al. (2002) alcançaram a mineralização total do diclofenaco em solução em menos de uma hora por meio da reação foto-Fenton.

BAEZA et al. (2011) determinaram as taxas de oxidação de sulfametoxazol, sulfametazina, sulfadiazina, bisfenol A e DIC realizadas com processo UV com 
lâmpada de mercúrio de baixa pressão e UV/ $\mathrm{H}_{2} \mathrm{O}_{2}$, com concentração de $10 \mathrm{mg} \mathrm{L}^{-1}$ $\mathrm{H}_{2} \mathrm{O}_{2}$. A remoção do DIC foi de aproximadamente $90 \%$, sendo o composto que apresentou maior taxa de degradação pelo processo $\mathrm{UV} / \mathrm{H}_{2} \mathrm{O}_{2}$.

Vogna et al. (2004) avaliaram a degradação de DIC por processos de ozonização e $\mathrm{UV} / \mathrm{H}_{2} \mathrm{O}_{2}$. Ambos mostraram-se eficazes na degradação do DIC, garantindo completa conversão do cloro orgânico em íons cloreto e mineralização de $32 \%$ para a ozonização e de $39 \%$ para o $\mathrm{UV} / \mathrm{H}_{2} \mathrm{O}_{2}$ após 90 minutos de tratamento.

\subsubsection{Ibuprofeno}

O ibuprofeno (IBU) (Figura 6) é empregado para o alívio dos sintomas da artrite, dismenorreia primária, febre, e como analgésico, especialmente para casos de doença inflamatória. É conhecido por apresentar bom efeito anti-plaquetário, sendo um fármaco anti-inflamatório não esteróide do ácido propiônico (ILLÉS et al., 2013).<smiles>CC(C)Cc1ccc(C(C)C(=O)O)cc1</smiles>

Figura 6 - Fórmula estrutural do Ibuprofeno.

Segundo Illés et al. (2013), o IBU é comumente detectado em efluentes de estações de tratamento de águas residuais e em águas superficiais em concentrações de $\mathrm{ng} \mathrm{L}^{-1}$ a $\mu \mathrm{g} \mathrm{L}^{-1}$. Embora muito baixa, nessa concentração o fármaco pode vir a apresentar risco para a saúde humana e também para o ecossistema aquático.

A degradação do IBU foi estudada a partir de diferentes aplicações de processos oxidativos avançados (POA), como é o caso dos trabalhos de Yuan et al. (2009) e Achilleos et al. (2010).

Yuan et al. (2009) estudaram a degradação dos compostos farmacêuticos IBU, difenidramina (DP), fenazona (PZ) e fenitoína (PHT) por fotólise e $U V / \mathrm{H}_{2} \mathrm{O}_{2}$ com lâmpada de mercúrio de baixa pressão (LP). Foi observada cinética de pseudo 
primeira-ordem para a degradação dos fármacos, tanto por fotólise direta como por $\mathrm{UV} / \mathrm{H}_{2} \mathrm{O}_{2}$. As remoções por fotólise direta (irradiância de1272 $\mathrm{mJ} \mathrm{cm}^{-2}$ ) foram de $27 \%$, $26 \%, 96 \%$ e $88 \%$ para os fármacos IBU, DP,PZ e PHT, respectivamente. Quando a irradiância empregada na fotólise direta foi diminuída $\left(40 \mathrm{~mJ} \mathrm{~cm}{ }^{-2}\right.$ ), não houve degradação dos fármacos IBU e DP, porém quando se adicionou $\mathrm{H}_{2} \mathrm{O}_{2}$ (concentração de $0,29 \mathrm{mmol} \mathrm{L}^{-1}$ ) as taxas de degradação aumentam (aproximadamente $26 \%$ de remoção para IBU e $19 \%$ para o DP); aumentando-se a concentração de $\mathrm{H}_{2} \mathrm{O}_{2}$ (concentração de $1 \mathrm{mmol} \mathrm{L}^{-1}$ ), ocorreu decréscimo da remoção (40\% e 27\% para IBU e DP, respectivamente).

Achilleos et al. (2010) tiveram como objetivo investigar a eficiência da fotólise e fotócatálise com suspensão de $\mathrm{TiO}_{2}$ para degradação do IBU e carbamazepina (CBZ), utilizando radiação UVA e luz solar. Os resultados dos experimentos de fotólise indicaram remoção de apenas 4\% para o IBU e 7\% para (CBZ) em 120 min de exposição. Com a presença do fotocatalisador a remoção do IBU foi de aproximadamente $62 \%$ e $74 \%$ para a CBZ após 120 min.

\subsection{MECANISMOS DE DEGRADAÇÃO}

Pozdnyakova et al. (2004) estudaram a fotólise do ACT empregando radiação UV de comprimento de onda $254 \mathrm{~nm}$. Foi confirmada a formação de apenas um subproduto pelo fato do espectro de absorção da solução apresentar apenas um isobéstico durante a fotólise. Esse subproduto é o 1-(2-amino-5-hidroxifenil)-etanona (P1), apresentado na Figura 7.

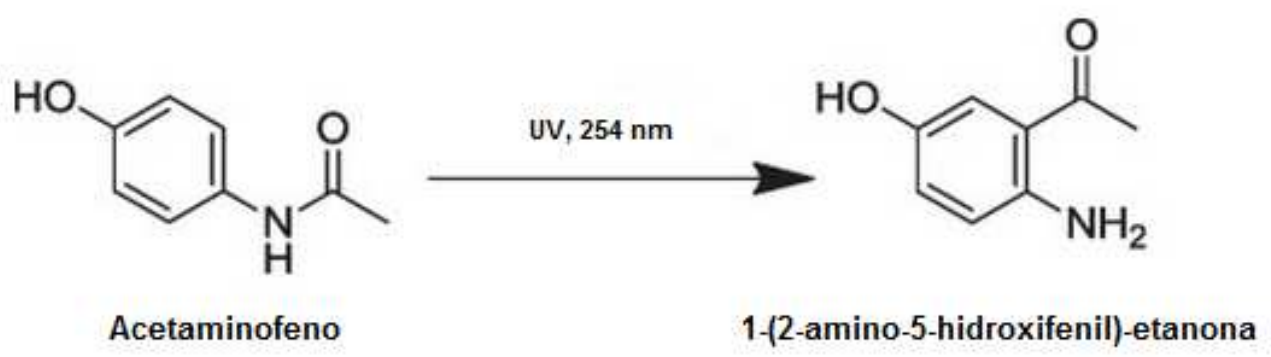

Figura 7 - Degradação do ACT com a formação de 1-(2-amino-5-hidroxifenil)-etanona (P1). 
Kawabata et al. (2012) estudaram a fotodegradação do ACT, exposto à radiação UVC de $254 \mathrm{~nm}$ com lâmpada $6 \mathrm{~W}$ de potência, por exposição de 96 horas. O estudo indicou que o ACT é fotodegradado por exposição à radiação UV em 254 nm e também mostrou-se a formação do subproduto 1-(2-amino-5-hidroxifenil)-etanona (P1) (Figura 7). Esse subproduto é gerado por uma reação de rearranjo intramolecular, pois possui a mesma fórmula molecular que o ACT. Neste estudo foi realizada a avaliação da toxicidade por bactérias luminescentes, indicando que a solução de ACT não era tóxica, e após a fotodegradação a solução mostrou-se tóxica, devido à formação de tal subproduto.

No estudo da degradação do ATL por processo UVA-UVB com exposição de 15 horas, realizado por Andrisano et al. (1999), o mecanismo proposto envolve a fotólise da ligação do grupo éter do ATL obtendo o principal subproduto identificado, o 2-(4hidroxifenil) acetamida (I). Os autores também sugerem que ocorre a desidratação do ATL originando o subproduto (II) em níveis de traços. Assim o mecanismo de reação da fotólise do ATL pode ser resumido como mostrado na Figura 8.<smiles>CC(C)NCC(O)COc1ccc(CC(N)=O)cc1</smiles><smiles>CC(C)NCC=COc1ccc(CC(N)=O)cc1</smiles>

Figura 8 - Via de mecanismo da fotólise do ATL. Fonte: Andrisano et al. (1999). 
Yuan et al. (2012) propuseram a via de degradação (Figura 9) do BZF durante a fotodegradação por processo $\mathrm{UV} / \mathrm{H}_{2} \mathrm{O}_{2}$.

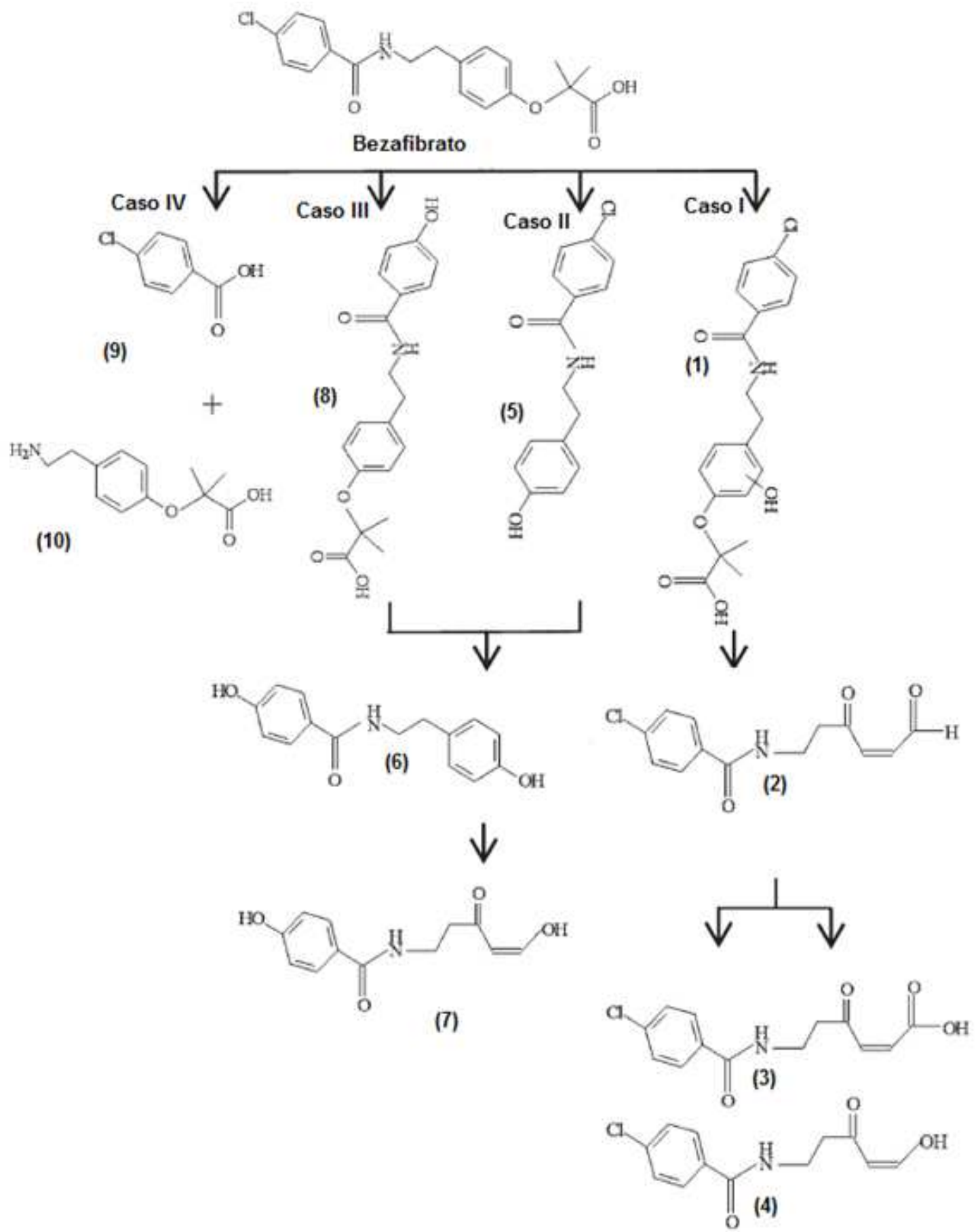

Figura 9 - Via de degradação do BZF por processo UV/H2O2. Adaptado de Yuan et al. (2012). 
A via proposta por Yuan et al. (2012) segue quatro casos. O primeiro caso envolve a hidroxilação do anel aromático formando o subproduto $1\left(377 \mathrm{~g} \mathrm{~mol}^{-1}\right)$, em seguida, ele sofre a abertura do anel que forma o subproduto $2\left(265 \mathrm{~g} \mathrm{~mol}^{-1}\right)$. O subproduto $3\left(281 \mathrm{~g} \mathrm{~mol}^{-1}\right)$ é resultado da reação de oxidação pelo radical hidroxila do subproduto $2\left(265 \mathrm{~g} \mathrm{~mol}^{-1}\right)$, e o subproduto $4\left(253 \mathrm{~g} \mathrm{~mol}^{-1}\right)$ foi obtido pela clivagem da ligação C-C do subproduto $2\left(265 \mathrm{~g} \mathrm{~mol}^{-1}\right)$, com o grupo aldeído substituído por um radical hidroxila. O segundo caso envolve a adição do radical hidroxila ao BZF formando o subproduto $5\left(275 \mathrm{~g} \mathrm{~mol}^{-1}\right)$, com a remoção da cadeia de fibrato. $O$ cloro é substituído pelo radical hidroxila originando assim o subproduto $6\left(257 \mathrm{~g} \mathrm{~mol}^{-1}\right)$ que poderá, através da reação de abertura do anel, formar o subproduto $7\left(235 \mathrm{~g} \mathrm{~mol}^{-1}\right)$. No terceiro caso, ocorre a reação de substituição e adição do radical hidroxila (subproduto 8) e em seguida, como no segundo caso, gerando os subprodutos 6 e 7. E no quarto caso, os subprodutos 9 e 10 (157 e $223 \mathrm{~g} \mathrm{~mol}^{-1}$, respectivamente) foram obtidos pela quebra da amida.

Pinto (2013) propõe a rota (inicial) de degradação do DIC via fotólise, como ilustrado na Figura 10. Primeiramente há perda de um dos cloros e a formação de uma ligação carbono-carbono entre anéis gerando o subproduto carbozol (1). A espécie 2 $\left(241 \mathrm{~g} \mathrm{~mol}^{-1}\right)$ é formada pela degradação desse intermediário ocasionando a perda do outro cloro e hidroxilação da espécie 2. E por fim mais um intermediário (espécie 3, 255 $\mathrm{g} \mathrm{mol}^{-1}$ ) quinona-imina, resultante da hidroxilação da porção ácido fenilacético do DIC. Constata-se também a formação de um subproduto (espécie 4, $161 \mathrm{~g} \mathrm{~mol}^{-1}$ ) devido à quebra de uma das ligações nitrogênio-carbono.

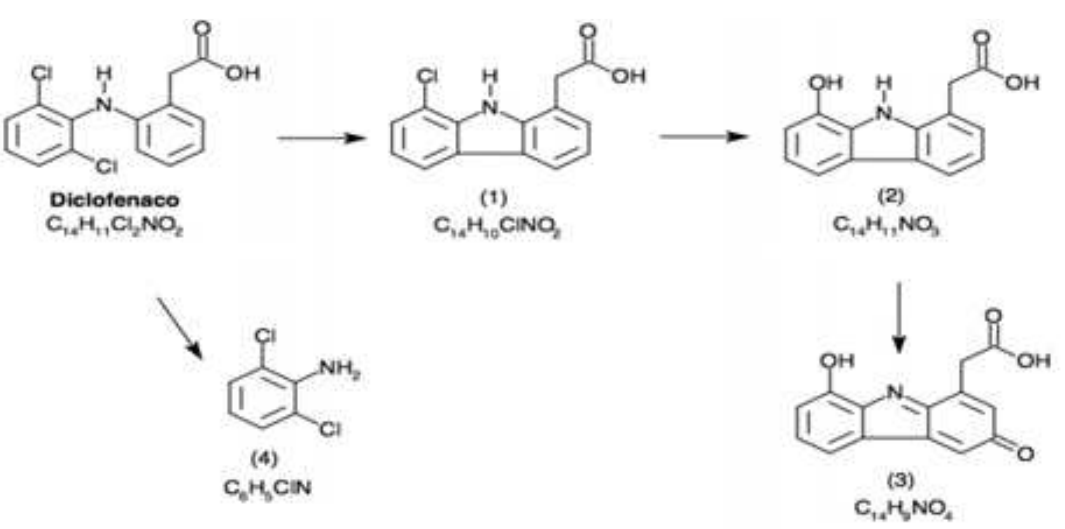

Figura 10 - Mecanismo inicial de degradação do diclofenaco via fotólise. Fonte: Pinto (2003). 
Keen et al. (2013) observaram a formação de dímero durante a radiação (UV) do DIC. Os dímeros formam produtos que apresentam cores visíveis. O oxigênio singlete mostrou um papel útil na formação de dímeros, formando produtos intermediários de epóxido. A via proposta de formação de dímeros está apresentada na Figura 11.

A via proposta por Keen et al. (2013) segue da seguinte maneira: o DIC perde um cloro fechando o anel médio (subproduto 1, carbozol) e então perde o segundo cloro (subproduto 2), no subproduto 2 pode ser adicionados dois átomos de oxigênio por meio de ligações duplas nos carbonos aromáticos, originando o subproduto 3. Para formação do subproduto 4 (epóxido), o composto DIC, ainda com os cloros, sofre a ligação de oxigênio e perda de dois átomos de hidrogênio. $O$ subproduto 5 é formado pela combinação do subproduto 4 e do DIC, formando um dímero com quatro cloros em sua composição. E por fim o subproduto 6 é formado pela combinação do subproduto 3 (átomos de oxigênios adicionado) com o DIC.

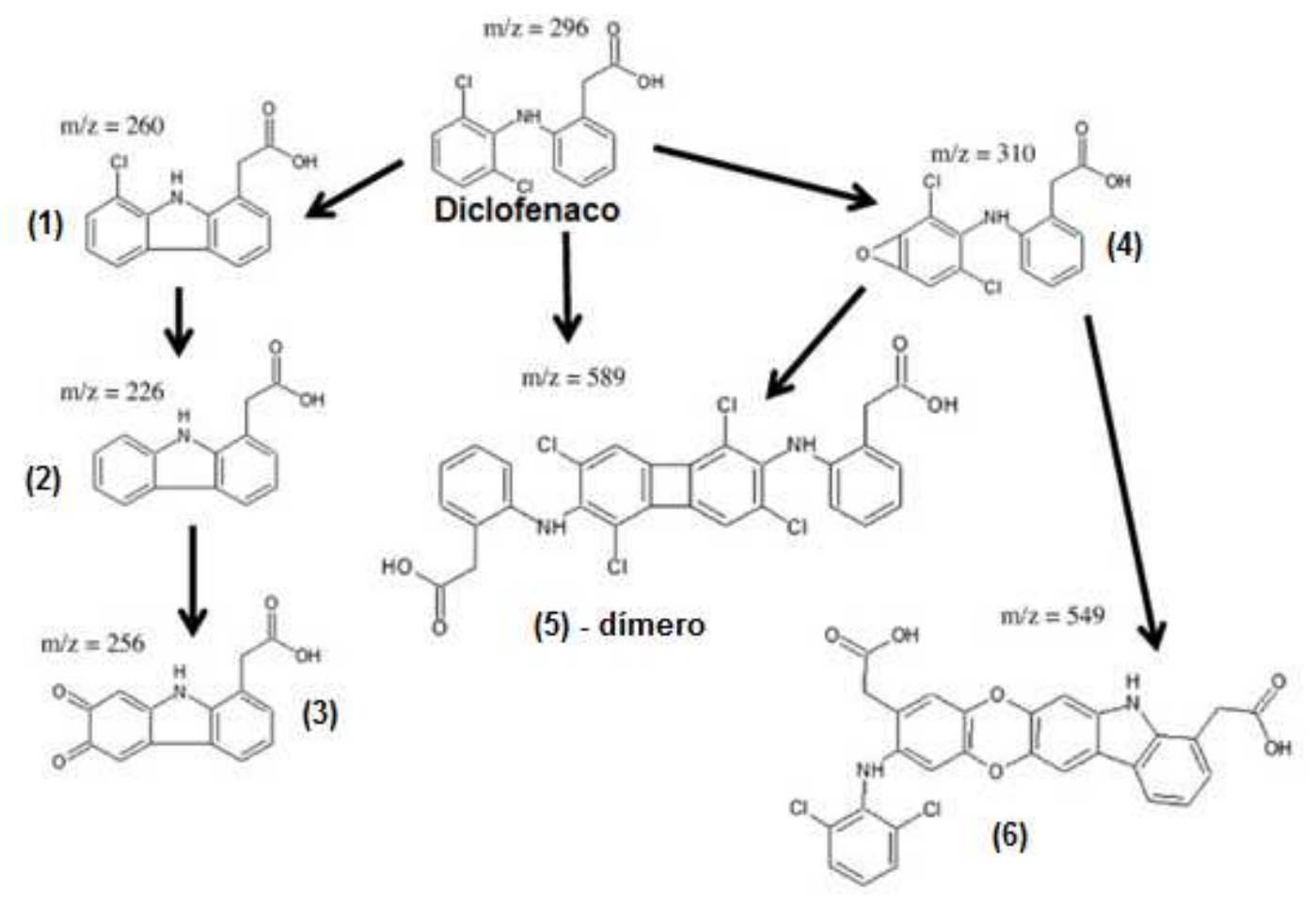

Figura 11 - Via de formação de dímero proposto. Adaptado de Keen et al. (2013).

A foto-transformação do ibuprofeno (IBU) foi estudada por Szabó et al. (2011), encontrando quatro subprodutos de degradação, apresentados na Tabela 5. 
Tabela 5 - Subprodutos de degradação do ibuprofeno por fotólise. Adaptado de Szabó et al. (2011).

\begin{tabular}{|c|c|c|}
\hline Subprodutos de degradação & $m / z$ & Estrutura \\
\hline 1-etil-4-(2-metilpropil)-benzeno & 162 & \\
\hline 1-etenil-4-(2-metilpropil)-benzeno & 160 & \\
\hline 1-(1-hidroxietil)-4-isobutil-benzeno & 178 & \\
\hline 4'-(2-metilpropil) acetofenona & 176 & \\
\hline
\end{tabular}

Szabó et al. (2011) confirmaram que ocorreu a descarboxilação do composto IBU. A formação de um derivado de acetofenona pode causar o aumento de taxa de fotodegradação, devido às suas propriedades de fotossensibilização.

\section{MATERIAIS E MÉTODOS}

\subsection{REAGENTES}

No preparo das soluções para obtenção das curvas de calibração cromatográfica, utilizou-se água milli-Q (Millipore). Para preparação da fase móvel foram utilizados ácido acético 100\% (Merck) e metanol grau HPLC (J. T. Baker). Para preparo das soluções de fármacos empregadas nos experimentos de degradação UV e $U V / \mathrm{H}_{2} \mathrm{O}_{2}$, utilizou-se água purificada por osmose inversa produzida no equipamento PURELAB Prima (ELGA). Para preparação das soluções usadas para ajuste de $\mathrm{pH}$ foram utilizados ácido sulfúrico 98\% P.A. e hidróxido de sódio P.A. (Vetec). Os fármacos utilizados nos experimentos foram: acetaminofeno (ACT), atenolol (ATL), bezafibrato (BZF), diclofenaco (DIC) e ibuprofeno (IBU), todos adquiridos da Sigma- 
Aldrich. $\mathrm{O} \mathrm{n}^{\circ} \mathrm{CAS}$, pureza, massa molar, as fórmulas molecular e estrutural são apresentados na Tabela 6.

Tabela 6 - Número CAS, pureza, massa molar, fórmulas molecular e estrutural dos fármacos.

\begin{tabular}{|c|c|c|c|}
\hline $\begin{array}{l}\text { Fármaco } \\
\left(n^{\circ} \mathrm{CAS}\right)\end{array}$ & Pureza & $\begin{array}{c}\text { Fórmula molecular } \\
\text { (massa molar) }\end{array}$ & Fórmula estrutural \\
\hline $\begin{array}{c}\text { Acetaminofeno } \\
(103-90-2)\end{array}$ & $\geq 99,0 \%$ & $\begin{array}{l}\mathrm{C}_{8} \mathrm{H}_{9} \mathrm{NO}_{2} \\
\left(151,16 \mathrm{~g} \mathrm{~mol}^{-1}\right)\end{array}$ & \\
\hline $\begin{array}{c}\text { Atenolol } \\
(29122-68-7)\end{array}$ & $\geq 98,0 \%$ & $\begin{array}{c}\mathrm{C}_{14} \mathrm{H}_{22} \mathrm{~N}_{2} \mathrm{O}_{3} \\
\left(266,34 \mathrm{~g} \mathrm{~mol}^{-1}\right)\end{array}$ & \\
\hline $\begin{array}{l}\text { Bezafibrato } \\
(41859-67-0)\end{array}$ & $\geq 98,0 \%$ & $\begin{array}{c}\mathrm{C}_{19} \mathrm{H}_{20} \mathrm{NClO}_{4} \\
\left(361,82 \mathrm{~g} \mathrm{~mol}^{-1}\right)\end{array}$ & \\
\hline $\begin{array}{l}\text { Diclofenaco } \\
(15307-79-6)\end{array}$ & n. c. & $\begin{array}{l}\mathrm{C}_{14} \mathrm{H}_{10} \mathrm{NNaCl}_{2} \mathrm{O}_{2} \\
\left(318,13 \mathrm{~g} \mathrm{~mol}^{-1}\right)\end{array}$ & \\
\hline $\begin{array}{c}\text { Ibuprofeno } \\
(15687-27-1)\end{array}$ & $\geq 98,0 \%$ & $\begin{array}{c}\mathrm{C}_{13} \mathrm{H}_{18} \mathrm{O}_{2} \\
\left(206,28 \mathrm{~g} \mathrm{~mol}^{-1}\right)\end{array}$ & $\mathrm{H}_{3}$ \\
\hline
\end{tabular}

n. c. não consta. 


\subsection{EQUIPAMENTO EXPERIMENTAL E PROCEDIMENTOS}

\subsubsection{Equipamento Experimental}

Os experimentos de fotólise UV e peroxidação fotoassistida $\left(\mathrm{UV} / \mathrm{H}_{2} \mathrm{O}_{2}\right)$ foram realizados em um reator fotoquímico tubular confeccionado em vidro borossilicato (diâmetro interno do tubo externo, 113,6 mm; comprimento irradiado, $1120 \mathrm{~mm}$ ), no interior do qual é inserida concentricamente uma lâmpada tubular de vapor de mercúrio de baixa pressão (LP) (Philips, modelo TUV), de potência elétrica 36 ou $75 \mathrm{~W}$. O espectro de emissão da lâmpada é ilustrado na Figura 12. O fluido escoa pela região anular entre a lâmpada e a parede interna do tubo externo, em contato direto com a parede da fonte radiante.

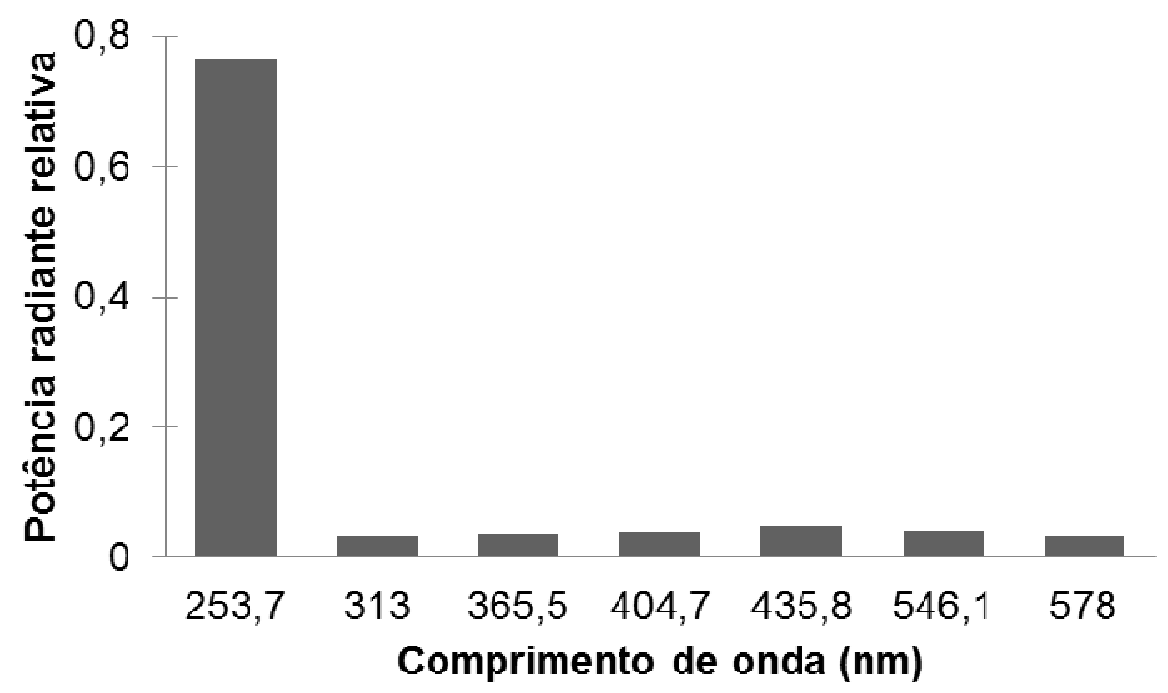

Figura 12 - Espectro da lâmpada de mercúrio de baixa pressão (LP). Fonte: fabricante.

O volume irradiado é igual a 3,93 L, sendo o comprimento da região irradiada igual a $1120 \mathrm{~mm}$. O reator foi operado em batelada com recirculação de líquido, conectado a um tanque de recirculação em vidro com volume de $1 \mathrm{~L}$. A temperatura foi mantida a $25{ }^{\circ} \mathrm{C}$ por meio de um banho termostático (marca Julabo, modelo EC). $\mathrm{O}$ conteúdo do tanque é agitado por meio de um agitador mecânico. A circulação de líquido é feita entre o tanque e o reator fotoquímico empregando-se uma bomba centrífuga; a vazão é ajustada por meio de uma válvula agulha e lida em um rotâmetro 
(Tecnal, TE139). A Figura 13 apresenta uma fotografia e a Figura 14 apresenta o esquema do equipamento experimental.

As medidas de $\mathrm{pH}$ foram realizadas empregando-se um equipamento Tecnal 3MP, anteriormente calibrado com soluções-tampão de $\mathrm{pH} 4$ e pH 7. O eletrodo do pHmetro foi inserido diretamente na solução contida no tanque de recirculação. $O$ programa usado para integração do sensor de $\mathrm{pH}$ da Tecnal modelo Tec3-MP via comunicação serial RS232, foi o Labview 2011 da National Instruments. O programa desenvolvido faz a interpretação do sinal do aparelho medidor de $\mathrm{pH}$, separa os dados de temperatura e da medida de $\mathrm{pH}$ e em média a cada 30 segundos armazena os dados em uma planilha, os valores interpretados bem como o instante de cada medição.

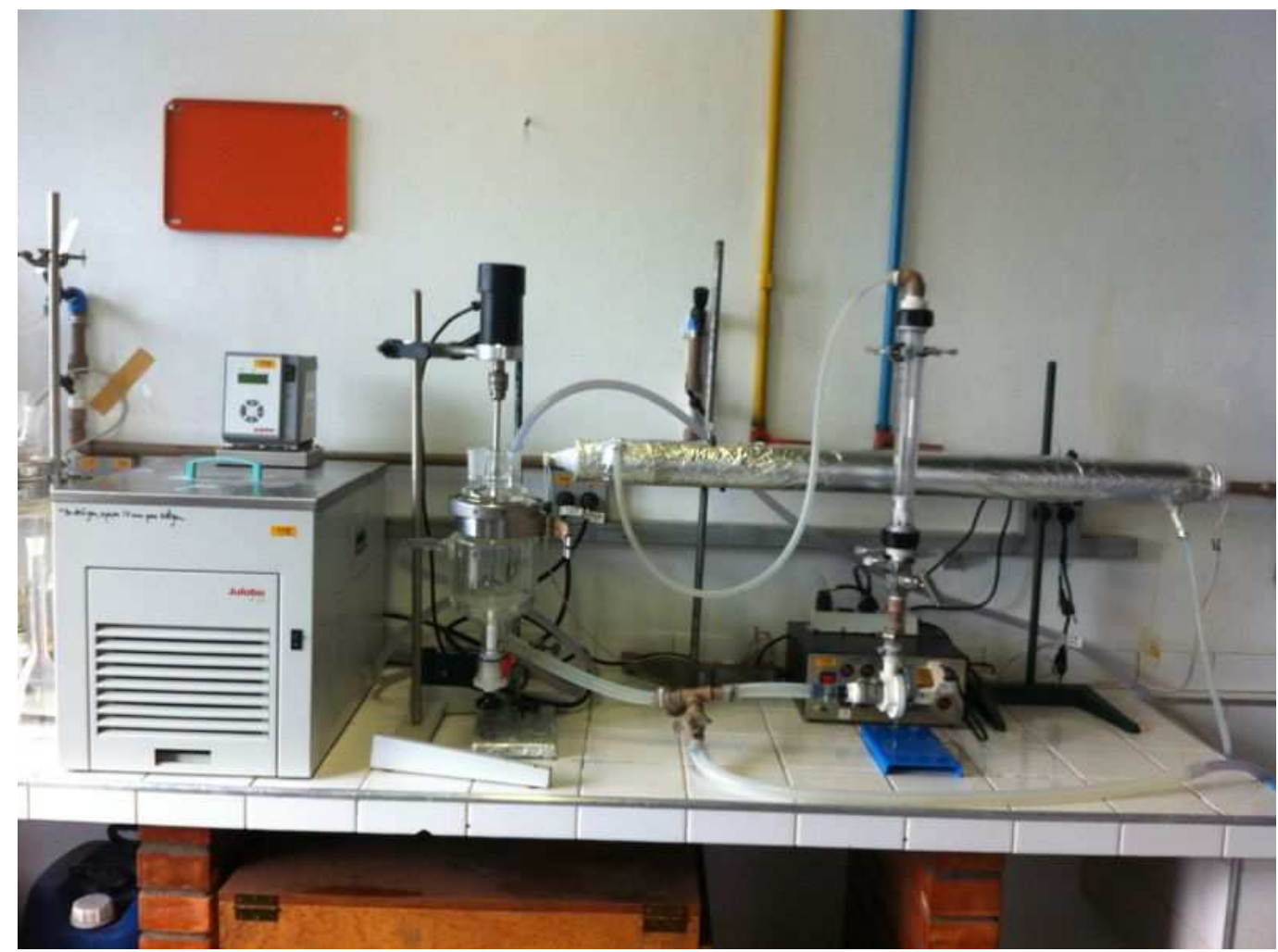

Figura 13 - Foto do equipamento experimental utilizado no trabalho. 


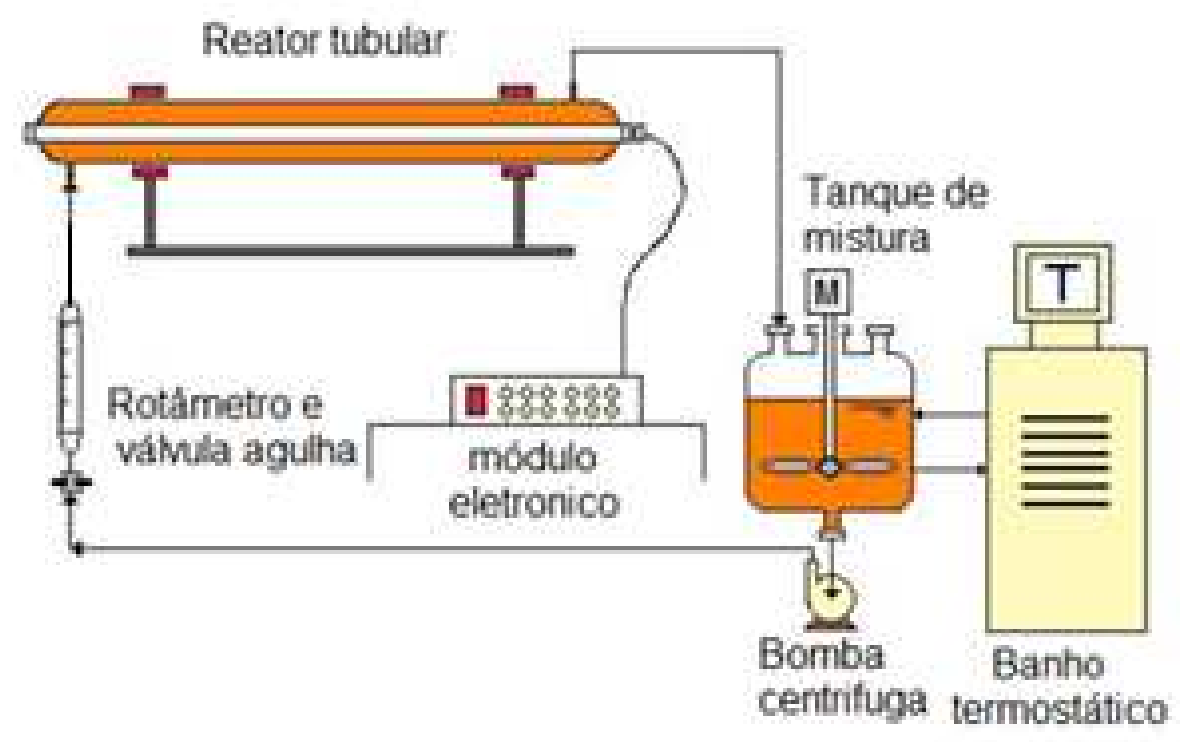

Figura 14 - Esquema do equipamento experimental empregado no trabalho. Adaptado de BASTOS (2012).

\subsubsection{Procedimentos}

\subsubsection{Determinação dos valores de $\mathrm{pK}_{\mathrm{a}}$ dos fármacos}

As constantes de equilíbrio ácido-base (e, logo, os valores de $\mathrm{pK}_{\mathrm{a}}$ ) de cada fármaco foram determinadas a partir de dez soluções aquosas de cada um, de mesma concentração (5 mg L$\left.{ }^{-1}\right)$, com pH entre 2 e 11, para as quais foram obtidos os espectros de absorção UV-visível empregando-se um espectrofotômetro Varian Cary 50. Os valores de pKa foram obtidos a partir dos gráficos de absorbância em função do $\mathrm{pH}$ para os comprimentos de onda em que se verificaram os máximos correspondentes às formas protonada e desprotonada de cada fármaco. 
4.2.2.2 Determinação dos coeficientes de absorção molar dos fármacos

Para determinar os coeficientes de absorção molar de cada fármaco, prepararam-se soluções com concentrações iguais a 0,5, 1, 2, 3 e $5 \mathrm{mg} \mathrm{L}^{-1}$. Foram preparadas soluções em pH 2, 5 e 12, ajustados com soluções de $\mathrm{H}_{2} \mathrm{SO}_{4}$ e de $\mathrm{NaOH}$. Após análise em espectrofotômetro UV-visível (Varian Cary 50), obtiveram-se os coeficientes angulares das curvas de absorbância em função da concentração (correspondentes ao coeficiente de absorção molar, conforme a Lei de Lambert-Beer, Equação 14) para o intervalo de comprimento de onda de 200 a $340 \mathrm{~nm}$. Nessa equação, $A$ é absorbância, $c$ é a concentração molar $\left(\mathrm{mol} \mathrm{L}^{-1}\right), \varepsilon$ é o coeficiente de absorção molar $\left(\mathrm{L} \mathrm{mol}^{-1} \mathrm{~cm}^{-1}\right)$ e l, o caminho óptico $(1 \mathrm{~cm})$.

$$
A=c . \varepsilon . l
$$

\subsubsection{Experimentos de hidrólise}

Os experimentos de hidrólise foram realizados para cada fármaco individualmente e também para a mistura entre eles; em todos os casos a concentração inicial do fármaco foi igual a $5 \mathrm{mg} \mathrm{L}^{-1}$. Utilizaram-se três diferentes valores de $\mathrm{pH}(3,7$ e 9$)$. Os ensaios foram realizados em ambiente escuro, a $25^{\circ} \mathrm{C}$, em frascos âmbar. $\mathrm{O}$ ajuste do $\mathrm{pH}$ foi feito com soluções de $\mathrm{H}_{2} \mathrm{SO}_{4}$ e $\mathrm{NaOH}$. Os experimentos foram realizados em triplicata e as amostras foram retiradas nos tempos $0 \mathrm{~h}, 6 \mathrm{~h}$ e $24 \mathrm{~h}$, após o que foram agitadas manualmente e analisadas por cromatografia líquida. 


\subsubsection{Experimentos de degradação por fotólise}

Antes de iniciar os experimentos realizou-se a limpeza do reator com água da rede e, em seguida, com água purificada por osmose inversa produzida no equipamento PURELAB Prima (ELGA).

Para preparar a solução aquosa dos fármacos, utilizou-se uma balança analítica (Mettler Toledo, modelo XS205 Dual Range) para pesar a massa de cada composto; a massa pesada foi dissolvida em água em um balão volumétrico de $2 \mathrm{~L}$, utilizando-se um banho ultrassônico (Fisher Scientific, modelo FS110); a solução do balão foi transferida para o reator e mais $3 \mathrm{~L}$ de água foram adicionados. $\mathrm{O} \mathrm{pH}$ foi ajustado ao valor inicial desejado $(\mathrm{pH}$ 2) e também no decorrer do experimento, com solução aquosa de $\mathrm{H}_{2} \mathrm{SO}_{4} 2 \mathrm{~mol} \mathrm{~L}^{-1}$. Por último, acionou-se o banho termostático para manter a temperatura do conteúdo do reator constante a $25^{\circ} \mathrm{C}$.

Antes de irradiar a solução, coletou-se a amostra inicial, após o que se acionou a lâmpada e deu-se início à coleta de amostras em tempos pré-determinados. As amostras foram caracterizadas segundo as técnicas analíticas descritas posteriormente.

Ao final do experimento, a solução foi descarregada e foi feita a limpeza do equipamento.

Os experimentos com a mistura de fármacos foram realizados segundo um planejamento fatorial completo em dois níveis $\left(2^{2}\right.$ ), para potência da lâmpada (36 ou 75 W) e para a concentração inicial do fármaco (5 ou $20 \mathrm{mg} \mathrm{L}^{-1}$ ). Para os experimentos realizados com os fármacos individuais variou-se apenas a concentração inicial (5 ou $20 \mathrm{mg} \mathrm{L}^{-1}$ ), para potência de $75 \mathrm{~W}$.

4.2.2.4.1 Experimentos de fotólise usando efluente de estação de tratamento de esgotos (ETE)

A fim de avaliar o efeito da matriz aquosa quanto à degradação dos fármacos estudados, alguns experimentos de fotólise foram realizados com o efluente tratado de 
uma estação de tratamento de esgoto (ETE) (unidade piloto do campo experimental de tratamento de esgoto do Centro Tecnológico de Hidráulica (CTH), Departamento de Engenharia Hidráulica e Sanitária da Escola Politécnica da USP). O esgoto sanitário que é encaminhado para a unidade piloto é proveniente do CRUSP - Conjunto Residencial da USP, composto dos esgotos dos apartamentos e do Restaurante Universitário.

O efluente coletado na saída da ETE foi filtrado e utilizado no mesmo dia para realização dos experimentos. Esse efluente filtrado foi empregado para preparação da solução contendo a mistura de fármacos; o procedimento foi idêntico ao descrito em 4.2.2.4. Os experimentos foram realizados em duplicata, para duas concentrações iniciais de cada fármaco (5 ou $20 \mathrm{mg} \mathrm{L}^{-1}$ ) e potência da lâmpada de $75 \mathrm{~W}$ em pH 2.

\subsection{Experimentos de degradação por peroxidação fotoassistida $\left(\mathrm{UV} / \mathrm{H}_{2} \mathrm{O}_{2}\right)$}

Os experimentos de degradação pelo processo $\mathrm{UV} / \mathrm{H}_{2} \mathrm{O}_{2}$ foram realizadas de forma análoga aos experimentos de fotólise (cf. 4.2.2.4), com adição da solução de $\mathrm{H}_{2} \mathrm{O}_{2}$ concentrada ( $23 \%$ em massa) em solução aquosa, previamente à irradiação.

$\mathrm{O}$ cálculo do volume de solução de $\mathrm{H}_{2} \mathrm{O}_{2}$ a ser utilizado foi realizado considerando a quantidade necessária para mineralização total de cada fármaco, estimada com base na estequiometria das reações a seguir:

i) Acetaminofeno:

$\mathrm{C}_{8} \mathrm{H}_{9} \mathrm{NO}_{2}+21 \mathrm{H}_{2} \mathrm{O}_{2} \rightarrow 8 \mathrm{CO}_{2}+25 \mathrm{H}_{2} \mathrm{O}+\mathrm{HNO}_{3}$

ii) Atenolol:

$\mathrm{C}_{14} \mathrm{H}_{22} \mathrm{~N}_{2} \mathrm{O}_{3}+41 \mathrm{H}_{2} \mathrm{O}_{2} \rightarrow 14 \mathrm{CO}_{2}+51 \mathrm{H}_{2} \mathrm{O}+2 \mathrm{HNO}_{3}$

iii) Bezafibrato:

$\mathrm{C}_{19} \mathrm{H}_{20} \mathrm{NClO}_{4}+46 \mathrm{H}_{2} \mathrm{O}_{2} \rightarrow 19 \mathrm{CO}_{2}+55 \mathrm{H}_{2} \mathrm{O}+\mathrm{HNO}_{3}+\mathrm{HCl}$ 
iv) Diclofenaco:

$\mathrm{C}_{14} \mathrm{H}_{10} \mathrm{NNaCl}_{2} \mathrm{O}_{2}+33 \mathrm{H}_{2} \mathrm{O}_{2} \rightarrow 14 \mathrm{CO}_{2}+37 \mathrm{H}_{2} \mathrm{O}+\mathrm{HNO}_{3}+\mathrm{HCl}+\mathrm{NaCl}$

v) Ibuprofeno:

$\mathrm{C}_{13} \mathrm{H}_{18} \mathrm{O}_{2}+33 \mathrm{H}_{2} \mathrm{O}_{2} \rightarrow 13 \mathrm{CO}_{2}+42 \mathrm{H}_{2} \mathrm{O}$

Foram realizados experimentos com a mistura dos fármacos com concentração inicial de cada de 5 ou $20 \mathrm{mg} \mathrm{L}^{-1}$ e potência da lâmpada de $75 \mathrm{~W}$.

\subsection{Análises}

4.3.1 Carbono Orgânico Total (TOC)

A concentração de carbono orgânico total (TOC) das amostras foi determinada empregando-se o equipamento Shimadzu, modelo TOC-5000A. O TOC foi determinado indiretamente pela diferença entre o conteúdo de carbono total da amostra (CT) e o carbono inorgânico (Cl).

\subsubsection{Espectrofotometria UV-visível}

Os espectros de absorção UV-visível foram obtidos em um espectrofotômetro Varian Cary 50. A varredura foi realizada entre 190 e 820 nm, com resolução de $1 \mathrm{~nm}$. Empregou-se uma cubeta de quartzo com caminho óptico de $1 \mathrm{~cm}$.

\subsubsection{Cromatografia Líquida de Alta Eficiência}

A quantificação dos fármacos foi realizada por cromatografia líquida de alta eficiência (HPLC), empregando-se um cromatógrafo Shimadzu modelo 10-AD, com 
detector UV-visível modelo SPD 20A. A análise cromatográfica foi otimizada para identificar e quantificar simultaneamente os cinco fármacos utilizados neste trabalho. Para separação dos compostos utilizou-se uma coluna C18 Luna (250 mm × 4,6 mm, 5 $\mu \mathrm{m})$ da Phenomenex, equipada com pré-coluna apropriada (Phenomenex). A temperatura da coluna foi mantida em $40^{\circ} \mathrm{C}$. A análi se foi realizada utilizando-se água milli-Q (fase A) e metanol (fase B), ambos contendo 0,2 \% de ácido acético (v/v) em sistema gradiente com vazão de $1 \mathrm{~mL} \mathrm{~min}^{-1}$. O gradiente empregado está descrito na Tabela 7.

Tabela 7 - Gradiente de eluição para a fase móvel água-metanol empregado na determinação dos fármacos em HPLC.

\begin{tabular}{ccc}
\hline Tempo $(\min )$ & Fase A (\%) & Fase B (\%) \\
\hline 0,01 & 90 & 10 \\
7 & 90 & 10 \\
10 & 20 & 80 \\
30 & 20 & 80 \\
32 & 90 & 10 \\
35 & 90 & 10 \\
\hline
\end{tabular}

Fase A: Água + 0,2\% ácido acético

Fase B: Metanol + 0,2\% ácido acético

Conforme este método, os tempos de retenção obtidos e o comprimento de onda mais indicado para análise de cada fármaco estão apresentados na Tabela 8.

Tabela 8 - Tempo de retenção e comprimento de onda mais indicado para análise.

\begin{tabular}{ccc}
\hline Fármaco & Tempo de retenção (min) & $\begin{array}{c}\text { Comprimento de } \\
\text { onda (nm) }\end{array}$ \\
\hline Acetominofeno & 11,1 & 254 \\
Atenolol & 5,8 & 225 \\
Bezafibrato & 14,9 & 225 \\
Diclofenaco & 16,9 & 254 \\
Ibuprofeno & 17,4 & 225 \\
\hline
\end{tabular}


A partir do método analítico empregado para determinação dos fármacos simultaneamente foram obtidas as curvas analíticas de calibração de cada fármaco individualmente, com concentrações conhecidas de cada composto.

As principais características das curvas analíticas estão apresentadas na Tabela 9, entre elas: as equações das curvas analíticas, coeficiente de determinação, limite de detecção (LD) e de quantificação (LQ) para cada composto.

Tabela 9 - Equações das curvas analíticas, coeficientes de determinação $\left(R^{2}\right)$, limite de detecção (LD) e de quantificação (LQ) para os contaminantes estudados.

\begin{tabular}{ccccc}
\hline Fármacos & Curva analítica & $\mathbf{R}^{2}$ & LD $\left(\mathbf{m g ~ L}^{-1}\right)$ & LQ $\left(\mathbf{m g ~ L}^{-1}\right)$ \\
\hline ACT & $\mathrm{A}=49284[\mathrm{ACT}]+92315$ & 0,998 & 0,19 & 0,59 \\
ATL & $\mathrm{A}=2646[\mathrm{ATL}]+778,43$ & 0,993 & 0,09 & 0,28 \\
BZF & $\mathrm{A}=40356[\mathrm{BZF}]-1123,8$ & 0,998 & 0,09 & 0,29 \\
DIC & $\mathrm{A}=13419[\mathrm{DIC}]-4135,5$ & 0,997 & 0,43 & 1,29 \\
IBU & $\mathrm{A}=27539[\mathrm{IBU}]+49,715$ & 0,998 & 0,006 & 0,018 \\
\hline
\end{tabular}

\subsubsection{Análise de Peróxido de Hidrogênio Residual}

Para determinar a concentração residual de $\mathrm{H}_{2} \mathrm{O}_{2}$ nos experimentos de peroxidação fotoassistida $\left(\mathrm{UV} / \mathrm{H}_{2} \mathrm{O}_{2}\right)$ utilizou-se o método descrita por Nogueira et al. (2005), segundo o qual faz-se reagir o peróxido de hidrogênio residual com metavanadato de amônio $\left(\mathrm{NH}_{4} \mathrm{VO}_{3}\right)$, que tem como produto de reação o íon peroxovanádio.

Para a análise, foram misturados $1,0 \mathrm{~mL}$ (para o ensaio de concentração inicial dos fármacos $5 \mathrm{mg} \mathrm{L}^{-1}$ ) ou $5,0 \mathrm{~mL}$ (para o ensaio de concentração inicial $20 \mathrm{mg} \mathrm{L}^{-1}$ ) de amostra a 1,0 mL de solução de metavanadato de amônio, completando-se o volume com água até $10,0 \mathrm{~mL}$. Essa solução de metavanadato de amônio possui 0,06 mol L-1 de metavanadato de amônio e $0,58 \mathrm{~mol} \mathrm{~L}^{-1}$ de ácido sulfúrico. A quantificação do íon peroxovanádio é então determinada espectrofotometricamente a partir da medida da absorbância da solução em 450 nm empregando-se um espectrofotômetro UV-visível (Varian Cary 50). 


\subsubsection{Análise por Fluorescência e Fosforescência}

Os espectros de fluorescência foram obtidos empregando-se um espectrofluorímetro Edinburgh FLS920. As medidas de fluorescência foram realizadas em acetonitrila e em água em $\mathrm{pH}$ 2. Os espectros de fosforescência estática foram obtidos com espectrofluorímetro Hitachi F-4500, existente no Laboratório de Fotodinâmica Molecular (Instituto de Química da USP), com excitação por lâmpada de Xenônio de 125 W. Neste caso, a cela de amostragem consiste de um tubo com a amostra mantida em $77 \mathrm{~K}$ por meio de uma camisa de quartzo contendo nitrogênio líquido em matriz vítrea orgânica de éter e 2-propanol em pH natural.

\subsubsection{Ensaios de Toxicidade}

Os ensaios de toxicidade foram realizados para amostras correspondentes ao tempo zero (antes da irradiação) e final após o experimento de fotólise, para experimentos realizados a partir de soluções de fármacos individuais; e para amostras correspondentes aos tempos de 0, 15, 45 e 120 minutos, para experimentos partindo de soluções da mistura dos fármacos. Os testes foram realizados empregando-se a bactéria luminescente Vibrio fischeri em um equipamento Microtox ${ }^{\circledR} 500$, conforme a norma CETESB/L.5227/dez/2001.

Para efeito desta norma é adotada a definição de $C E_{50}$, que corresponde à concentração efetiva do agente tóxico que causa $50 \%$ de redução na quantidade de luz emitida pelo microrganismo-teste (Vibrio fischeri), após sua exposição a esse agente durante um determinado período de tempo.

A classificação de toxicidade das amostras utilizada baseou-se no trabalho de Tonkes et al. (1999), segundo o qual valores de $\mathrm{CE}_{50}<10 \%$ permitem classificar as amostras como tóxicas e $\mathrm{CE}_{50}<1 \%$ permitem classificar as amostras como muito tóxicas. 


\subsubsection{Actinometria}

A taxa de incidência de fótons no reator fotoquímico foi avaliada por meio de actinometria de ferrioxalato (BRAUN, 1991).

Em uma sala escura foi preparada a solução de ferrioxalato $\left(0,75 \mathrm{~mol} \mathrm{~L}^{-1}\right.$ de ácido oxálico $\left(\mathrm{H}_{2} \mathrm{C}_{2} \mathrm{O}_{4} .2 \mathrm{H}_{2} \mathrm{O}\right)$ e $0,15 \mathrm{~mol} \mathrm{~L}^{-1}$ de $\left.\mathrm{Fe}_{2}\left(\mathrm{SO}_{4}\right)_{3} .5 \mathrm{H}_{2} \mathrm{O}\right)$, com volume de $5 \mathrm{~L}$. Após encapar o reator com papel alumínio, foi adicionada a solução do actinômetro ao reator fotoquímico. Para evitar a oxidação do $\mathrm{Fe}^{2+}$ pelo $\mathrm{O}_{2}$ dissolvido, borbulhou-se $\mathrm{N}_{2}$ no interior do tanque de mistura, durante o experimento. O experimento teve duração de 30 minutos. A cada 2 minutos coletaram-se amostras de $0,25 \mathrm{~mL}$, as quais eram transferidas para frascos âmbar encapados com papel alumínio, contendo $24,75 \mathrm{~mL}$ de solução complexante composta de ácido acético $0,5 \mathrm{~mol} \mathrm{~L}^{-1}$; acetato de sódio $0,5 \mathrm{~mol}$ $\mathrm{L}^{-1}$ e 1,10-fenantrolina $0,01 \mathrm{~mol} \mathrm{~L}^{-1}$.

Deixou esse frasco em repouso por 90 minutos, para o actinômetro reagir com o complexante, e após leu-se a absorbância da solução em espectrofotômetro UV-visível no comprimento de onda $510 \mathrm{~nm}$, para determinação de $\mathrm{Fe}^{2+}$.

\section{RESULTADOS E DISCUSSÃO}

\subsection{CARACTERIZAÇÃO ACTINOMÉTRICA DO REATOR FOTOQUÍMICO}

Os resultados da avaliação actinométrica empregando solução $0,15 \mathrm{~mol} \mathrm{~L}^{-1}$ do actinômetro ferrioxalato de potássio, no reator fotoquímico irradiado com a lâmpada de baixa pressão de mercúrio de $75 \mathrm{~W}$, estão apresentados na Figura 15. Para a lâmpada de 36 W, estão apresentados na Figura 16. 


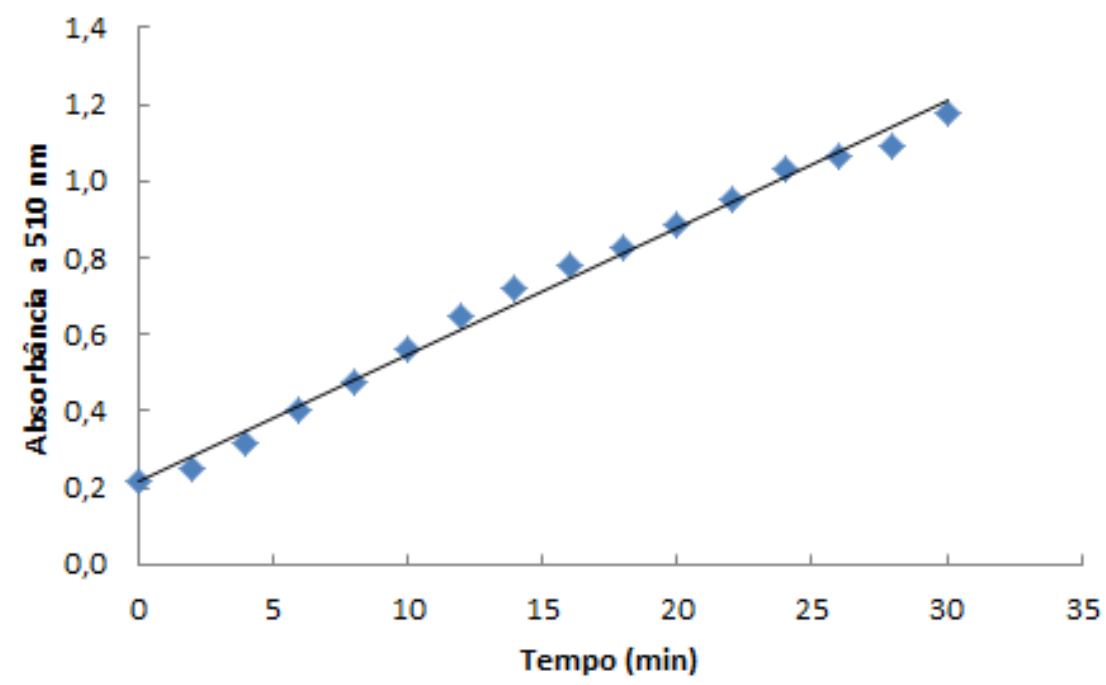

Figura 15 - Resultado do experimento actinométrico empregando ferrioxalato de potássio $0,15 \mathrm{~mol} \mathrm{~L}^{-1}$ no reator irradiado com lâmpada LP Hg de 75 W.

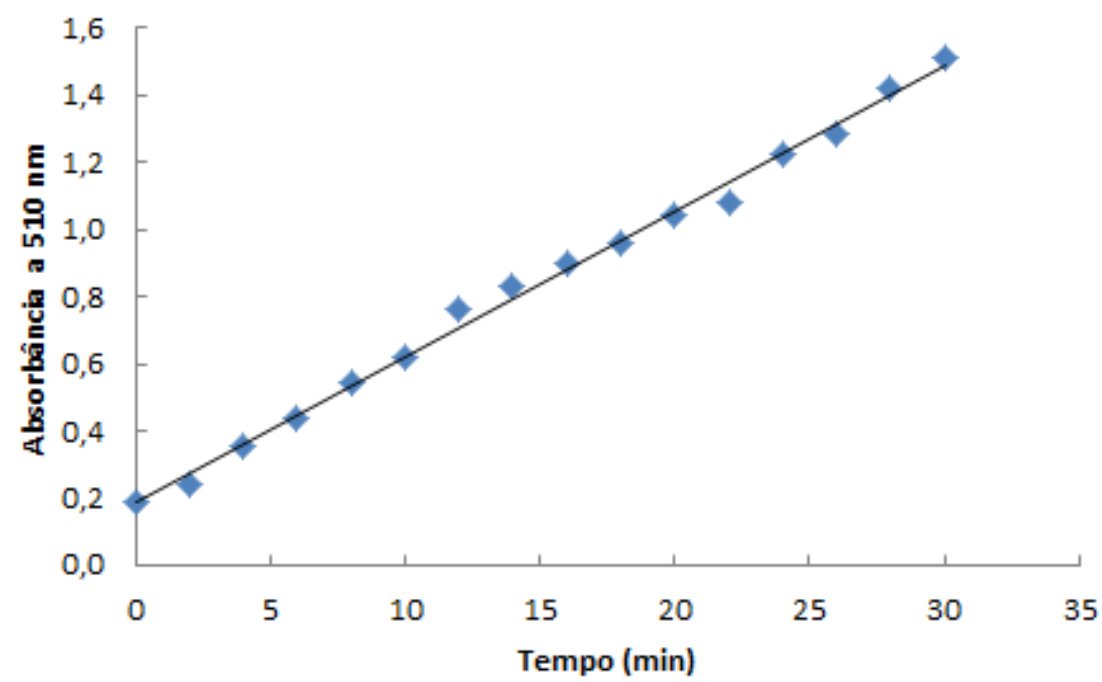

Figura 16 - Resultado do experimento actinométrico empregando ferrioxalato de potássio $0,15 \mathrm{~mol} \mathrm{~L}^{-1}$ no reator irradiado com lâmpada LP Hg de 36 W.

Considera-se a lâmpada LP Hg como sendo monocromática para o comprimento de onda de 253,7 nm e, aplica-se a Equação de Planck (Equação 20). Tem-se que o quantum de radiação e igual a $7,829 \times 10^{-19} \mathrm{~J} \mathrm{foton}^{-1}$.

$\mathrm{E}=\mathrm{hc} / \lambda$ 
Sendo $\mathrm{h}=$ constante de Planck $\left(6,6256 \times 10^{-34} \mathrm{~J} \mathrm{~s}\right.$ foton $\left.^{-1}\right), \mathrm{c}=$ velocidade da luz $\left(2,9979 \times 10^{8} \mathrm{~m} \mathrm{~s}^{-1}\right), \lambda=$ comprimento de onda da radiação $(\mathrm{m})$. O cálculo da taxa de incidência de fótons para lâmpada de $75 \mathrm{~W}$ considerou o intervalo de 8 a 22 min de reação actinométrica (Figura 15), pois corresponde ao tempo de irradiação tal que a absorbância medida do actinômetro encontra-se no intervalo de 0,4 a 1,0. Sabe-se que o rendimento quântico para formação de $\mathrm{Fe}^{2+}$ a partir de $\mathrm{Fe}^{3+}$ é igual a 1,23 íons/fóton absorvido (BRAUN et al., 1991). Como resultado, obtém-se $3,61 \times 10^{-5} \mathrm{~mol} \mathrm{Fe}^{2+} \mathrm{s}^{-1}$, o que equivale a $1,84 \times 10^{19}$ fótons $\mathrm{s}^{-1}$.

Para o cálculo da taxa de incidência de fótons da lâmpada de 36 W, considerou-se o intervalo de 6 a 18 min de reação actinométrica (Figura 16), pois corresponde ao tempo de irradiação tal que a absorbância medida do actinômetro encontra-se no intervalo de 0,4 a 1,0. Dentro desse intervalo, tem-se geração fotoquímica de aproximadamente $4,00 \times 10^{-5} \mathrm{~mol} \mathrm{Fe}^{2+} \mathrm{s}^{-1}$, o que equivale a $2,04 \times 10^{19}$ fótons $\mathrm{s}^{-1}$. Com base nesses resultados e sabendo-se que a energia do fóton a 253,7 $\mathrm{nm}$ é de $7,829 \times 10^{-19} \mathrm{~J}$, para a lâmpada LP Hg $75 \mathrm{~W}$ a potência radiante no UV-C foi de aproximadamente $14,4 \mathrm{~W}$ e para a lâmpada LP Hg $36 \mathrm{~W}$, potência radiante foi de aproximadamente $16 \mathrm{~W}$. Dessa forma, para o volume irradiado do reator empregado e considerando a geometria do sistema e o campo de radiação associado, a taxa de incidência de fótons por unidade de volume não é muito diferente para as duas fontes radiantes (lâmpadas empregadas). Pode-se admitir que o campo de radiação seja axialmente uniforme, embora haja variações radiais. 


\subsection{ENSAIO DE HIDRÓLISE}

Na Figura 17, estão apresentados os resultados médios das triplicatas dos ensaios de hidrólises para a mistura dos fármacos e para os fármacos individuais.
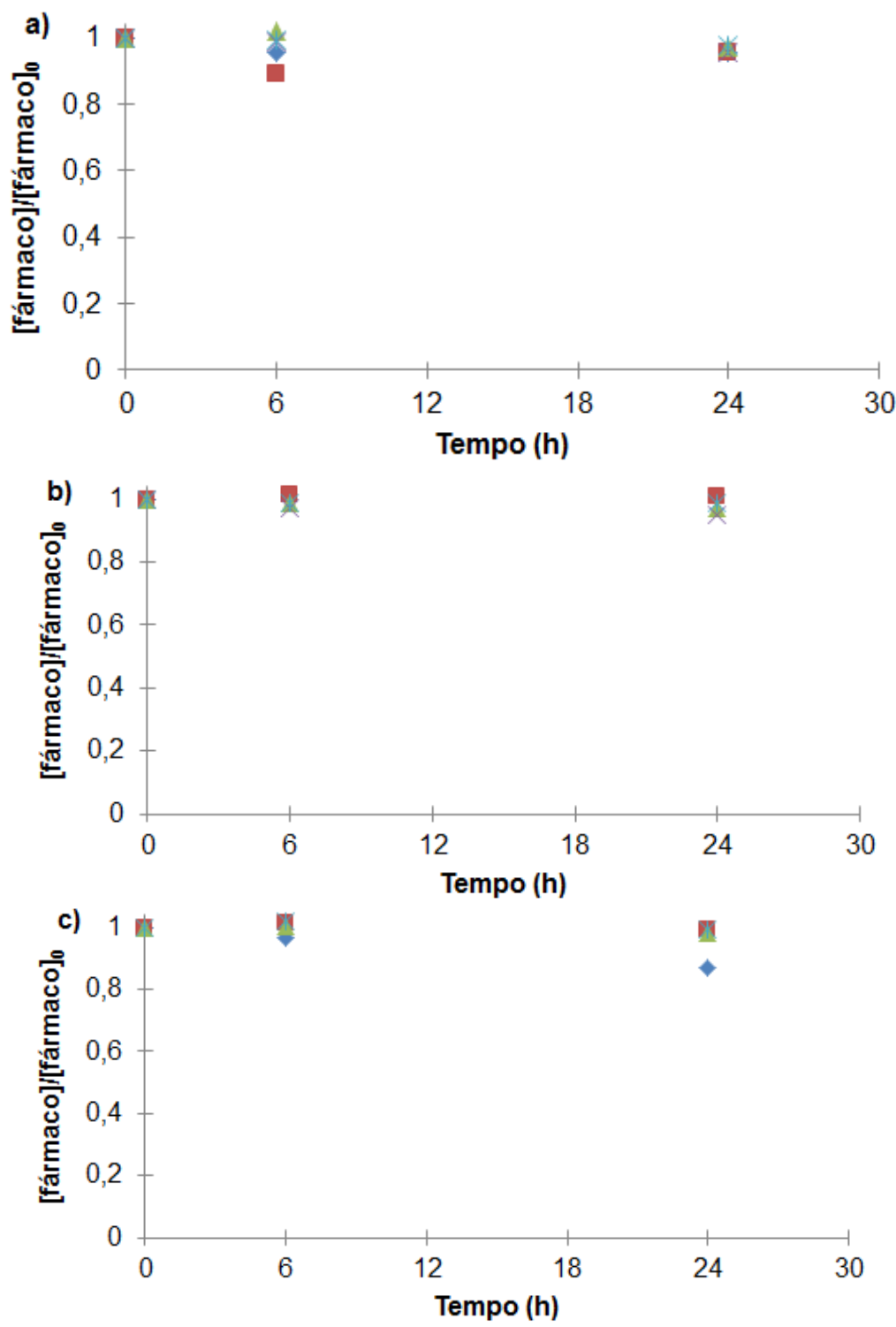

Figura 17 - Resultados dos experimentos de hidrólise dos fármacos estudados. (a) Hidrólise da mistura dos fármacos em pH 3. (b) Hidrólise dos fármacos individuais em $\mathrm{pH}$ 3. (c) Hidrólise da mistura dos fármacos em pH 7. (d) Hidrólise dos fármacos individuais em $\mathrm{pH}$ 7. (e) Hidrólise da mistura dos fármacos em pH 9. (f) Hidrólise dos fármacos individuais em pH 9. A concentração indicada refere-se à concentração inicial nominal de $5 \mathrm{mg} \mathrm{L}^{-1}$ de cada fármaco na solução aquosa. 

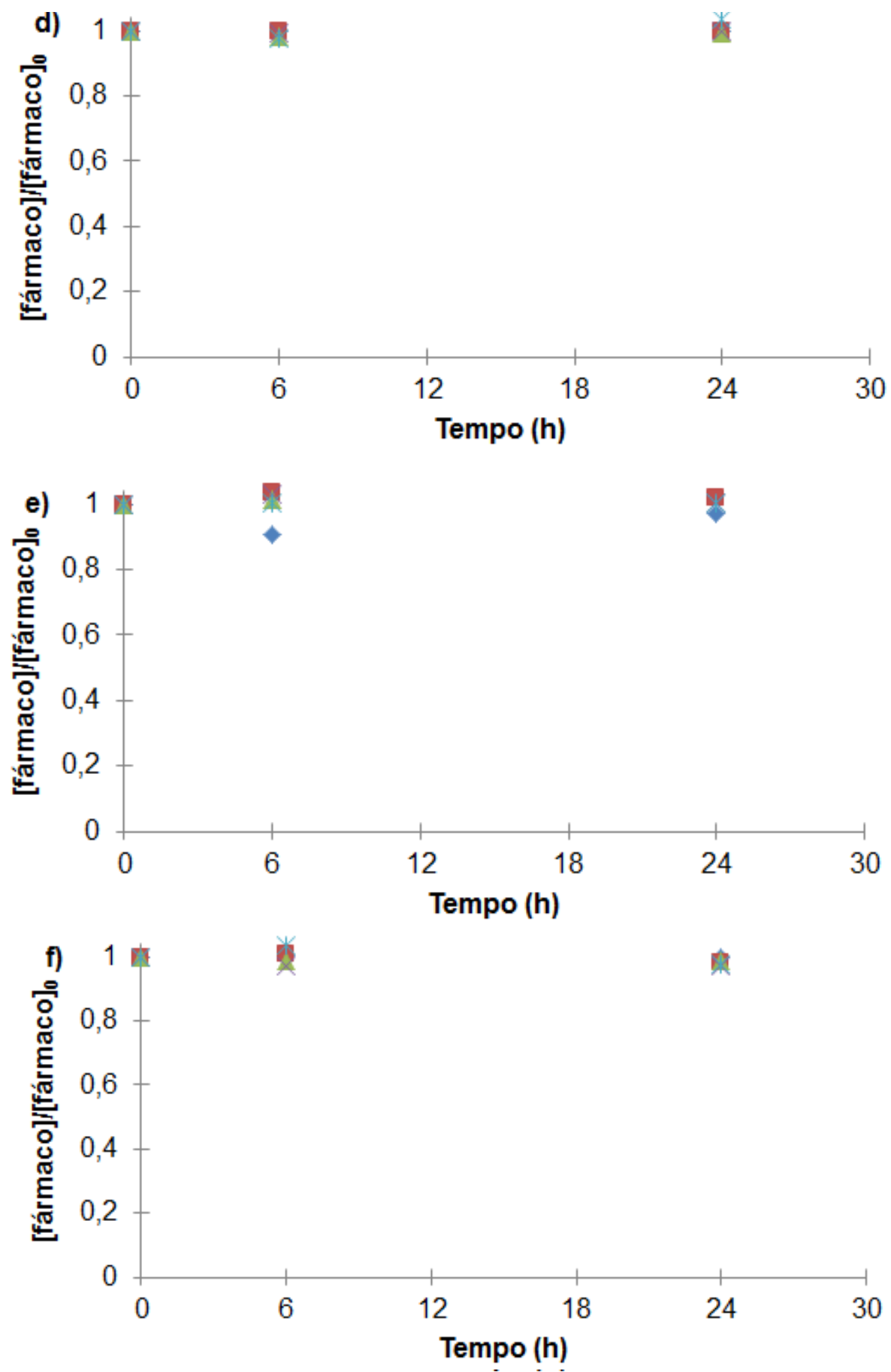

Figura 17 (cont.) - Resultados dos experimentos de hidrólise dos fármacos estudados. (a) Hidrólise da mistura dos fármacos em pH 3. (b) Hidrólise dos fármacos individuais em pH 3. (c) Hidrólise da mistura dos fármacos em pH 7. (d) Hidrólise dos fármacos individuais em pH 7. (e) Hidrólise da mistura dos fármacos em pH 9. (f) Hidrólise dos fármacos individuais em $\mathrm{pH} 9$. A concentração indicada refere-se à concentração inicial nominal de $5 \mathrm{mg} \mathrm{L}^{-1}$ de cada fármaco na solução aquosa. 
Os experimentos comprovam que durante 24 horas, independentemente dos valores de $\mathrm{pH}$, as soluções apresentaram estabilidade, não sendo observada hidrólise dos fármacos individuais, nem em mistura. Resultados similares foram obtidos por $\mathrm{Yu}$ et al. (2011), Radjenovića et al. (2009), Wanga et al. (2012), Pérez-Estrada et al. (2005) e Zeng et al. (2012). A implicação importante dessa conclusão é que nos experimentos de degradação por fotólise realizados neste trabalho a degradação dos fármacos tem como causa a interação da radiação UV de $254 \mathrm{~nm}$ com os fármacos. Do ponto de vista ambiental é importante ressaltar a persistência dos fármacos em ambientes aquáticos.

\subsection{DETERMINAÇÃO DOS VALORES DE pKa}

As constantes de equilíbrio ácido-base (e, logo, os valores de $\mathrm{pK}_{\mathrm{a}}$ ) de cada composto foram determinadas a partir de dez soluções aquosas de mesma concentração $\left(5 \mathrm{mg} \mathrm{L}^{-1}\right)$ com pH entre 2 e 11, para as quais foram obtidos os espectros de absorção UV-visível. Os valores de pKa foram obtidos a partir dos gráficos de absorbância em função do $\mathrm{pH}$ para os comprimentos de onda em que se verificaram os máximos correspondentes às formas protonada e desprotonada de cada fármaco. Os resultados estão apresentados na Tabela 10.

Tabela 10 - Resultados das medidas de pKa para os fármacos estudados.

\begin{tabular}{|c|c|c|c|c|}
\hline Composto & $\mathrm{pK}_{\mathrm{a}}$ experimental & $\begin{array}{c}\mathrm{pK}_{\mathrm{a}} \\
\text { literatura }\end{array}$ & $\begin{array}{c}\text { Diferença } \\
(\%)\end{array}$ & Referência \\
\hline Acetaminofeno & 9,0 & 9,4 & 4,1 & $\begin{array}{l}\text { LORPHENSRI et al. (2006) e } \\
\text { KING et al.(2004) }\end{array}$ \\
\hline Atenolol & 9,3 & 9,4 & 1,1 & MARTÍNEZ et al. (2000) \\
\hline Bezafibrato & 3,5 & 3,6 & 2,8 & $\begin{array}{c}\text { KUJAWA-ROELEVELD et al. } \\
\text { (2008) e TAMBOSI (2008) }\end{array}$ \\
\hline Diclofenaco & 4,0 & 4,2 & 4,8 & $\begin{array}{l}\text { SERRANO et al. (2011), } \\
\text { KUJAWA-ROELEVELD et al. } \\
\text { (2008) e MELOUN et al. (2007) }\end{array}$ \\
\hline Ibuprofeno & 4,7 & 4,9 & 4,1 & $\begin{array}{c}\text { SERRANO et al. (2011), KING } \\
\text { et al.(2004) e KUJAWA- } \\
\text { ROELEVELD et al. (2008) }\end{array}$ \\
\hline
\end{tabular}


Nas Figuras 18, 19, 20, 21 e 22 estão apresentadas as fórmulas estruturais das formas neutra, protonada e desprotonada de cada fármaco e os gráficos de porcentagem de cada forma em função do pH para os fármacos em estudo. Esses gráficos foram obtidos por um programa computacional ChemAxon (versão disponível no site chemicalize.org).

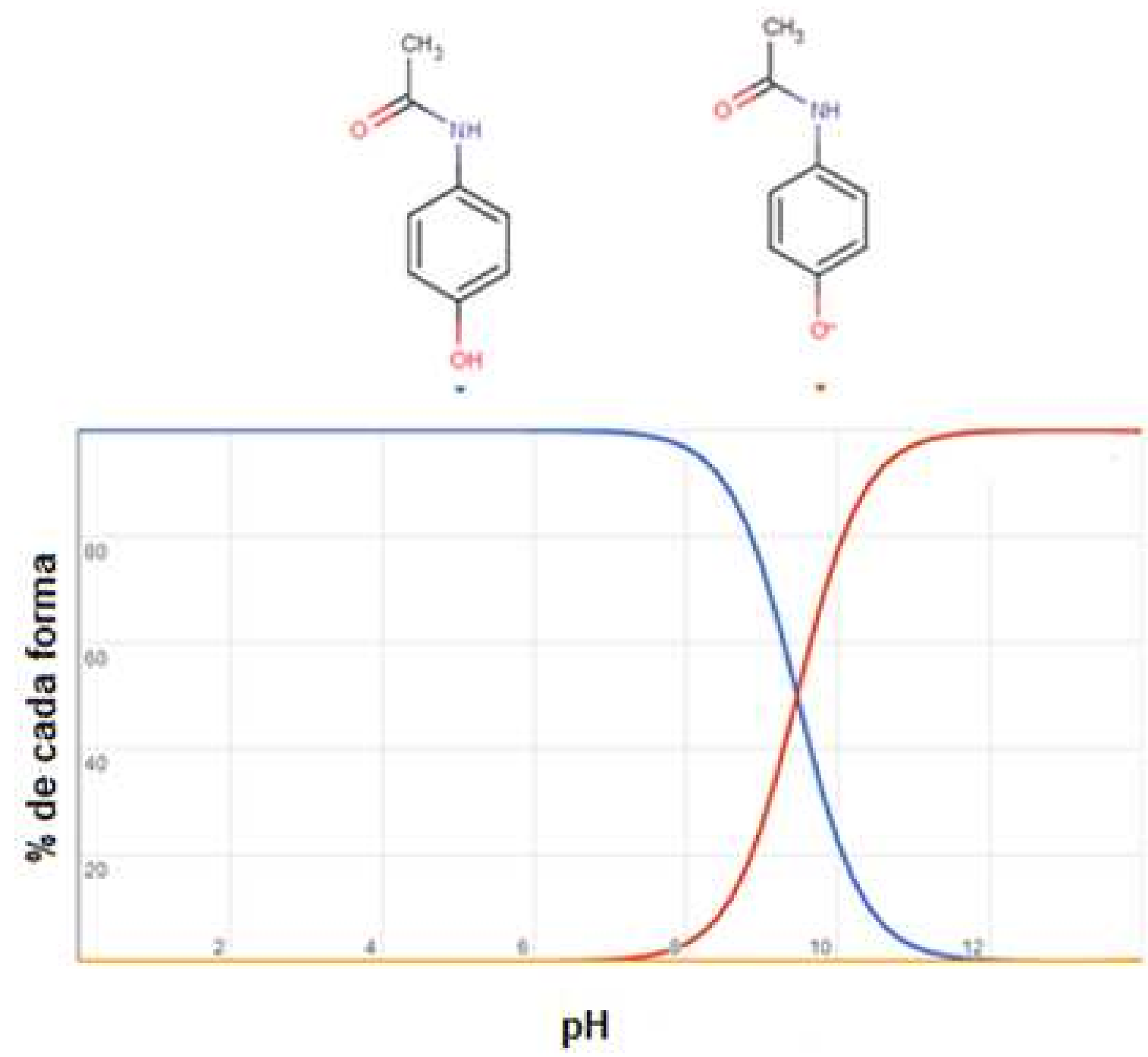

Figura 18 - Fórmulas estruturais das formas neutra e desprotonada e distribuição das formas em equilíbrio em função do $\mathrm{pH}$ para o acetaminofeno (ACT). 

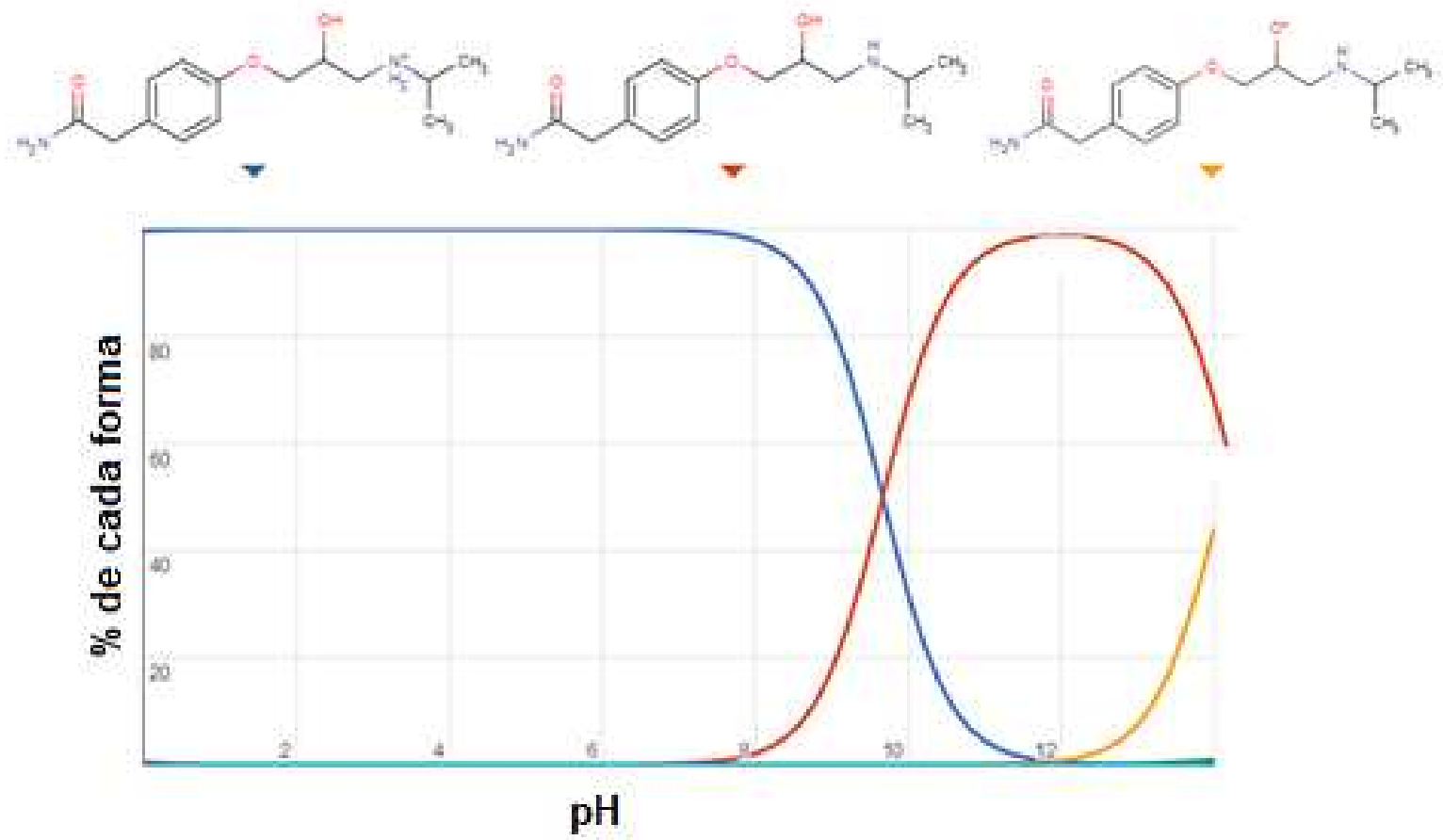

Figura 19 - Fórmulas estruturais das formas neutra, protonada e desprotonada e distribuição das formas em equilíbrio em função do pH para o atenolol (ATL). 
66

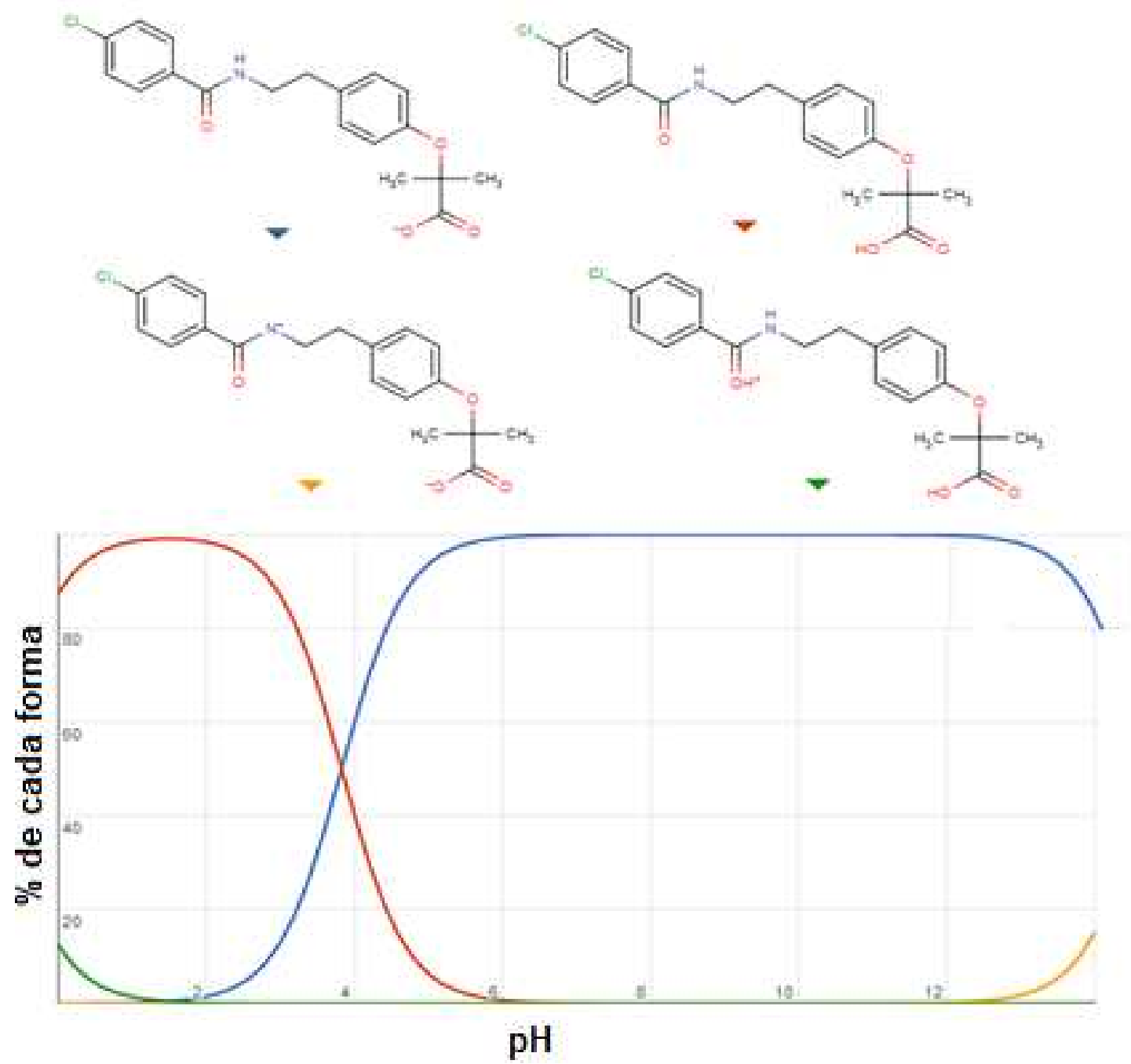

Figura 20 - Fórmulas estruturais das formas neutra, protonada e desprotonada e distribuição das formas em equilíbrio em função do $\mathrm{pH}$ para o bezafibrato (BZF). 

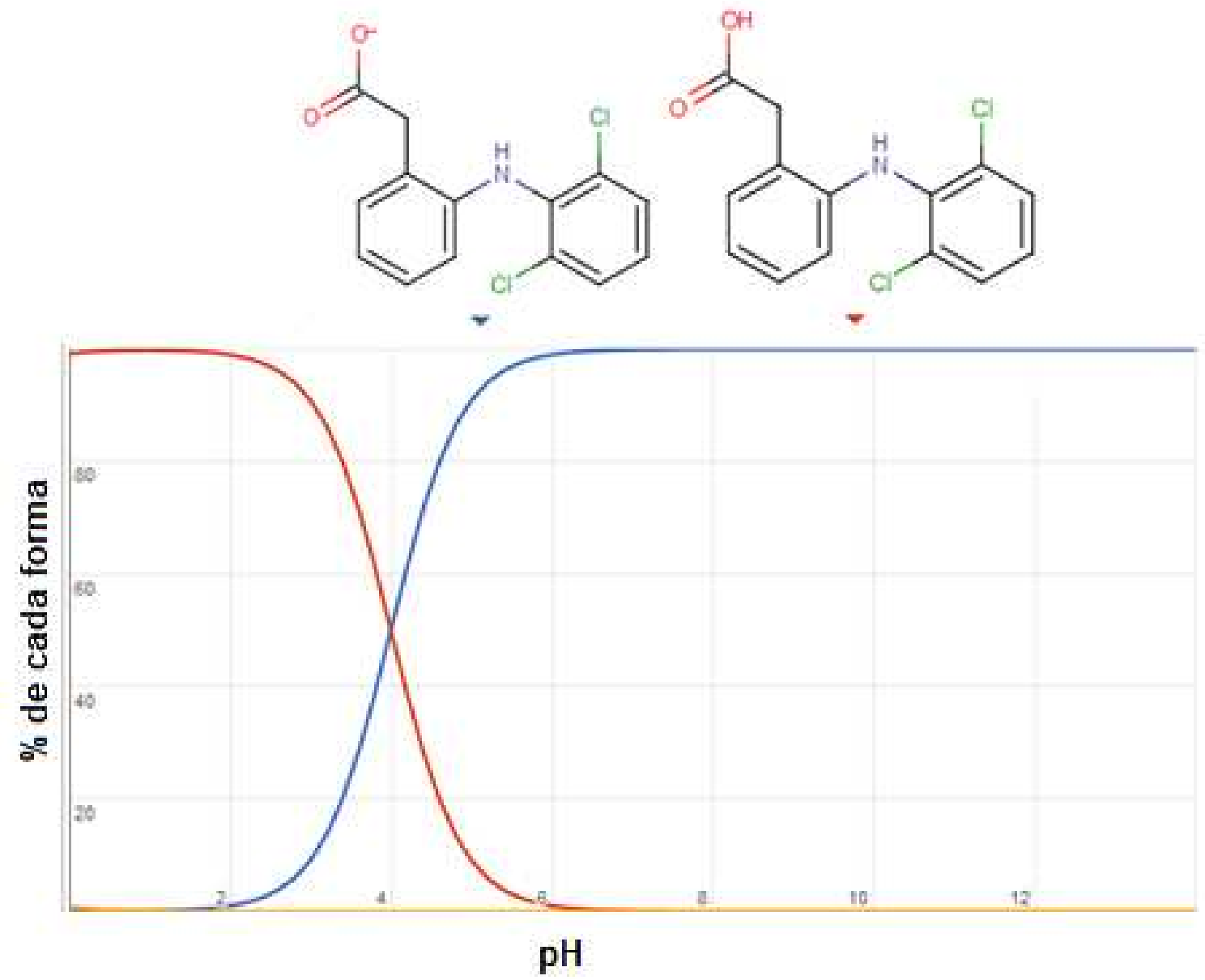

Figura 21 - Fórmulas estruturais das formas neutra, protonada e desprotonada e distribuição das formas em equilíbrio em função do $\mathrm{pH}$ para o diclofenaco (DIC). 


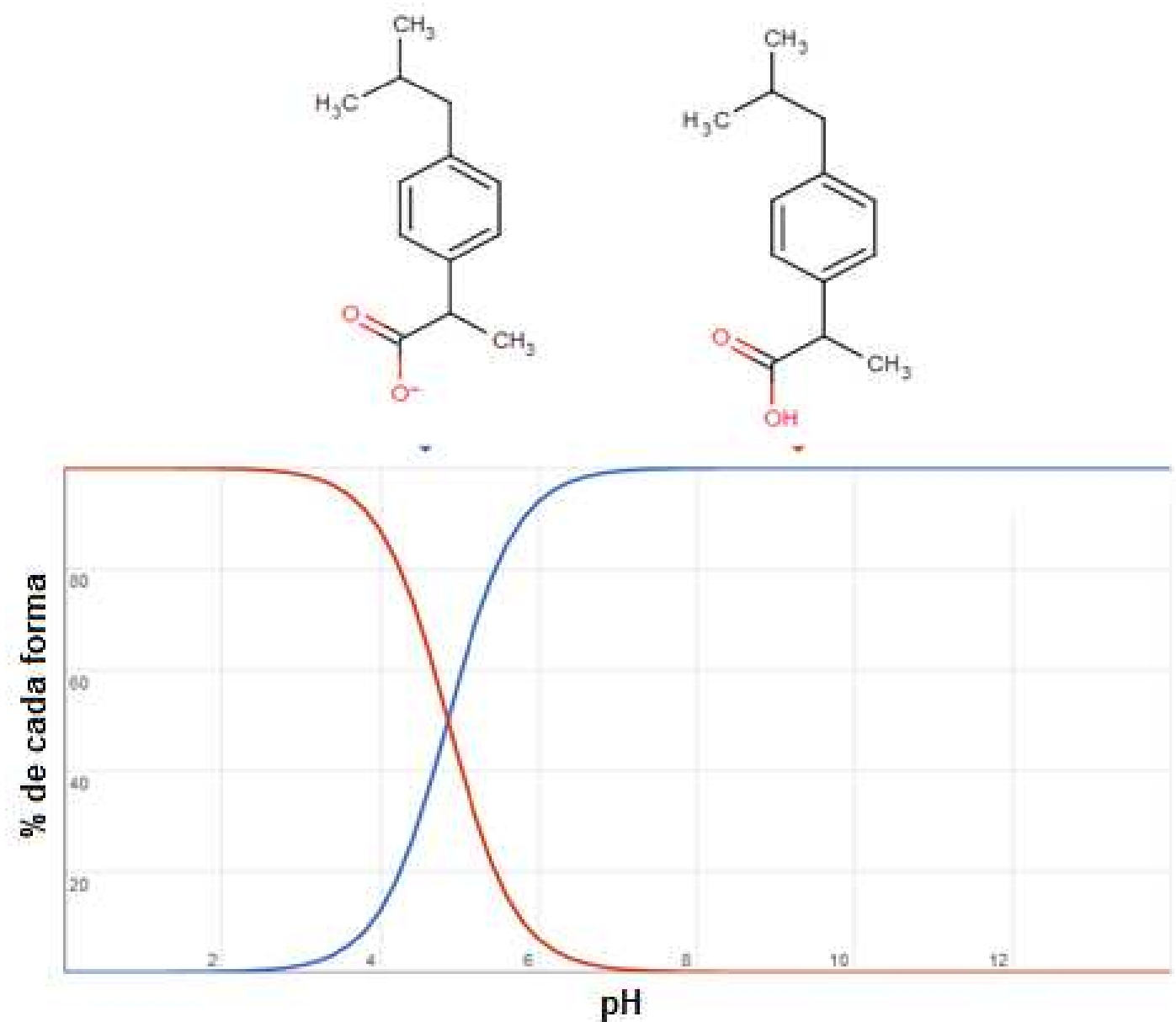

Figura 22 - Fórmulas estruturais das formas neutra, protonada e desprotonada e distribuição das formas em equilíbrio em função do pH para o ibuprofeno (IBU).

Desse modo, todos os fármacos estão na sua forma neutra nos experimentos de fotólise realizados em $\mathrm{pH} \leq 2$, à exceção do atenolol (ATL) que está na sua forma protonada. $\mathrm{O}$ valor do $\mathrm{pH}$ das soluções para realizar os experimentos foi selecionado de modo que as moléculas do fármaco em solução aquosa estejam, em sua totalidade, em uma de suas formas. 


\subsection{DETERMINAÇÕES DOS COEFICIENTES DE ABSORÇÃO MOLAR}

O coeficiente de absorção molar ( $\varepsilon$ ) é uma grandeza característica da espécie em solução e depende do comprimento de onda da radiação UV-visível absorvida. Conforme a Lei de Beer-Lambert trata-se da constante de proporcionalidade que relaciona a absorbância com o caminho óptico e a concentração da espécie absorvedora de fótons.

Na Figura 23 são apresentados os valores do coeficiente de absorção molar em função do comprimento de onda para cada fármaco em estudo, nos $\mathrm{pH} 2,5$ e 12. A Figura 24 compara os valores de $\varepsilon$ em $254 \mathrm{~nm}$ para cada fármaco, em alguns casos muito dependentes do $\mathrm{pH}$. Para os fármacos atenolol (ATL), bezafibrato (BZF), diclofenaco (DIC) e ibuprofeno (IBU), a variação dos valores é pequena, porém para o acetaminofeno (ACT) há um deslocamento importante na curva em pH 12 para comprimentos de onda maiores (red shift).

A absorção da radiação UV (254 nm) pelo acetaminofeno (ACT) é superior à dos demais fármacos $\left(\varepsilon=8990 \mathrm{~L} \mathrm{~mol}^{-1} \mathrm{~cm}^{-1}\right)$, enquanto a absorção pelo atenolol (ATL) $\mathrm{e}$ pelo ibuprofeno (IBU) é comparativamente muito inferior $\left(\varepsilon=725\right.$ e $1080 \mathrm{~mol}^{-1} \mathrm{~cm}^{-1}$, respectivamente). Os valores de $\varepsilon$ mostram ainda que os fármacos competem pela absorção da radiação incidente em 254 nm (OPPENLÄNDER, 2003). 

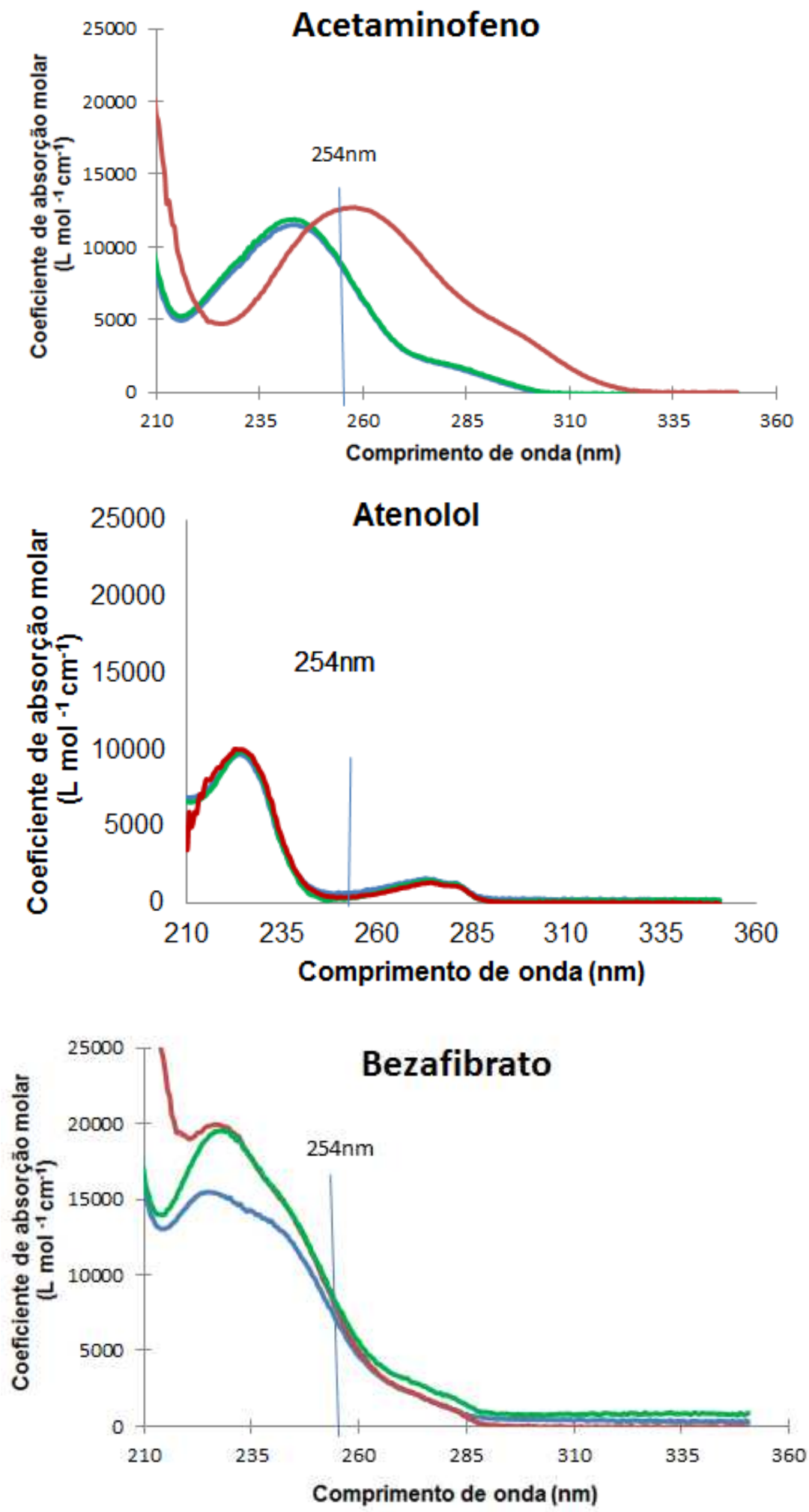

Figura 23 - Coeficiente de absorção molar dos fármacos estudados em função do comprimento de onda em pH 2, 5 e 12. ( $-\mathrm{pH} 2-\mathrm{pH} 5-\mathrm{pH} 12)$ 

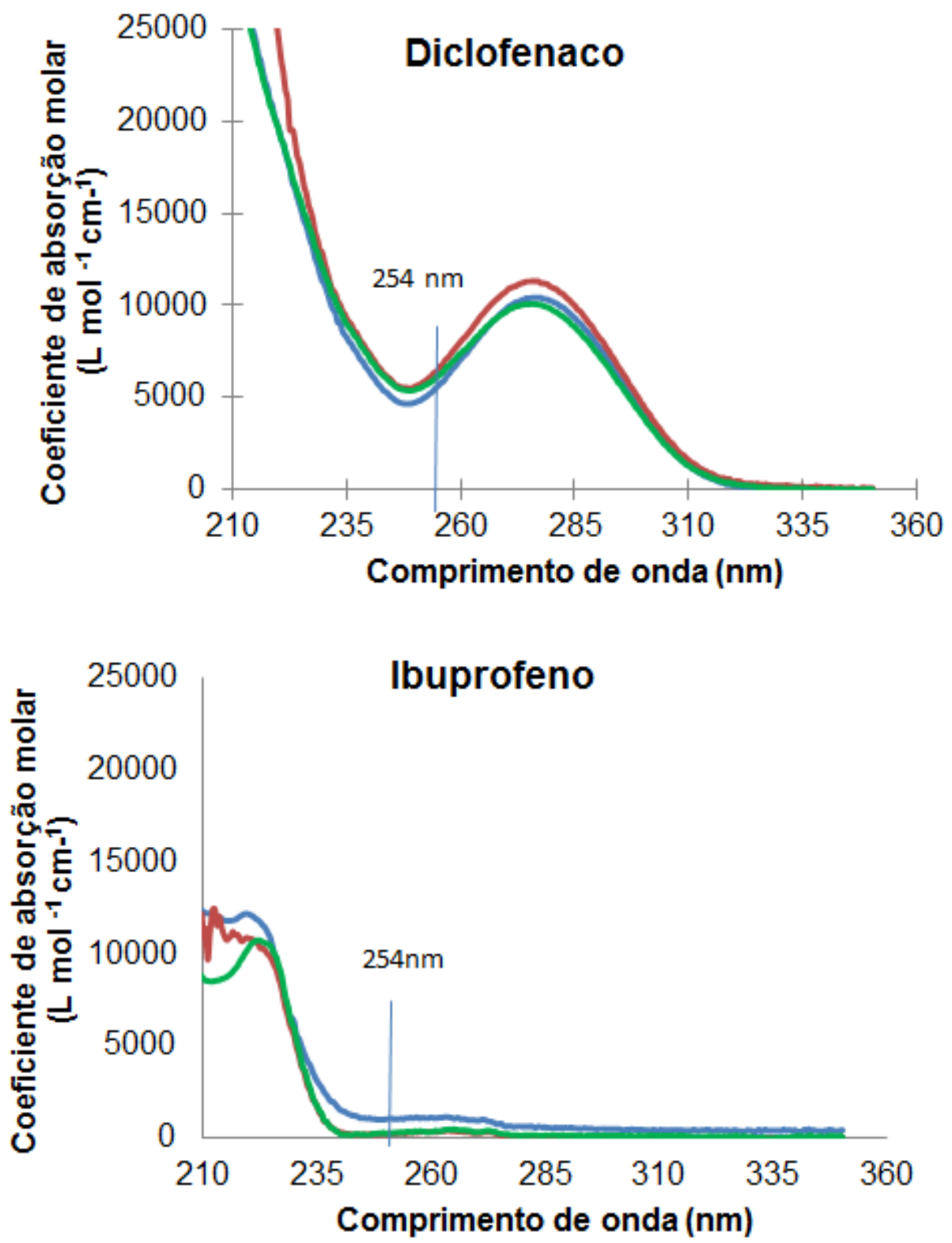

Figura 23 (cont.) - Coeficiente de absorção molar dos fármacos estudados em função do comprimento de onda em pH 2, 5 e 12. ( $-\mathrm{pH} 2-\mathrm{pH} 5-\mathrm{pH}$ 12)

Em geral, as transições eletrônicas $\pi \rightarrow \pi^{\star}$ estão associadas a maiores valores de coeficiente de absorção molar que os correspondentes às transições eletrônicas $n$ $\rightarrow \pi^{*}$ e, portanto, maior probabilidade de ocorrer. As transições $n \rightarrow \pi^{*}$ podem ocorrer em moléculas contendo átomos com pares de elétrons não-ligantes, tais como nitrogênio e oxigênio, e são responsáveis pelas bandas de maior comprimento de onda do espectro de absorção dos fármacos (PARSON, 2005). 


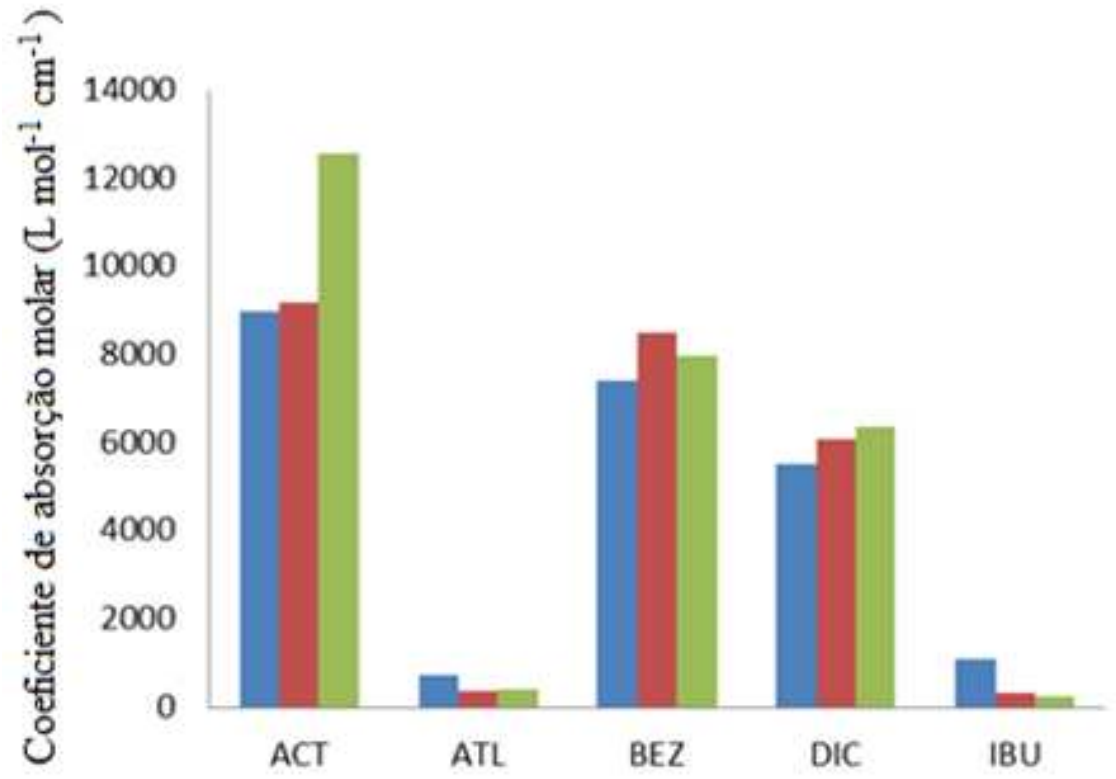

Figura 24 - Coeficientes de absorção molar dos fármacos estudados em $254 \mathrm{~nm}$ a diferentes pH.

$( \pm \mathrm{pH} 2=\mathrm{pH} 5=\mathrm{pH} 12)$

\subsection{DETERMINAÇÃO DOS ESPECTROS DE FLUORESCÊNCIA E FOSFORESCÊNCIA}

Segundo Oliveira (2011), a luminescência molecular é formalmente dividida em fluorescência e fosforescência, dependendo da natureza do estado excitado envolvido no processo. Na fluorescência o estado excitado envolvido é singlete, em que o spin do elétron no orbital de maior energia mantém sua orientação original. Na fosforescência, o spin do elétron que foi promovido ao estado excitado é invertido (estado excitado triplete). A fluorescência é um fenômeno luminescente mais comum que a fosforescência, competindo eficientemente com processos de desativação nãoradiativos do estado excitado. Como consequência direta disso, é possível observar facilmente fluorescência à temperatura ambiente e diretamente em solução, o que torna o procedimento experimental fluorimétrico bastante simples.

Foram realizadas as medidas de fluorescência dos fármacos em estudo, em acetonitrila e em água sob pH 2; os resultados (normalizados) dessas medidas estão 
ilustrados na Figura 25. Observa-se que os espectros de excitação são aproximadamente a imagem especular dos espectros de emissão de fluorescência, com exceção do DIC, de modo que não deve haver diferenças importantes entre as geometrias moleculares de equilíbrio dos estados fundamental e excitado, bem como os níveis vibracionais desses estados devem ser similares (BRAUN et al., 1991).

Na Figura 26 estão apresentados os espectros de emissão de fosforescência obtidos com excitação dos fármacos por lâmpada de xenônio de $125 \mathrm{~W}$; as medidas foram realizadas a $77 \mathrm{~K}$ por meio de uma camisa de quartzo com nitrogênio líquido. Como esperado, as bandas da fosforescência são emitidas em maiores comprimentos de onda em relação à absorção e à fluorescência.

Dessa forma, é possível a geração de estados triplete dos fármacos a partir de estados singlete por meio do mecanismo de cruzamento entre sistemas (ISC); os estados singlete são obtidos por excitação direta a partir do estado fundamental; para o fármaco diclofenaco (DIC) não foi possível obter o espectro de emissão de fosforescência.

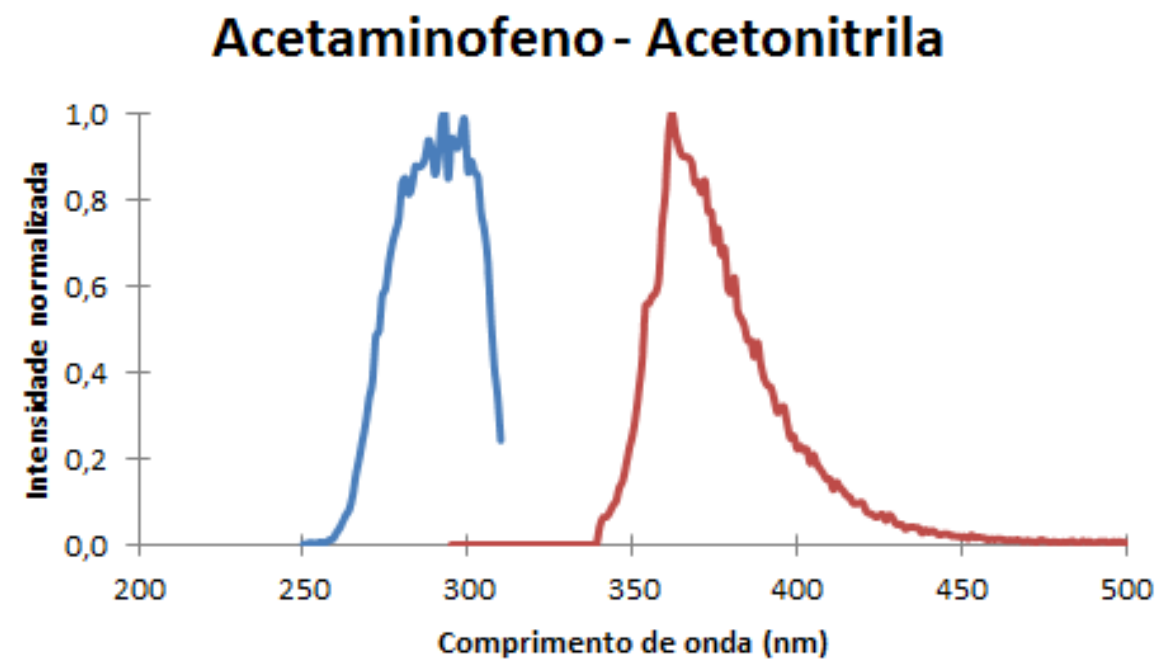

Figura 25 - Espectros de excitação (absorção) e de emissão (fluorescência) dos fármacos.

( - Excitação -Emissão). $\lambda_{\text {excitação }}$ para o $A C T=320 \mathrm{~nm}, \lambda_{\text {excitação }}$ para o $A T L=300 \mathrm{~nm}, \lambda_{\text {excitação }}$ para 0 $\mathrm{BZF}=305 \mathrm{~nm}, \lambda_{\text {excitação }}$ para o $\mathrm{DIC}=350 \mathrm{~nm}, \lambda_{\text {excitação }}$ para o IBU= $290 \mathrm{~nm}$. 


\section{Acetaminofeno - água pH 2}

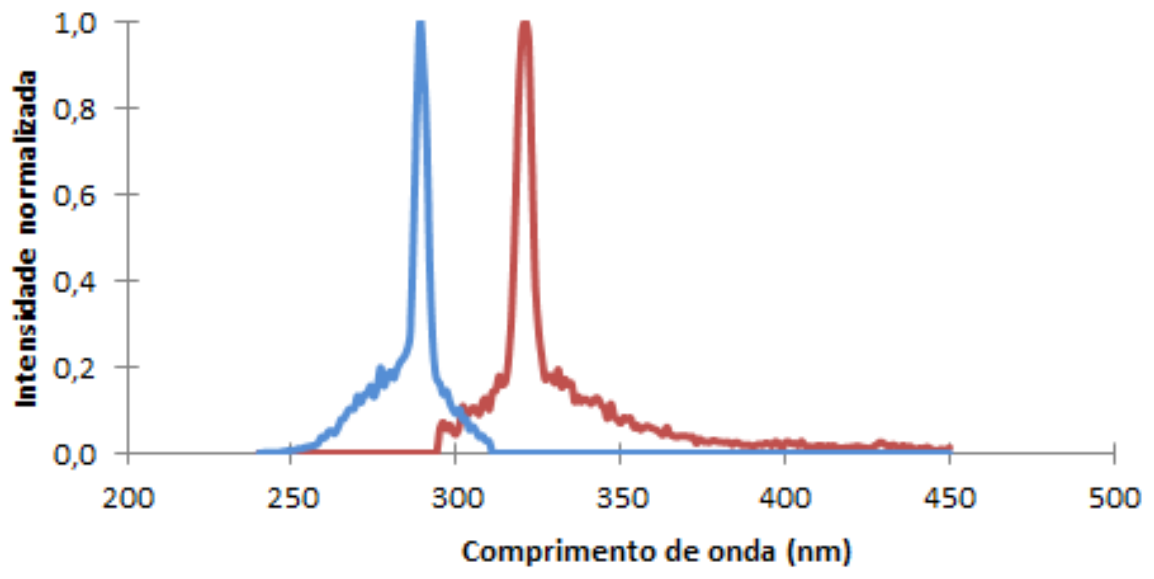

Atenolol - Acetonitrila

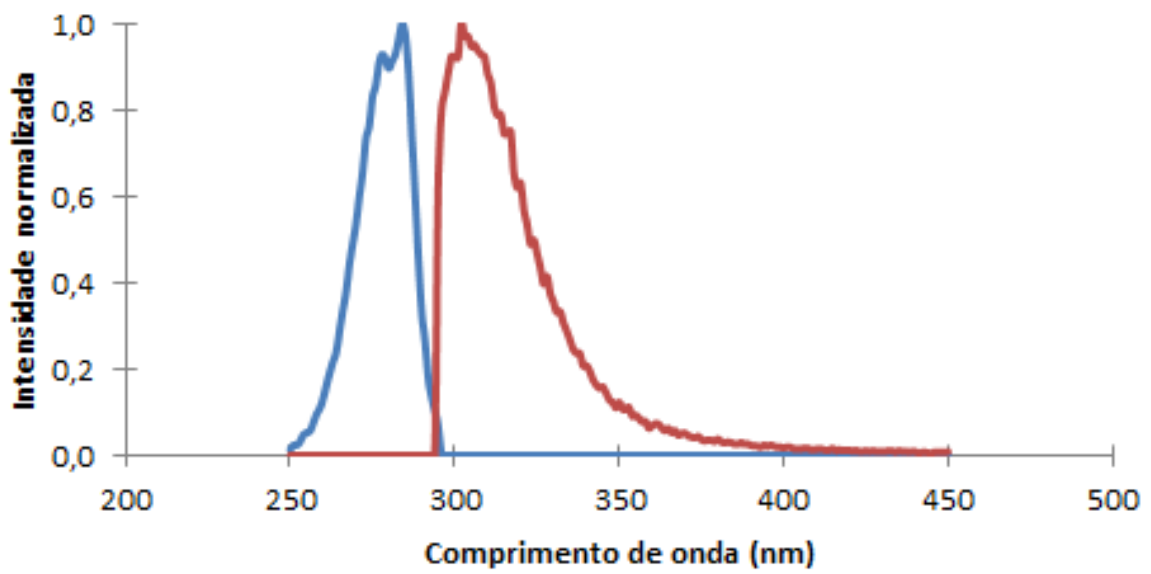

\section{Atenolol- água ph2}

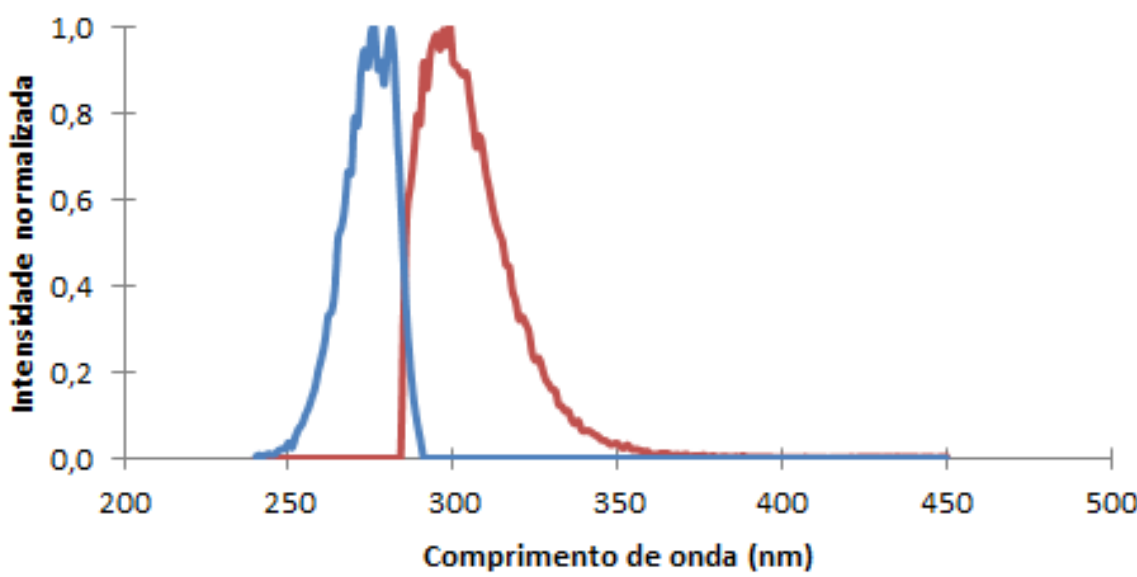

Figura 25 (cont.) - Espectros de excitação (absorção) e de emissão (fluorescência) dos fármacos.

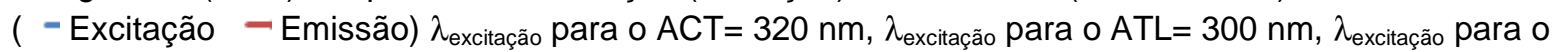
$\mathrm{BZF}=305 \mathrm{~nm}, \lambda_{\text {excitação }}$ para o $\mathrm{DIC}=350 \mathrm{~nm}, \lambda_{\text {excitação }}$ para o IBU $=290 \mathrm{~nm}$. 


\section{Bezafibrato - Acetonitrila}

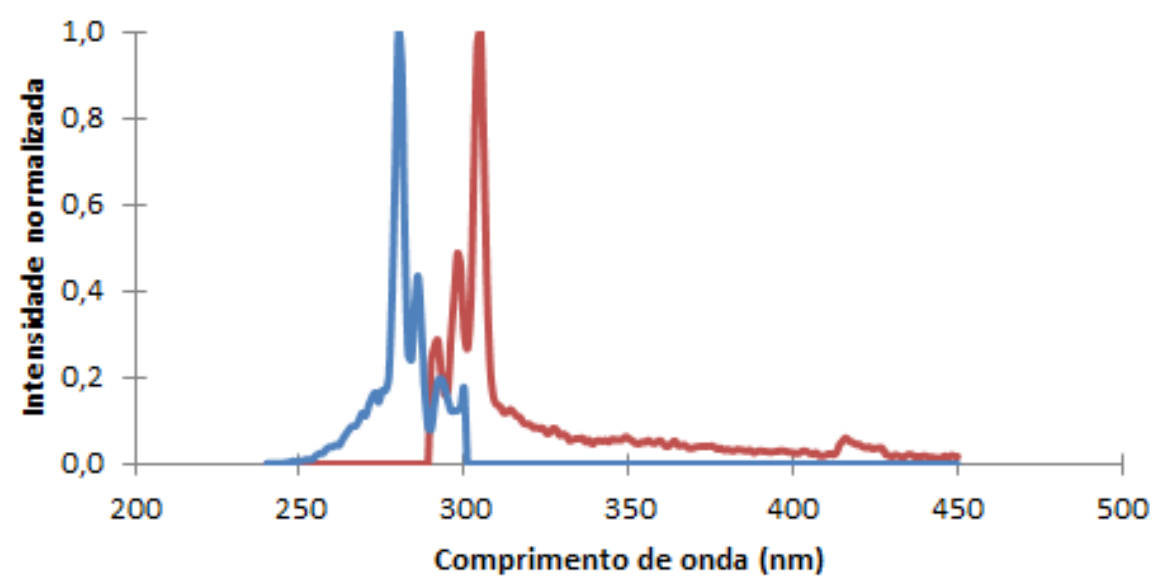

\section{Bezafibrato - água pH2}

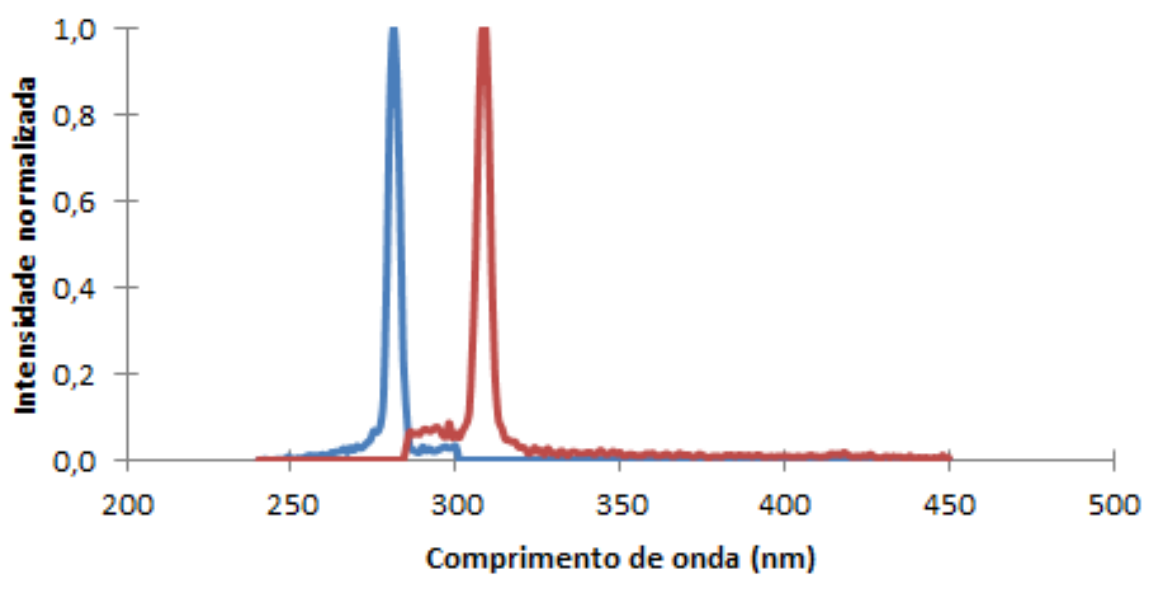

Diclofenaco - Acetonitrila

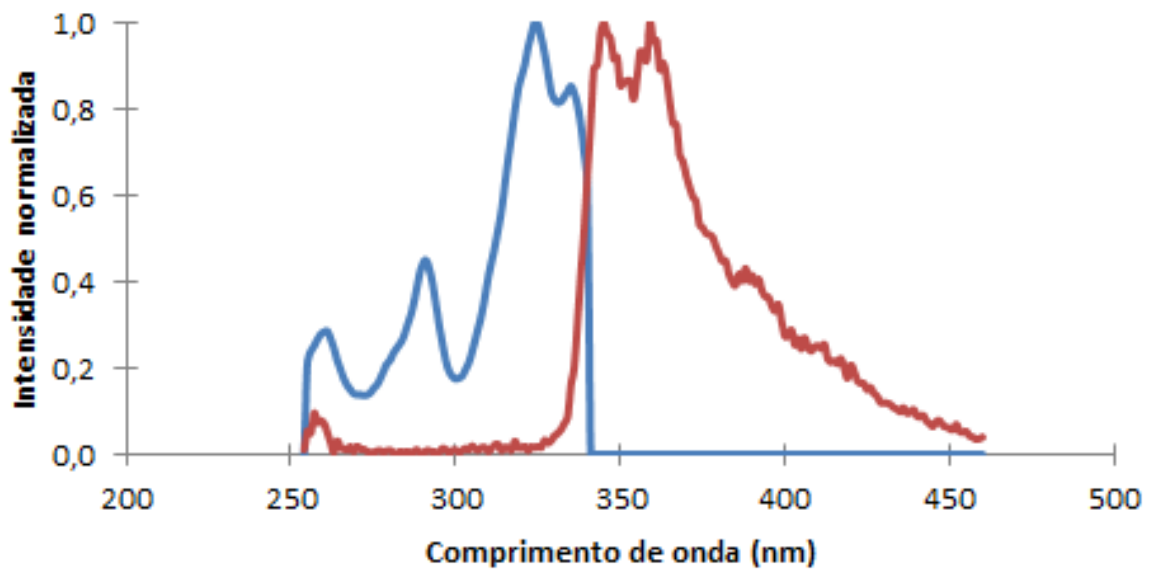

Figura 25 (cont.) - Espectros de excitação (absorção) e de emissão (fluorescência) dos fármacos.

( - Excitação -Emissão) $\lambda_{\text {excitação }}$ para o ACT $=320 \mathrm{~nm}, \lambda_{\text {excitação }}$ para o $A T L=300 \mathrm{~nm}, \lambda_{\text {excitação }}$ para 0 $\mathrm{BZF}=305 \mathrm{~nm}, \lambda_{\text {excitação }}$ para o $\mathrm{DIC}=350 \mathrm{~nm}, \lambda_{\text {excitação }}$ para o IBU $=290 \mathrm{~nm}$. 


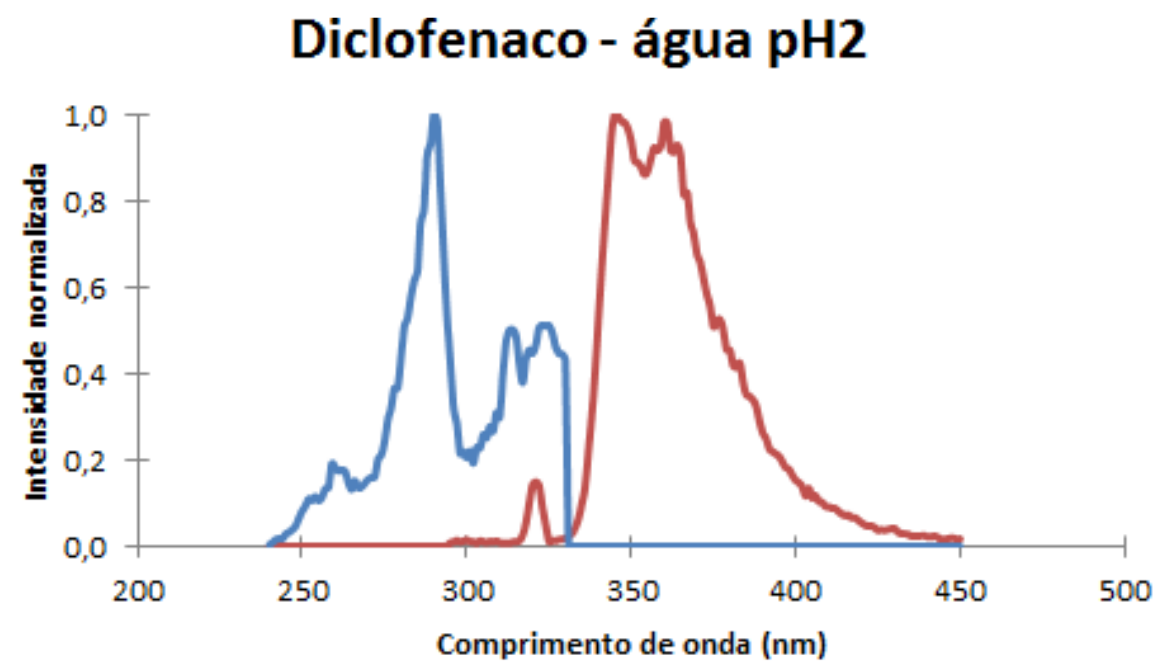

\section{Ibuprofeno - Acetonitrila}
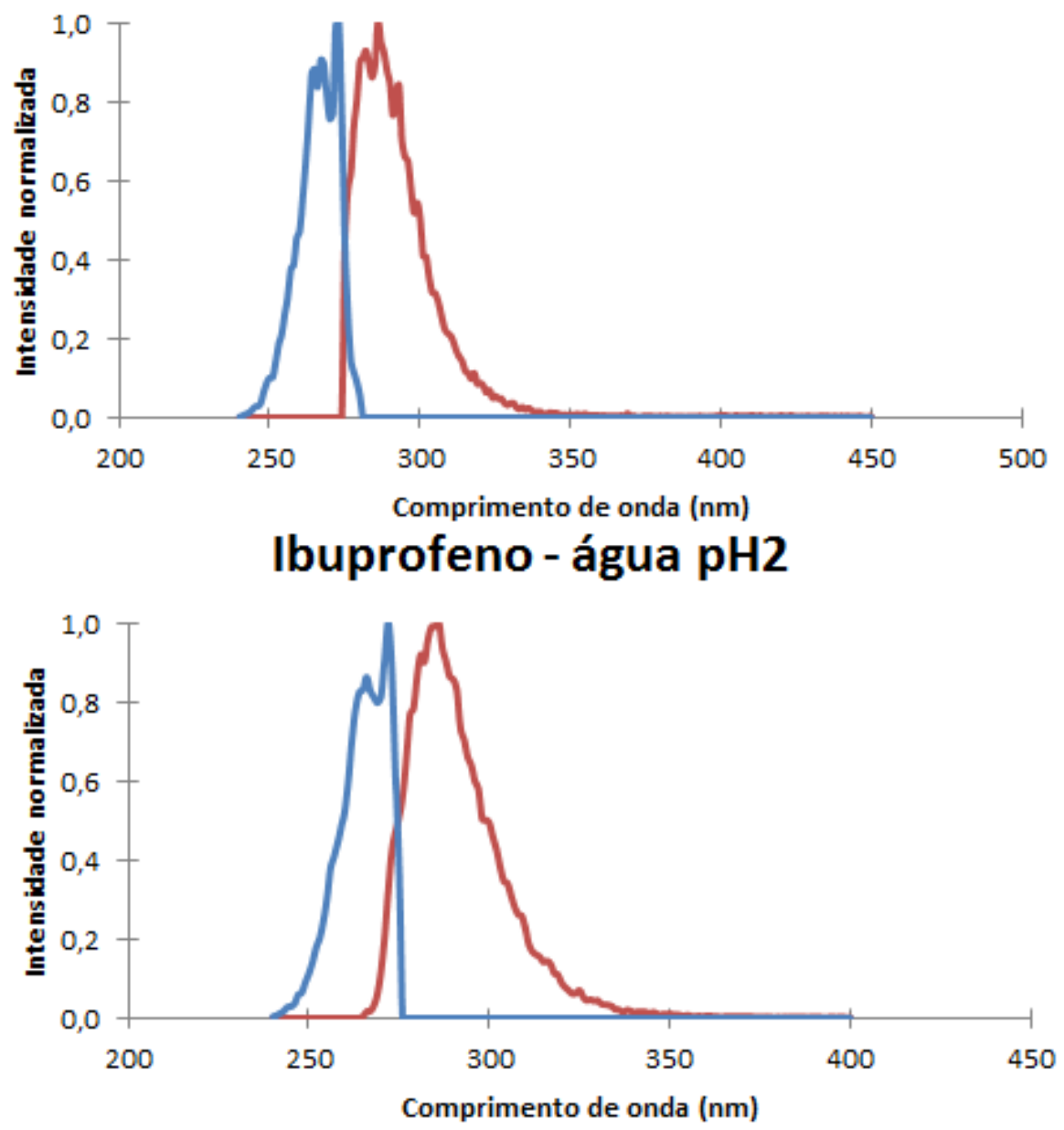

Figura 25 (cont.) - Espectros de excitação (absorção) e de emissão (fluorescência) dos fármacos.

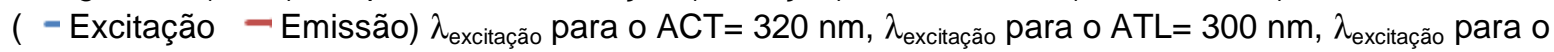
$\mathrm{BZF}=305 \mathrm{~nm}, \lambda_{\text {excitação }}$ para o $\mathrm{DIC}=350 \mathrm{~nm}, \lambda_{\text {excitação }}$ para o IBU= $290 \mathrm{~nm}$. 

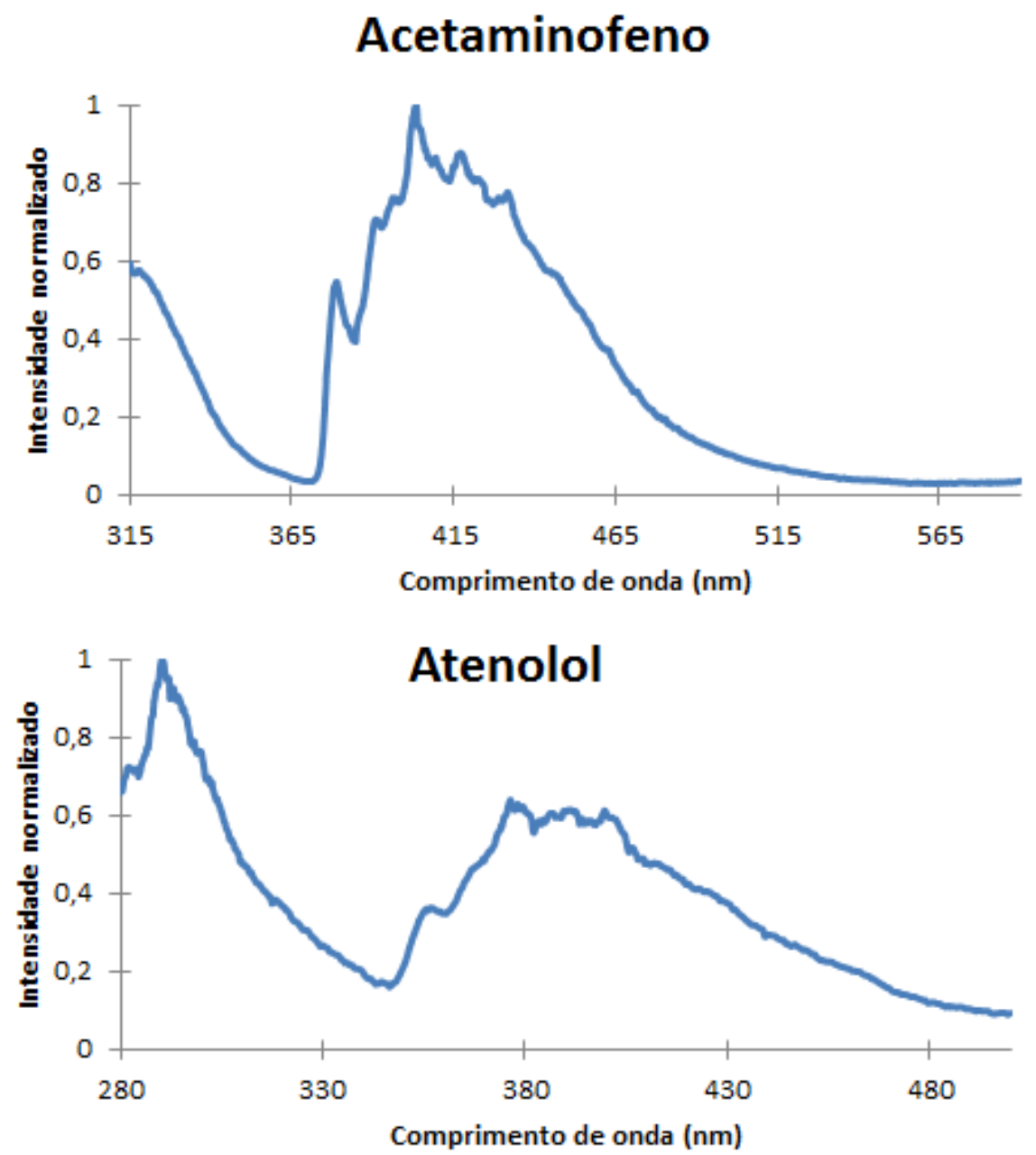

Bezafibrato

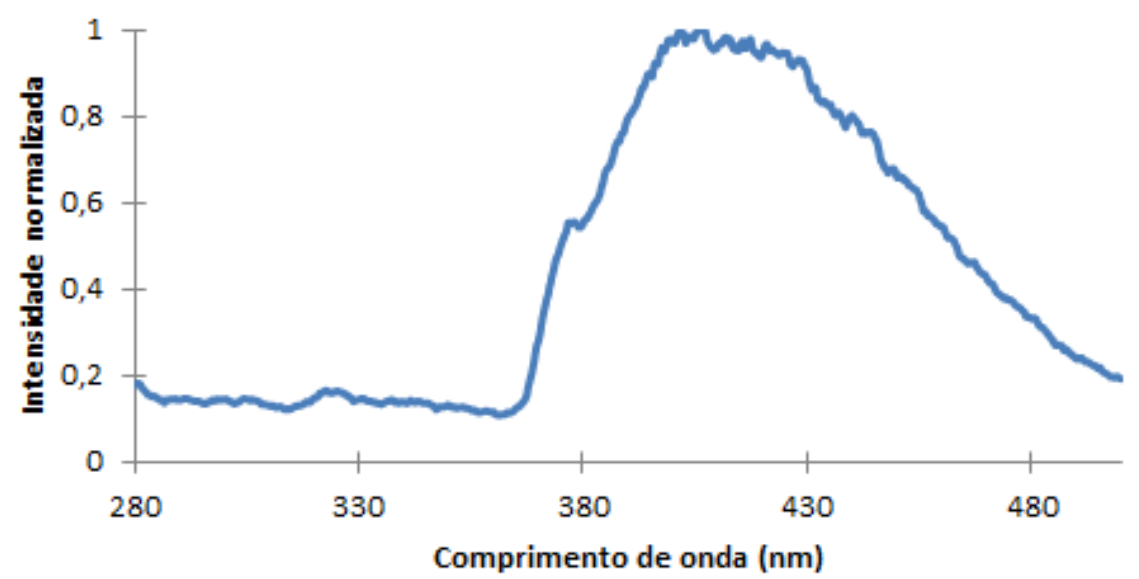

Figura 26 - Espectros de fosforescência dos fármacos em estudo em matriz vítrea orgânica de éter e 2propanol em pH natural. $\lambda_{\text {excitação }}$ para o $\mathrm{ACT}=305 \mathrm{~nm}, \lambda_{\text {excitação }}$ para $\circ \mathrm{ATL}=270 \mathrm{~nm}, \lambda_{\text {excitação }}$ para 0 $B Z F=270 \mathrm{~nm}, \lambda_{\text {excitação }}$ para $\circ \mathrm{IBU}=270 \mathrm{~nm}$. 


\section{Ibuprofeno}

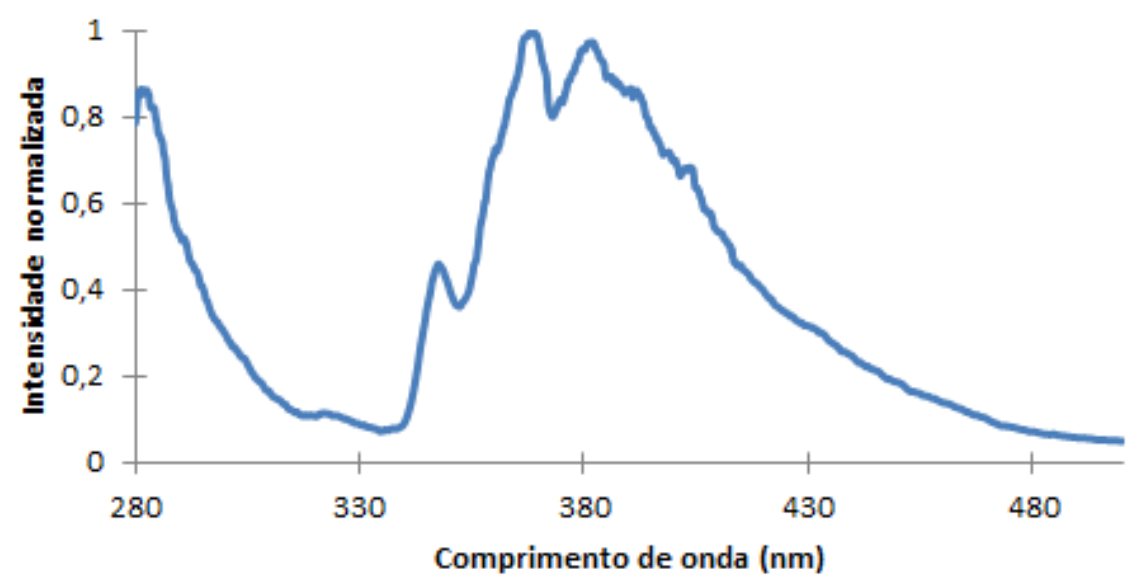

Figura 26 (cont.) - Espectros de fosforescência dos fármacos em estudo em matriz de vitrio orgânico de éter e 2-propanol em pH natural. $\lambda_{\text {excitação }}$ para o $A C T=305 \mathrm{~nm}, \lambda_{\text {excitação }}$ para $\circ \mathrm{ATL}=270 \mathrm{~nm}, \lambda_{\text {excitação }}$ para o $\mathrm{BZF}=270 \mathrm{~nm}, \lambda_{\text {excitação }}$ para $\circ \mathrm{IBU}=270 \mathrm{~nm}$.

\subsection{ESTUDO DA DEGRADAÇÃO DOS FÁRMACOS POR FOTÓLISE}

\subsubsection{Degradação dos fármacos por fotólise na mistura}

O experimento de fotólise com a solução dos fármacos foi realizado em duplicata em pH 2, empregando lâmpadas de $36 \mathrm{~W}$ e $75 \mathrm{~W}$ e concentrações iniciais de cada fármaco de 5 e $20 \mathrm{mg} \mathrm{L}^{-1}$, segundo 0 planejamento fatorial $2^{2}$. Os gráficos de concentração e TOC (normalizados) em função do tempo, para os experimentos de fotólise sob radiação UV (254 nm), são apresentados na Figura 27.

Ressalta-se que apenas os experimentos de fotólise dos fármacos em mistura foram realizados com as duas potências das lâmpadas (36 e $75 \mathrm{~W}$ ). Os resultados indicaram não haver influência importante da potência, de modo que os demais experimentos foram realizados apenas com a lâmpada de $75 \mathrm{~W}$. De fato, os resultados da actinometria (seção 5.1) confirmam que para a geometria do campo de radiação, as potências radiantes em $254 \mathrm{~nm}$ (e logo as respectivas taxas de emissão de fótons por unidade de volume) para as duas lâmpadas foram muito similares. Porém haveria economia energética se fosse empregada a lâmpada de $36 \mathrm{~W}$. 

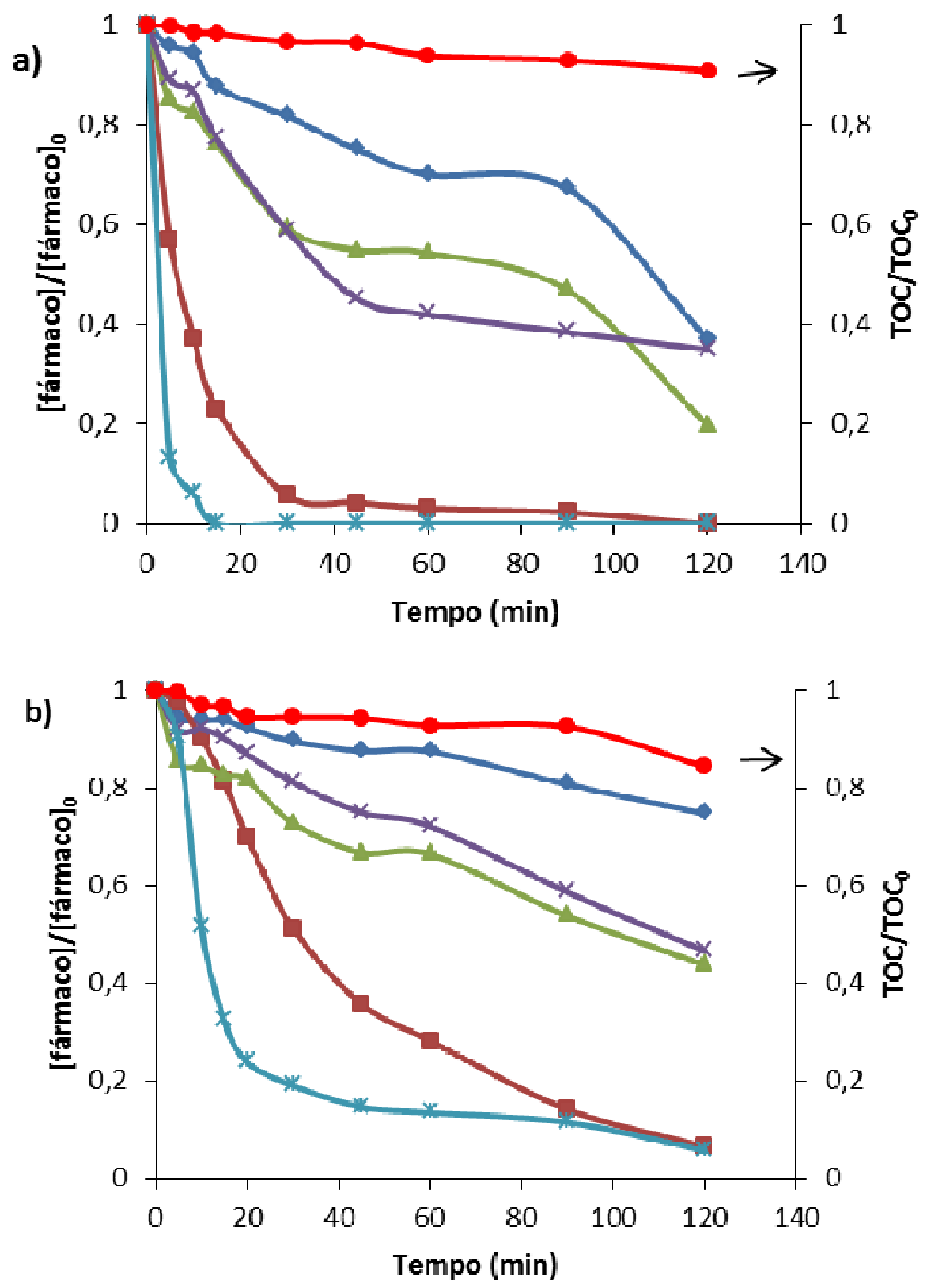

Figura 27 - Resultados dos experimentos de fotólise dos fármacos estudados. (a) $5 \mathrm{mg} \mathrm{L}^{-1}$ e $36 \mathrm{~W}$; (b) 20 $\mathrm{mg} \mathrm{L}^{-1}$ e $36 \mathrm{~W}$; (c) $5 \mathrm{mg} \mathrm{L}^{-1}$ e $75 \mathrm{~W}$; (d) $20 \mathrm{mg} \mathrm{L}^{-1}$ e $75 \mathrm{~W}$. A concentração indicada refere-se à concentração inicial nominal de cada fármaco na solução aquosa em pH 2 e $25{ }^{\circ} \mathrm{C}$.

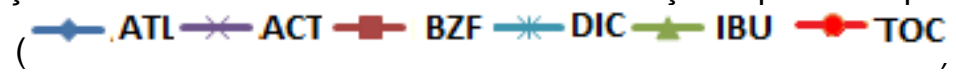



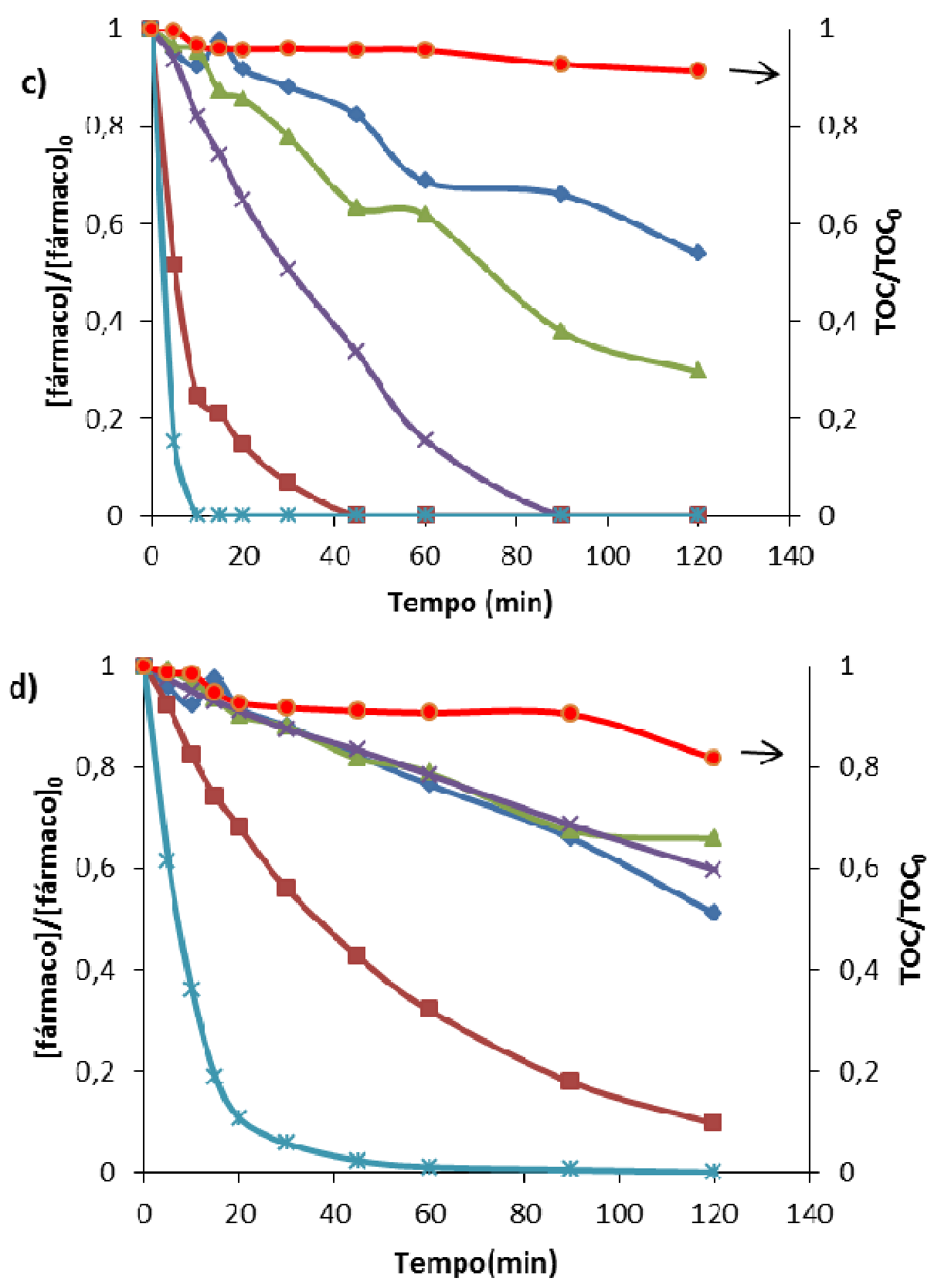

Figura 27 (cont.) - Resultados dos experimentos de fotólise dos fármacos estudados. (a) $5 \mathrm{mg} \mathrm{L}^{-1}$ e 36 W; (b) $20 \mathrm{mg} \mathrm{L}^{-1}$ e $36 \mathrm{~W}$; (c) $5 \mathrm{mg} \mathrm{L}^{-1}$ e $75 \mathrm{~W}$; (d) $20 \mathrm{mg} \mathrm{L}^{-1}$ e $75 \mathrm{~W}$. A concentração indicada refere-se à concentração inicial nominal de cada fármaco na solução aquosa em pH 2 e $25{ }^{\circ} \mathrm{C}$.

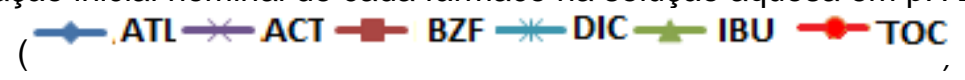

Os resultados da Figura 27 mostram que as velocidades de degradação dos fármacos diminuem com o aumento da concentração inicial, para as duas potências estudadas, e pouco se alteram com a potência elétrica, uma vez que a diferença entre 
as potências radiantes correspondentes a cada lâmpada é pequena (16 W e 14,4 W para as lâmpadas de 36 e $75 \mathrm{~W}$ de potência elétrica, respectivamente. A fotólise permite degradar facilmente o diclofenaco (DIC) e o bezafibrato (BZF), mas para os outros fármacos há necessidade de maior tempo de exposição. $O$ atenolol (ATL) apresenta o menor valor do coeficiente de absorção molar $\varepsilon$ (Figura 24), o que está de acordo com a menor degradação por fotólise; resultado similar foi encontrado por Salgado et al., 2013. Por outro lado, a degradação do acetaminofeno (ACT) foi mais lenta que a do diclofenaco (DIC) e a do bezafibrato (BZF), particularmente para maior concentração inicial, de modo que a fotólise do acetaminofeno (ACT) ocorre com menor rendimento quântico. Para o ibuprofeno (IBU) obteve-se comportamento semelhante em todos os experimentos, sendo necessário maior tempo de exposição para degradá-lo completamente.

$\mathrm{Na}$ Tabela 11 estão apresentados os resultados da análise dos dados de concentração em função do tempo segundo modelos de pseudo ordem zero ou pseudo primeira-ordem (constante de velocidade, coeficiente de determinação, $R^{2}$, tempo de meia-vida e porcentagem de remoção em $120 \mathrm{~min}$ ) para os experimentos: (A) $5 \mathrm{mg} \mathrm{L}^{-1}$ e $36 \mathrm{~W}$; (B) $20 \mathrm{mg} \mathrm{L}^{-1}$ e $36 \mathrm{~W}$; (C) $5 \mathrm{mg} \mathrm{L}^{-1}$ e $75 \mathrm{~W}$; (D) $20 \mathrm{mg} \mathrm{L}^{-1}$ e $75 \mathrm{~W}$.

Analisando os resultados apresentados na Tabela 11, para o acetaminofeno (ACT), pode-se observar que quando o produto $\varepsilon[A C T]$ em $t=0$ é baixo (Figura 27c) a concentração do fármaco diminuiu seguindo aproximadamente comportamento de pseudo primeira-ordem e que quando o produto $\varepsilon[A C T]$ em $t=0$ é alto (Figura $27 \mathrm{~b}$ e 27d), o comportamento da concentração com o tempo foi de ordem zero; no caso do experimento realizado com $[A C T]_{0}=5 \mathrm{mg} \mathrm{L}^{-1}$ e $36 \mathrm{~W}$, no entanto, houve modificação do comportamento da concentração com o tempo após aproximadamente 45 minutos.

OPPENLÄNDER (2003) discute o efeito da concentração inicial e do coeficiente de absorção molar sobre a evolução da concentração do composto durante a fotólise em sistemas batelada, o que pode ser aplicado para o caso da degradação 0 acetaminofeno (ACT). Como apresentado pelo autor, o balanço molar para um composto $M$ que sofre fotólise em solução aquosa em um sistema batelada exposto à radiação monocromática resulta na Equação 21, em que $\Phi_{M}$ é o rendimento quântico 
da fotólise de $\mathrm{M}, E_{P, 0}$ é o fluxo fotônico incidente (mantido constante), A é a área irradiada, $\mathrm{V}$ é o volume irradiado, lé o caminho óptico e $\mathrm{N}_{\mathrm{a}}$,

$$
-\frac{d[M]}{d t}=\Phi_{M} \cdot E_{P, 0} \cdot\left(1-10^{-\varepsilon_{\lambda}^{M} \cdot[M] l}\right) \frac{A}{N a \cdot V}
$$

Quando a absorção de radiação pelo composto $M$ for alta, devido ao fato do valor coeficiente de absorção molar a um determinado comprimento de onda for alto e/ou a concentração de $\mathrm{M}$ for alta $\left(A_{\lambda}=\varepsilon_{\lambda}^{M} \cdot[M] l>2\right)$, então o termo $10^{-\varepsilon_{\lambda}^{M} \cdot[M] l}$ torna-se próximo de zero. Nesse caso, a integração da Equação 21 resulta:

$$
[M]_{t}=[M]_{0}-\Phi_{M} \cdot E_{P, 0} \cdot \frac{A}{N a \cdot V} \cdot t
$$

Sendo assim, o processo de degradação de $M$ por fotólise segue cinética aparente de ordem zero.

Quando a absorção for baixa $\left(A_{\lambda}=\varepsilon_{\lambda}^{M} \cdot[M] l \ll 1\right)$, então:

$$
10^{-\varepsilon_{\lambda}^{M} \cdot[M] l} \cong 2,303 \varepsilon_{\lambda}^{M} \cdot[M] l
$$

Nesse caso, a integração da Equação (21) fica:

$$
[M]_{t}=[M]_{0} \exp \left[-\left(\Phi_{M} \cdot E_{P, 0} \cdot 2,303 \varepsilon_{\lambda}^{M} \cdot[M] l \cdot \frac{A}{N a . V}\right) t\right]
$$

A qual corresponde a um modelo cinético de pseudo primeira-ordem.

No caso da mistura de fármacos, a Equação (21) deve ser multiplicada pelo fator $\frac{\varepsilon .[M]}{\sum \varepsilon .[M]}$, que representa a fração da radiação incidente absorvida pelo fármaco em relação à absorção pela mistura. Assim, o emprego desse modelo deve ser analisado 
com cautela, porque há formação de subprodutos de degradação que também interferem na absorção de radiação UV.

Para os fármacos atenolol (ATL), bezafibrato (BZF), diclofenaco (DIC) e ibuprofeno (IBU), não ocorrerem mudanças nos comportamentos das taxas de degradação com a variação da concentração inicial.

Por sua vez, os valores de TOC mostraram um pequeno decréscimo em todos os experimentos (13\% ao final de 120 minutos), o que comprova a persistência dos produtos de degradação formados.

Tabela 11: Modelos de decaimento da concentração dos fármacos conforme a Figura 27 (mistura dos fármacos), coeficiente de determinação $\left(R^{2}\right)$, constante de velocidade $(k)$, tempo de meia vida $\left(t \frac{1}{2}\right)$ e porcentagem de remoção em 120 min dos experimentos: (A) $5 \mathrm{mg} \mathrm{L}^{-1}$ e $36 \mathrm{~W}$; (B) $20 \mathrm{mg} \mathrm{L}^{-1}$ e $36 \mathrm{~W}$; (C) $5 \mathrm{mg} \mathrm{L}^{-1}$ e $75 \mathrm{~W}$; (D) $20 \mathrm{mg} \mathrm{L}^{-1}$ e $75 \mathrm{~W}$.

\begin{tabular}{|c|c|c|c|c|c|}
\hline Composto & Modelo & $\mathbf{R}^{2}$ & Constante $(\mathbf{k})^{\mathrm{a}}$ & $t(1 / 2) \quad(\min )$ & $\begin{array}{c}\text { \% Remoção } \\
\text { (120 min) }\end{array}$ \\
\hline \multicolumn{6}{|c|}{ A } \\
\hline Acetaminofeno & - & - & - & 42 & 65 \\
\hline Atenolol & {$[\mathrm{ATL}]=1,0145 \mathrm{e}^{-0,007 t}$} & 0,8897 & 0,007 & 112 & 65 \\
\hline Bezafibrato & {$[B Z F]=0,6702 e^{-0,059 t}$} & 0,9152 & 0,059 & 11,7 & 99 \\
\hline Diclofenaco & {$[D I C]=0,8107 \mathrm{e}^{-0,28 \mathrm{t}}$} & 0,9367 & 0,28 & 2,5 & 99 \\
\hline Ibuprofeno & {$[\mathrm{IBU}]=0,9344 \mathrm{e}^{-0,011 \mathrm{t}}$} & 0,9005 & 0,011 & 90 & 80 \\
\hline \multicolumn{6}{|c|}{ B } \\
\hline Acetaminofeno & {$[A C T]=-0,0042 t+0,9588$} & 0,9863 & 0,0042 & 114,1 & 53 \\
\hline Atenolol & {$[\mathrm{ATL}]=0,968 \mathrm{e}^{-0,002 t}$} & 0,9629 & 0,002 & 346,5 & 25 \\
\hline Bezafibrato & {$[B Z F]=1,0796 \mathrm{e}^{-0,023 t}$} & 0,9967 & 0,023 & 30,1 & 94 \\
\hline Diclofenaco & {$[D I C]=0,7267 \mathrm{e}^{-0,034 t}$} & 0,8226 & 0,034 & 12 & 97 \\
\hline Ibuprofeno & {$[\mathrm{IBU}]=0,914 \mathrm{e}^{-0,006 t}$} & 0,9697 & 0,006 & 112 & 56 \\
\hline \multicolumn{6}{|c|}{$\mathrm{C}$} \\
\hline Acetaminofeno & {$[A C T]=1,12 e^{-0,03 t}$} & 0,9707 & 0,03 & 30 & 99 \\
\hline Atenolol & {$[\mathrm{ATL}]=1,0033 \mathrm{e}^{-0,005 t}$} & 0,96 & 0,005 & 125 & 40 \\
\hline Bezafibrato & {$[B Z F]=0,7961 \mathrm{e}^{-0,086 t}$} & 0,9628 & 0,086 & 8,1 & 99 \\
\hline Diclofenaco & {$[\mathrm{DIC}]=1,0882 \mathrm{e}^{-0,189 t}$} & 0,9766 & 0,189 & 3,66 & 99 \\
\hline Ibuprofeno & {$[\mathrm{IBU}]=1,0388 \mathrm{e}^{-0,01 \mathrm{t}}$} & 0,987 & 0,01 & 74 & 71 \\
\hline \multicolumn{6}{|c|}{ D } \\
\hline Acetaminofeno & {$[A C T]=-0,0033 t+0,9847$} & 0,9964 & 0,0033 & 130 & 40 \\
\hline Atenolol & {$[A T L]=1,0159 e^{-0,005 t}$} & 0,9718 & 0,005 & 138,63 & 49 \\
\hline Bezafibrato & {$[B Z F]=1,0067 e^{-0,019 t}$} & 0,9997 & 0,019 & 36,5 & 90 \\
\hline Diclofenaco & {$[D I C]=0,7282 e^{-0,076 t}$} & 0,9709 & 0,076 & 9,1 & 99 \\
\hline Ibuprofeno & {$[\mathrm{IBU}]=0,9897 \mathrm{e}^{-0,004 t}$} & 0,9723 & 0,004 & 173,28 & 34 \\
\hline
\end{tabular}

${ }^{a}$ Para pseudo ordem zero, $[\mathrm{k}]=\mathrm{mg} \mathrm{L}^{-1} \mathrm{~min}^{-1}$; para pseudo primeira-ordem, $[\mathrm{k}]=\mathrm{min}^{-1}$. 


\subsubsection{Degradação dos fármacos isolados por fotólise}

Os experimentos de fotólise com a solução de cada fármaco individualmente foram realizados em pH 2, com lâmpada $75 \mathrm{~W}$ e concentrações iniciais do fármaco de 5 ou $20 \mathrm{mg} \mathrm{L}^{-1}$. Os resultados de concentração e TOC (normalizados) em função do tempo, nos experimentos de fotólise empregando radiação UV $(254 \mathrm{~nm})$, são apresentados nas Figuras 28 e 29, respectivamente.

Comparando as Figuras 27c e 27d com a Figura 28, observa-se que as concentrações do diclofenaco (DIC) e do bezafibrato (BZF) diminuem mais acentuadamente em função do tempo de irradiação quando comparadas às dos demais fármacos, independentemente de se encontrarem na mistura ou isoladamente. Além disso, fica claro que as taxas de degradação dos fármacos de maneira geral são maiores quando irradiados isoladamente, já que em mistura há competição pelos fótons, o que depende da forma como cada fármaco absorve a radiação incidente, isto é, dos valores de seus coeficientes de absorção molar. 

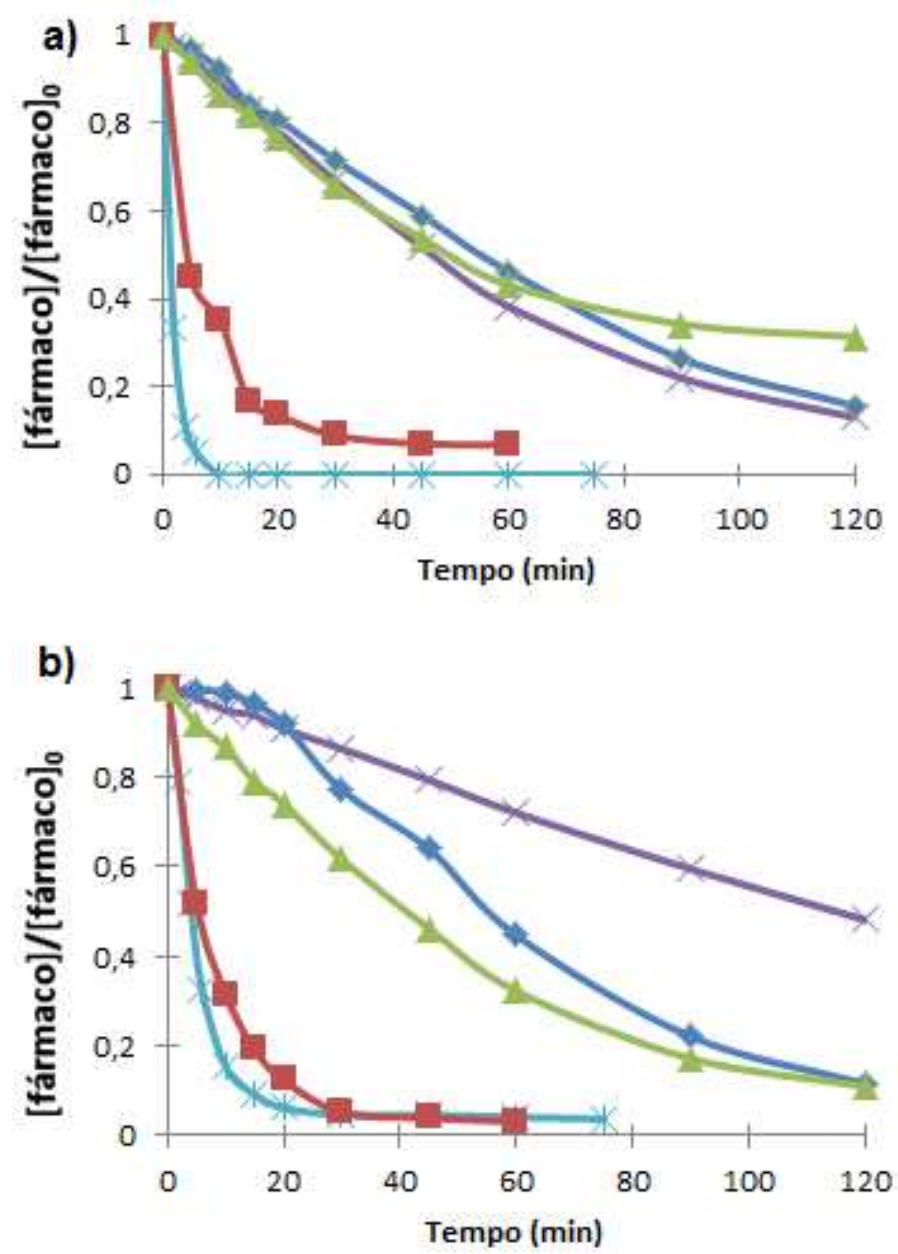

Figura 28 - Resultados dos experimentos de fotólise dos fármacos individualmente. (a) $5 \mathrm{mg} \mathrm{L}^{-1}$ e $75 \mathrm{~W}$; (b) $20 \mathrm{mg} \mathrm{L}^{-1} \mathrm{e} 75 \mathrm{~W}$. A concentração indicada refere-se à concentração inicial nominal de cada fármaco na solução aquosa em pH 2 e 25 C. $(\multimap$ ATL $\leftarrow$ ACT $\rightarrow$ BZF $\because$ DIC $\rightarrow$ IBU ;

$\mathrm{Na}$ Tabela 12, estão apresentados os resultados da análise dos dados de concentração em função do tempo segundo modelos de pseudo ordem zero ou pseudo primeira-ordem (constante de velocidade, coeficiente de determinação, $R^{2}$, tempo de meia vida e a porcentagem de remoção em 120 min para os experimentos (dos fármacos isoladamente): (A) $5 \mathrm{mg} \mathrm{L}^{-1}$ e $75 \mathrm{~W}$; (B) $20 \mathrm{mg} \mathrm{L}^{-1}$ e $75 \mathrm{~W}$.

Analisando a Tabela 12, para o caso da fotólise dos fármacos isoladamente, a redução da concentração em função do tempo seguiu comportamento de pseudo primeira-ordem, exceto para o ACT no experimento realizado com maior concentração inicial. 
Tabela 12: Modelos de decaimento da concentração dos fármacos conforme a Figura 28 (fármacos isoladamente), coeficiente de determinação $\left(R^{2}\right)$, constante de velocidade $(k)$, tempo de meia vida (t $\left.1 / 2\right)$ e porcentagem de remoção em 120 min dos experimentos: (A) $5 \mathrm{mg} \mathrm{L}^{-1}$ e $75 \mathrm{~W}$; (B) $20 \mathrm{mg} \mathrm{L}^{-1}$ e $75 \mathrm{~W}$.

\begin{tabular}{|c|c|c|c|c|c|}
\hline Composto & Modelo & $\mathbf{R}^{2}$ & $\begin{array}{c}\text { Constante } \\
(\mathbf{k})^{\mathrm{a}}\end{array}$ & $t(1 / 2) \quad(\min )$ & $\begin{array}{c}\% \\
\text { Remoção } \\
\text { (120 min) }\end{array}$ \\
\hline \multicolumn{6}{|c|}{ A } \\
\hline Acetaminofeno & {$[A C T]=1,0585 \mathrm{e}^{-0,017 t}$} & 0,9964 & 0,017 & 52,5 & 85 \\
\hline Atenolol & {$[\mathrm{ATL}]=1,0855 \mathrm{e}^{-0,016 \mathrm{t}}$} & 0,991 & 0,016 & 60 & 90 \\
\hline Bezafibrato & {$[B Z F]=0,7581 \mathrm{e}^{-0,08 t}$} & 0,9334 & 0,08 & 7 & 94 \\
\hline Diclofenaco & {$[D I C]=0,9407 \mathrm{e}^{-0,51 t}$} & 0,9936 & 0,51 & 1,4 & 94 \\
\hline Ibuprofeno & {$[\mathrm{IBU}]=0,9336 \mathrm{e}^{-0,01 \mathrm{t}}$} & 0,9569 & 0,01 & 65 & 69 \\
\hline \multicolumn{6}{|c|}{ B } \\
\hline Acetaminofeno & $\begin{array}{c}{[\mathrm{ACT}]=-0,0044 \mathrm{t}+} \\
0,9954\end{array}$ & 0,9985 & 0,0044 & 115,52 & 52 \\
\hline Atenolol & {$[A T L]=1,2234 \mathrm{e}^{-0,019 t}$} & 0,9728 & 0,019 & 55 & 90 \\
\hline Bezafibrato & {$[B Z F]=0,6955 e^{-0,074 t}$} & 0,9322 & 0,074 & 9,4 & 98 \\
\hline Diclofenaco & {$[D I C]=0,7195 \mathrm{e}^{-0,11 t}$} & 0,9015 & 0,11 & 6,3 & 98 \\
\hline Ibuprofeno & {$[\mathrm{IBU}]=1,0432 \mathrm{e}^{-0,019 t}$} & 0,9966 & 0,019 & 40 & 90 \\
\hline
\end{tabular}

${ }^{\mathrm{a}}$ Para pseudo ordem zero, $[\mathrm{k}]=\mathrm{mg} \mathrm{L}^{-1} \mathrm{~min}^{-1}$; para pseudo-primeira ordem, $[\mathrm{k}]=\mathrm{min}^{-1}$.

No caso do atenolol e do bezafibrato, o produto $\varepsilon[A T L]$ e $\varepsilon[\mathrm{IBU}]$ em $\mathrm{t}=0$ é baixo, independentemente da concentração inicial, já que os valores do coeficiente de absorção molar $\varepsilon$ desses fármacos é baixo. Nesses casos, a concentração do fármaco diminuiu seguindo aproximadamente um comportamento de pseudo primeira-ordem, conforme discutido por OPPENLÄNDER (2003).

Os valores de TOC correspondentes, apresentados na Figura 29, indicam pequena mineralização dos fármacos, com 12,6\% de remoção de TOC ao final de 120 minutos, o que comprova a persistência dos produtos de degradação formados. 

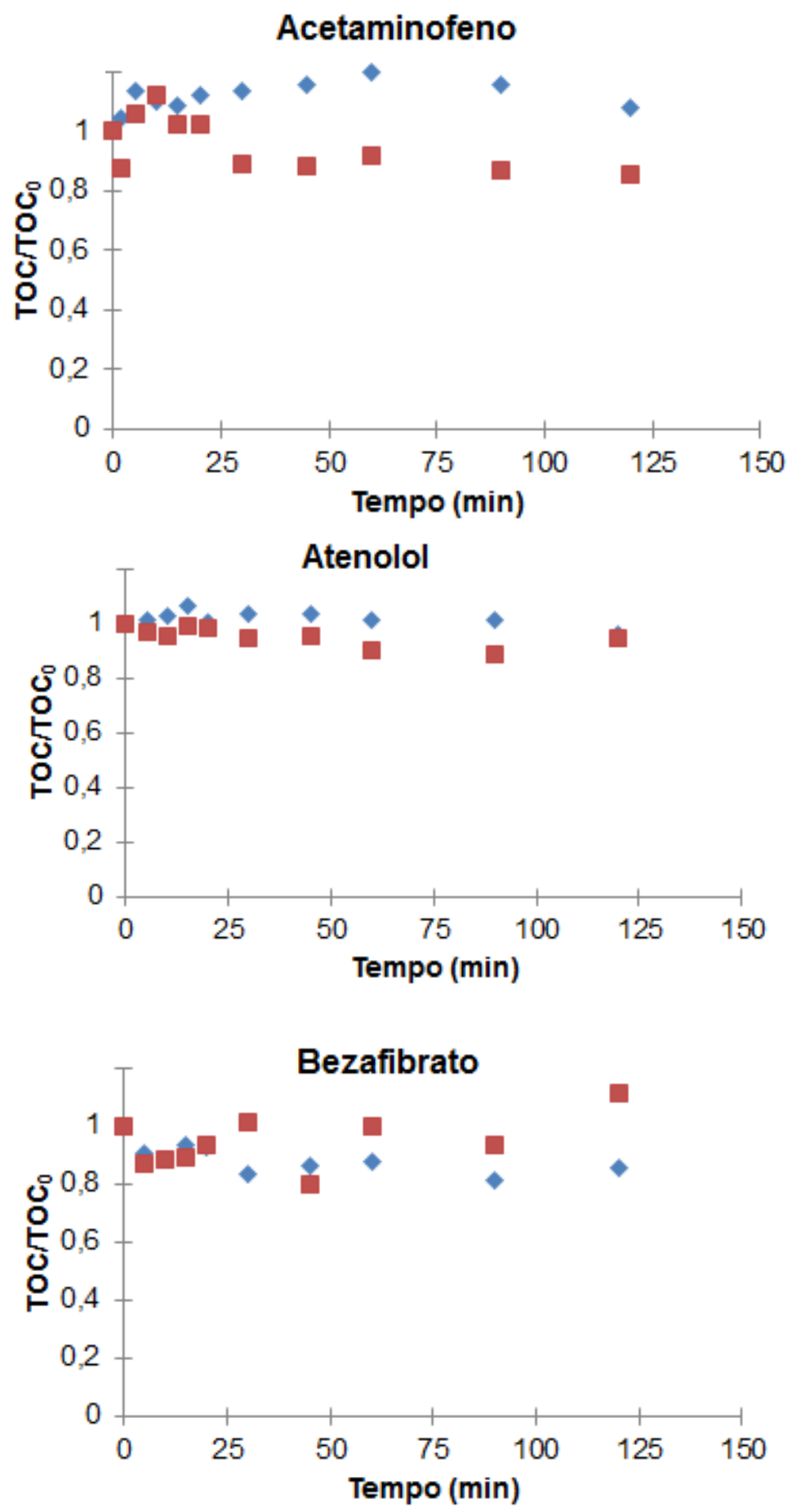

Figura 29 - Resultados de TOC (normalizado) dos experimentos de fotólise dos fármacos individualmente. Experimentos realizados com lâmpada de $75 \mathrm{~W}$. ( $5 \mathrm{mg} \mathrm{L}^{-1} \bullet 20 \mathrm{mg} \mathrm{L}^{-1}$ ) 

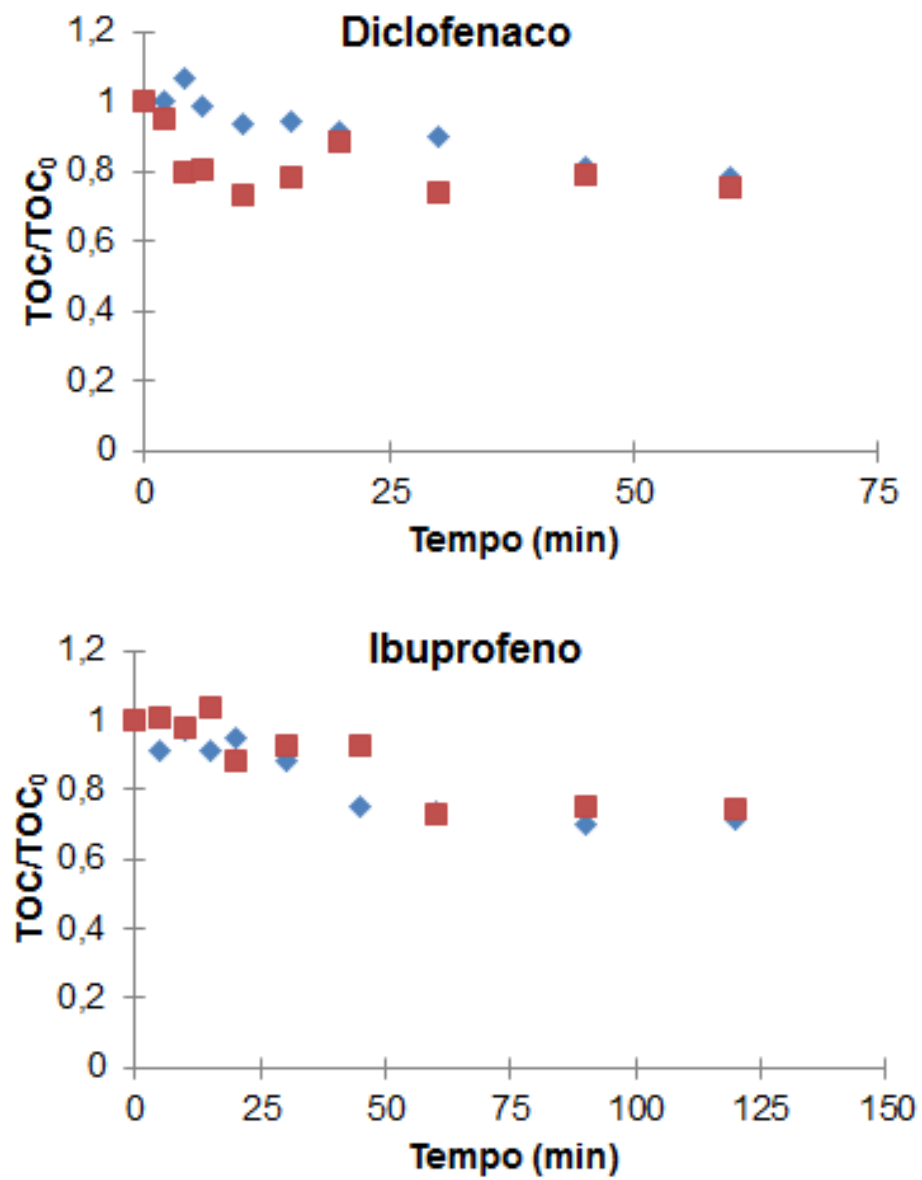

Figura 29 (cont.) - Resultados de TOC (normalizado) dos experimentos de fotólise dos fármacos individualmente. Experimentos realizados com lâmpada de $75 \mathrm{~W}$. ( $5 \mathrm{mg} \mathrm{L}^{-1} \bullet 20 \mathrm{mg} \mathrm{L}^{-1}$ ) 


\subsubsection{Avaliação espectrofotométrica}

Para verificar o comportamento da absorção do meio aquoso no decorrer da fotólise, obtiveram-se os espectros de absorção UV-visível, apresentados nas Figuras 30 e 31 , para o caso dos experimentos realizados com cada fármaco isoladamente e para 0 caso dos experimentos realizados com a mistura dos fármacos, respectivamente.

\section{Acetaminofeno}

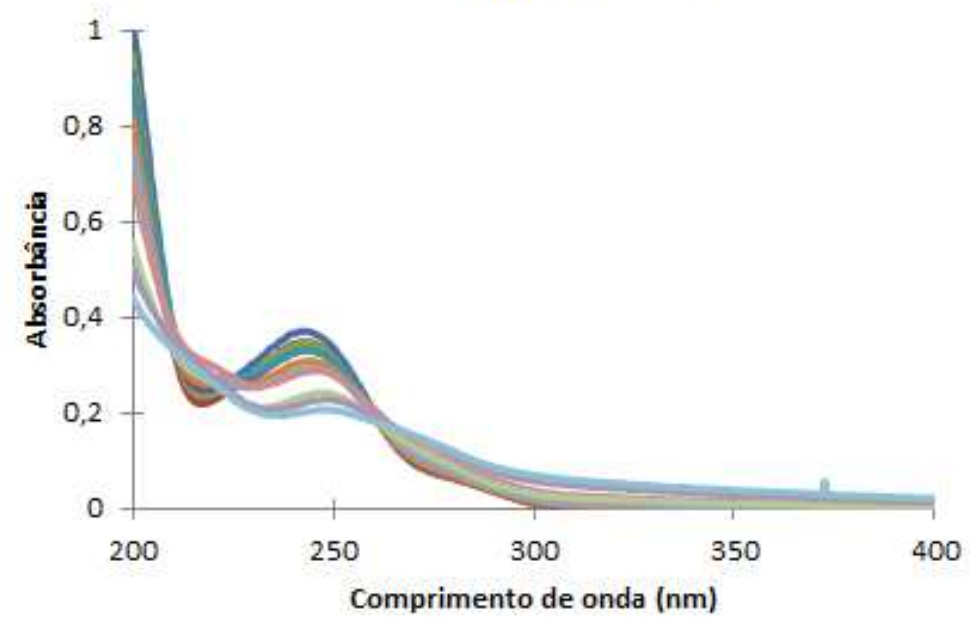

\section{Atenolol}

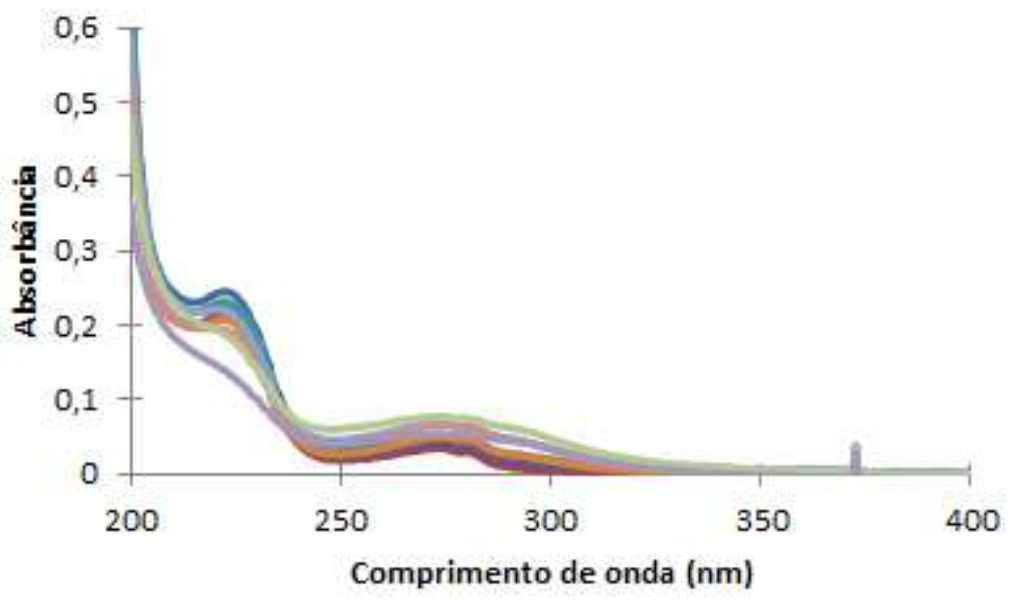

Figura 30 - Espectros de absorção UV-visível dos fármacos em função do tempo, à concentração nominal inicial de $5 \mathrm{mg} \mathrm{L}^{-1}$ e potência da lâmpada $75 \mathrm{~W}$ em pH 2 e $25 \mathrm{C}$. ( $-0 \mathrm{~min}-5 \mathrm{~min}-10$ $\min -15 \mathrm{~min}-20 \mathrm{~min}-30 \mathrm{~min}-45 \mathrm{~min}-60 \mathrm{~min}-90 \mathrm{~min}-120 \mathrm{~min})$ 


\section{Bezafibrato}

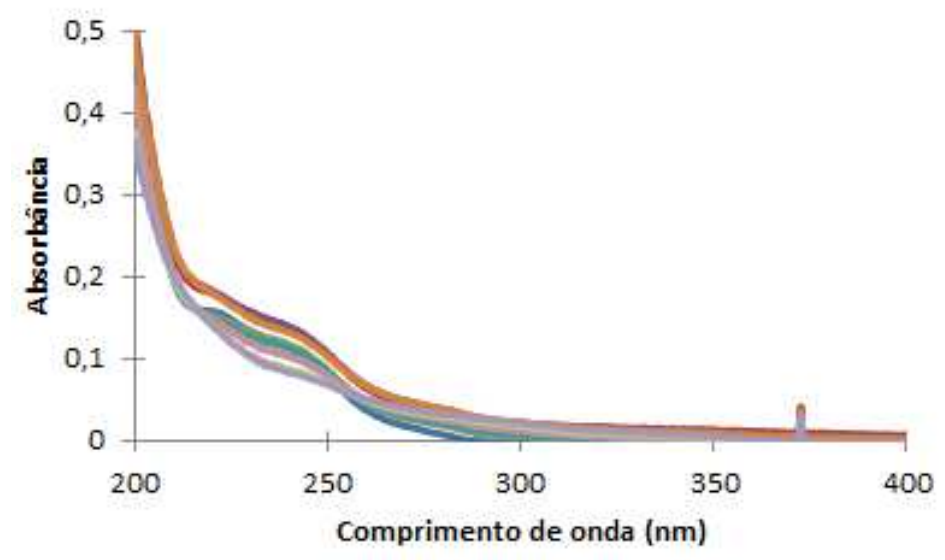

Diclofenaco

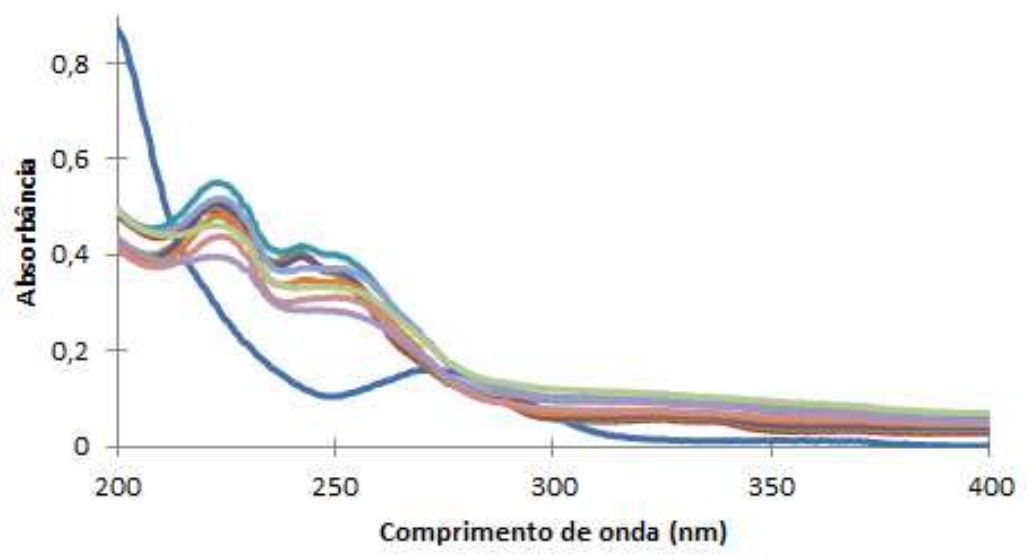

\section{Ibuprofeno}

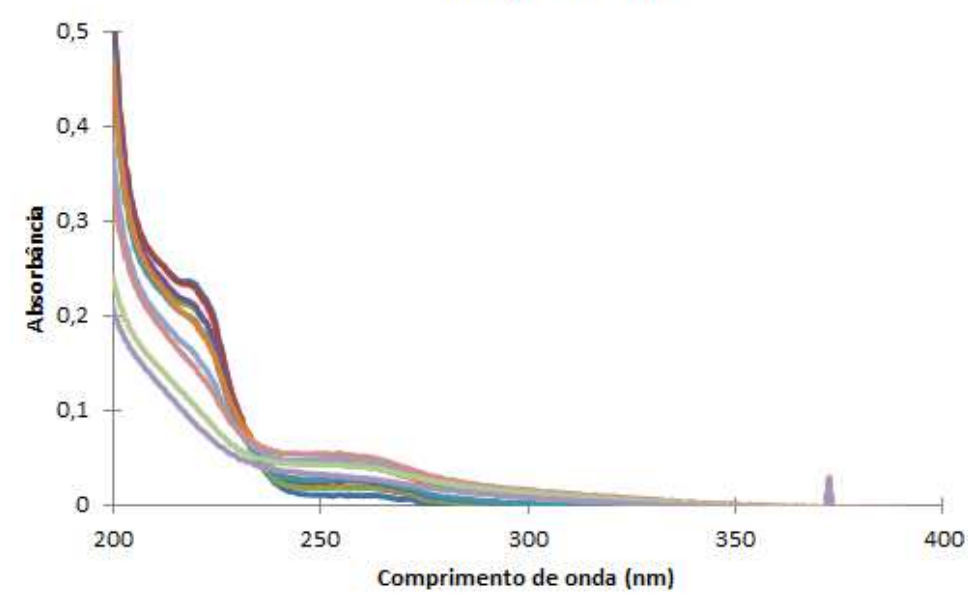

Figura 30 (cont.) - Espectros de absorção UV-visível dos fármacos em função do tempo, à concentração inicial nominal de $5 \mathrm{mg} \mathrm{L}^{-1}$ e potência da lâmpada $75 \mathrm{~W} \mathrm{em} \mathrm{pH} 2$ e $25{ }^{\circ} \mathrm{C}$. ( $-0 \mathrm{~min}-5 \mathrm{~min}-10$ $\min -15 \min -20 \min -30 \mathrm{~min}-45 \mathrm{~min}-60 \mathrm{~min}-90 \mathrm{~min}-120 \mathrm{~min})$ 


\section{Acetaminofeno}

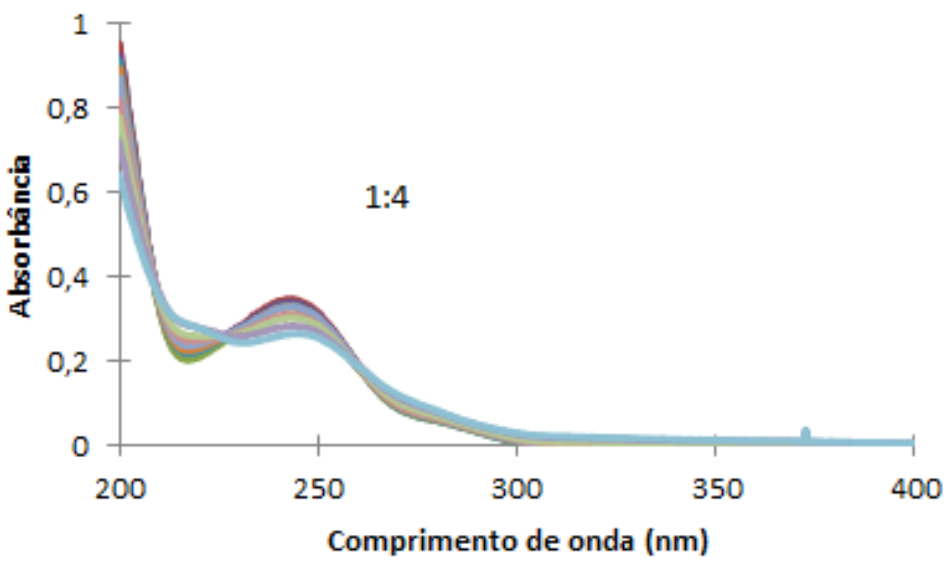

\section{Atenolol}

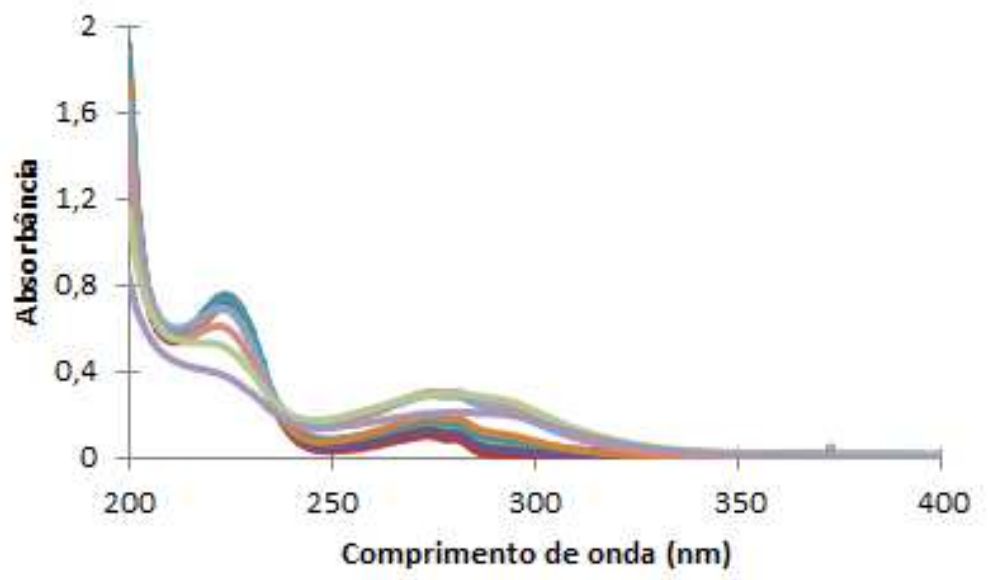

Bezafibrato

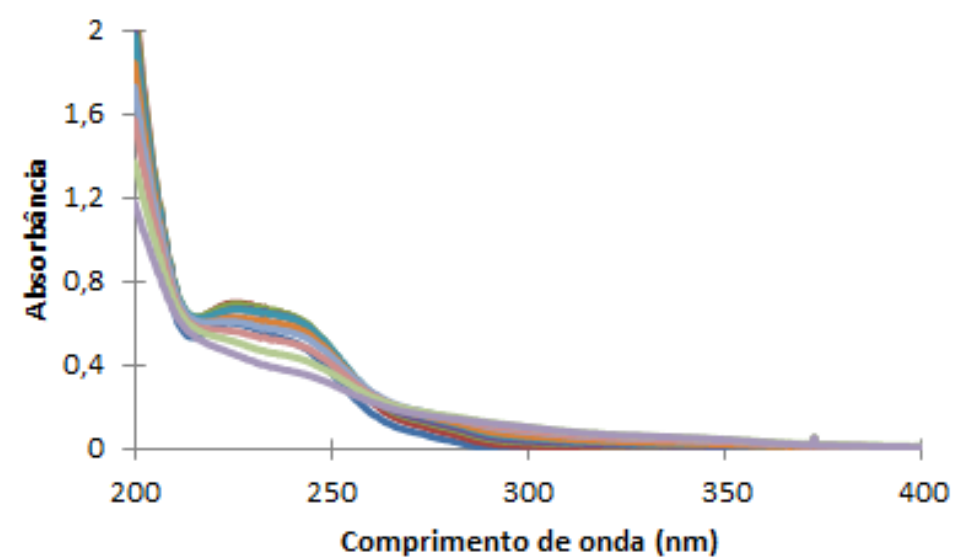

Figura 30 (cont.) - Espectros de absorção UV-visível dos fármacos em função do tempo, à concentração inicial nominal de $20 \mathrm{mg} \mathrm{L}^{-1}$ e potência da lâmpada $75 \mathrm{~W} \mathrm{em} \mathrm{pH} 2$ e $25{ }^{\circ} \mathrm{C}$. ( $-0 \mathrm{~min}-5 \mathrm{~min}-10$ $\min -15 \min -20 \min -30 \mathrm{~min}-45 \mathrm{~min}-60 \mathrm{~min}-90 \mathrm{~min}-120 \mathrm{~min}$. (1:4 - diluição de 1 parte de solução para 3 partes de água para leitura no espectrofotometro) 


\section{Diclofenaco}

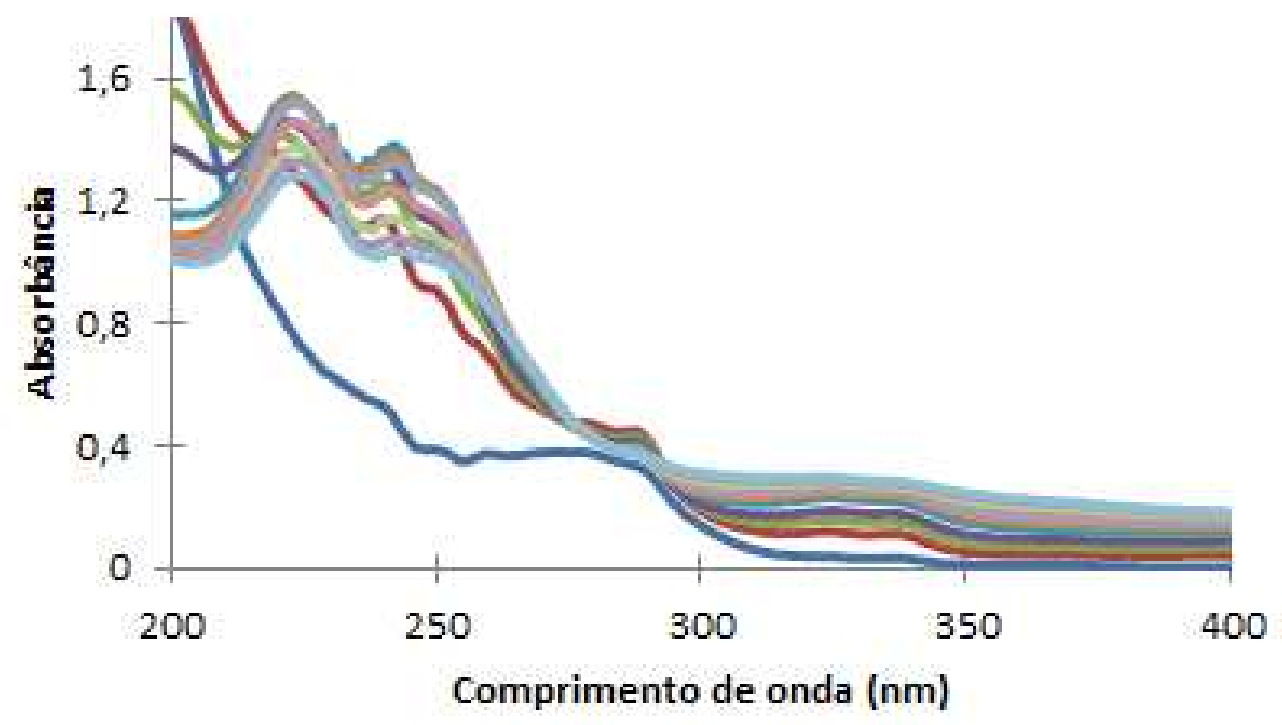

Ibuprofeno

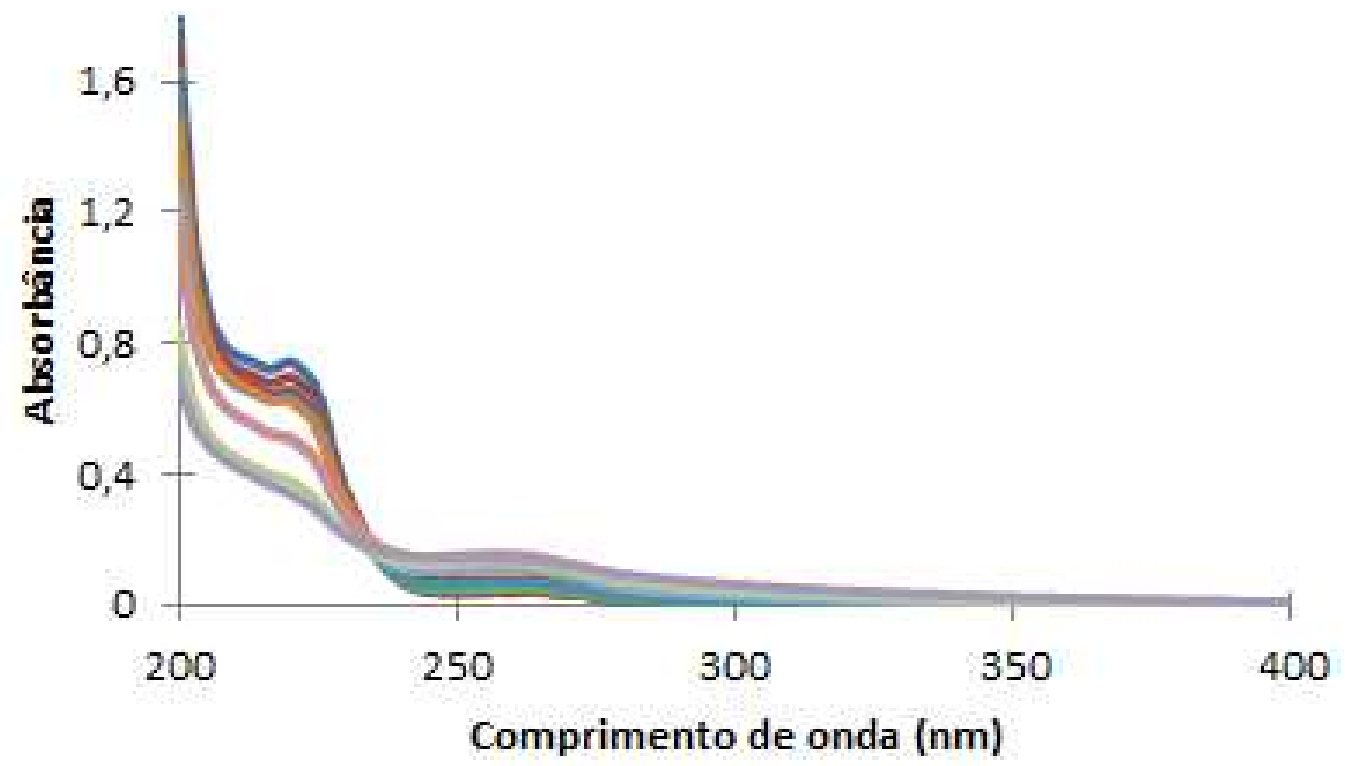

Figura 30 (cont.) - Espectros de absorção UV-visível dos fármacos em função do tempo, à concentração inicial nominal de $20 \mathrm{mg} \mathrm{L}^{-1}$ e potência da lâmpada $75 \mathrm{~W}$ em pH 2 e 25 C. ( $-0 \mathrm{~min}-5 \mathrm{~min}-10$ $\min -15 \min -20 \mathrm{~min}-30 \mathrm{~min}-45 \mathrm{~min}-60 \mathrm{~min}-90 \mathrm{~min}-120 \mathrm{~min}$ ). (1:4 - diluição de 1 parte de solução para 3 partes de água para leitura no espectrofotometro) 

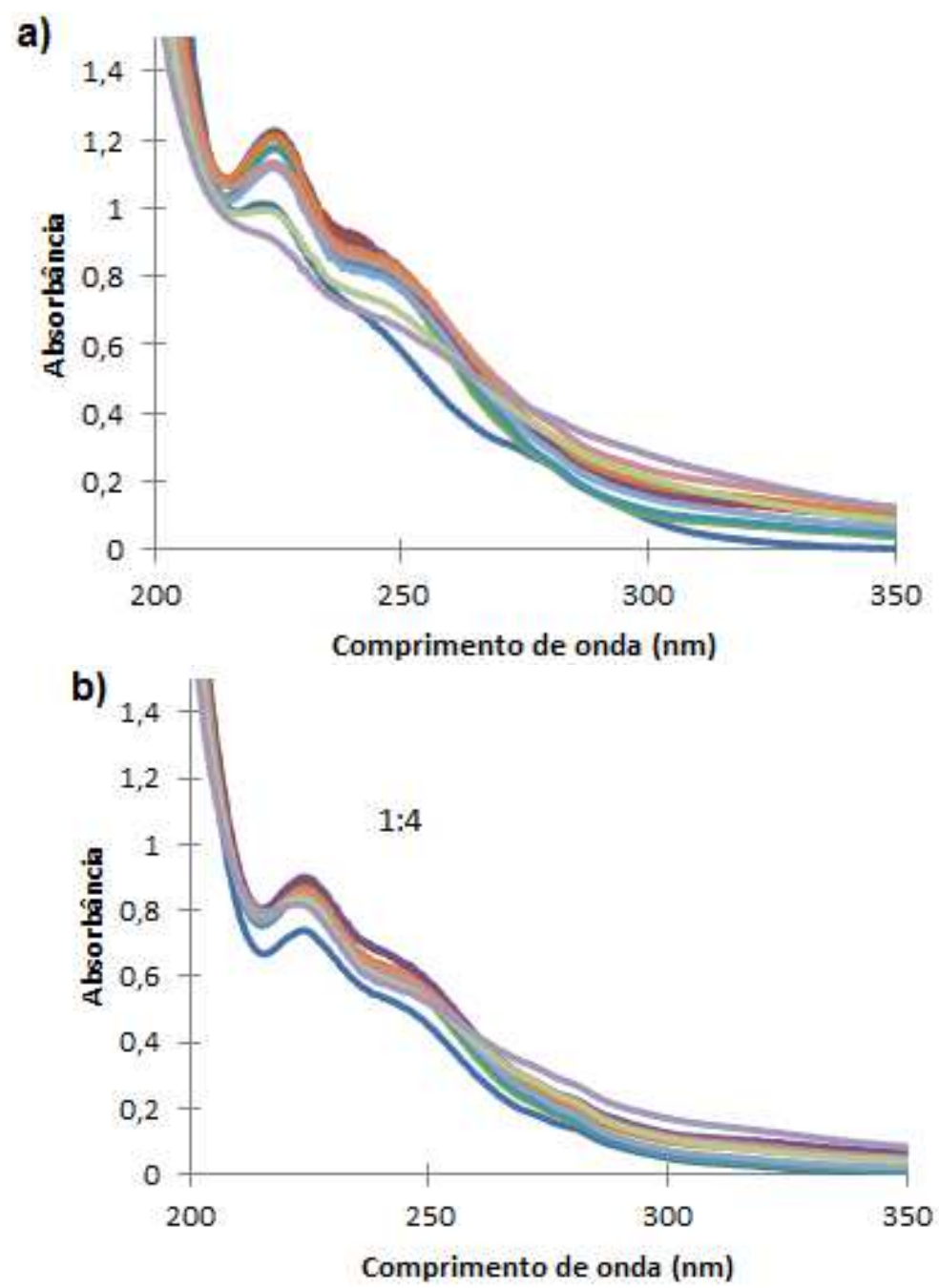

Figura 31 - Espectros de absorção UV-visível em função do tempo, para a mistura dos fármacos. (a) 5 $\mathrm{mg} \mathrm{L}^{-1}$ de cada fármaco e $75 \mathrm{~W}$. (b) $20 \mathrm{mg} \mathrm{L}^{-1}$ de cada fármaco e $75 \mathrm{~W}$ em pH 2 e $25 \mathrm{C}$. ( -0 min $5 \mathrm{~min}-10 \mathrm{~min}-15 \mathrm{~min}-20 \mathrm{~min}-30 \mathrm{~min}-45 \mathrm{~min}-60 \mathrm{~min}-90 \mathrm{~min}-120 \mathrm{~min}) .(1: 4$ diluição de 1 parte de solução para 3 partes de água para leitura no espectrofotometro)

Observa-se que os comportamentos dos espectros são bastante similares entre si, com exceção do diclofenaco (DIC), para o qual se nota que a curva correspondente ao tempo zero está inferior às demais após os experimentos de fotólise; isso está associado à coloração formada (alaranjado) após o processo de fotólise, o que, segundo Keen et al. (2013), deve-se à formação de dímero (subproduto 5 - Figura 11) durante a radiação (UV) do DIC. Para os outros fármacos sempre há redução da absorbância com o decorrer da fotólise, o que se deve a sua degradação. 


\subsubsection{Análise de toxicidade}

\subsubsection{Avaliação da toxicidade da mistura dos fármacos}

Na Tabela 13 são apresentados os resultados dos ensaios de toxicidade obtidos a partir da bactéria luminescente Vibrio fischeri, para as amostras retiradas dos experimentos de degradação por fotólise com a mistura de fármacos. Observa-se que os valores de $\mathrm{CE}_{50}$ seguiram o mesmo comportamento em todos os experimentos, diminuindo a partir do valor inicial $(2,4 \pm 0,9 \%)$ até 15 minutos, aumentando em 45 minutos e diminuindo novamente após 120 minutos de tratamento. A classificação proposta por Tonkes et al. (1999) considera que as amostras com um valor de $\mathrm{CE}_{50}$ inferior a $10 \%$ são consideradas tóxicas e amostras com um valor de $\mathrm{CE}_{50}$ inferior a $1 \%$ como muito tóxicas. Em todos os experimentos de fotólise as amostras tornaram-se mais tóxicas frente ao organismo-teste após irradiação UV prolongada, apesar de em alguns casos ocorrer degradação rápida e praticamente total de alguns fármacos, obtendo-se concentrações abaixo do limite de quantificação cromatográfico. Dessa forma, as taxas de remoção de TOC muito baixas obtidas nos experimentos estão associadas à formação de produtos de degradação persistentes e de maior toxicidade.

Tabela 13 - Valores de CE50 (\%) nos tempos de 0, 15, 45 e 120 min de degradação por fotólise da solução de mistura de fármacos. ${ }^{a}$

\begin{tabular}{|c|c|c|c|c|}
\hline Experimentos $^{b}$ & $0 \mathrm{~min}$ & $15 \mathrm{~min}$ & $45 \mathrm{~min}$ & $120 \mathrm{~min}$ \\
\hline $5 \mathrm{mg} \mathrm{L}^{-1} / 75 \mathrm{~W}$ & 1,4 & 0,9 & 1,6 & 0,5 \\
\hline $20 \mathrm{mg} \mathrm{L}^{-1} / 75 \mathrm{~W}$ & 2,3 & 1,3 & 2,0 & 1,2 \\
\hline $5 \mathrm{mg} \mathrm{L}^{-1} / 36 \mathrm{~W}$ & 2,2 & 1,5 & 1,5 & 0,7 \\
\hline $20 \mathrm{mg} \mathrm{L}^{-1} / 36 \mathrm{~W}$ & 3,4 & 1,4 & 1,6 & 0,8 \\
\hline
\end{tabular}


5.6.4.2 Avaliação da toxicidade dos fármacos individualmente

Os ensaios de toxidade obtidos a partir da bactéria Vibrio fischeri das amostras retiradas dos experimentos de degradação por fotólise realizados com as soluções dos fármacos isoladamente estão apresentados na Tabela 14. Comparando os valores de $\mathrm{CE}_{50}$, da Tabela 13 e Tabela 14, observa-se que os resultados da toxicidade dos experimentos com a solução de mistura de fármacos mostram valores de $\mathrm{CE}_{50}$ inferiores aos valores da solução de fármacos individualmente, notando-se um efeito acumulativo dos contaminantes, indicando que existe algum efeito combinado devido à mistura de todos os fármacos e isso pode ser explicado pela formação de subprodutos tóxicos. O mesmo resultado foi obtido por Bernabeu et al. (2012).

Analisando os resultados da Tabela 14, observa-se que no caso do atenolol (ATL) e do diclofenaco (DIC) houve aumento dos valores de $\mathrm{CE}_{50}$ após passarem pelo processo de degradação por fotólise, ou seja, houve formação de subprodutos menos tóxicos que os fármacos presentes inicialmente, o que leva a concluir que o processo de fotólise para esses fármacos individualmente seja mais eficiente que quando eles se encontram na solução da mistura de fármacos. Para os fármacos acetaminofeno (ACT), bezafibrato (BZF) e ibuprofeno (IBU), houve também um decréscimo nos valores de $\mathrm{CE}_{50}$. Trovó et al. (2009) realizaram ensaios similares e também observaram o aumento da toxicidade após a degradação dos fármacos.

Tabela 14 - Valores de $\mathrm{CE}_{50}(\%)$ no tempo inicial e tempo final de degradação por fotólise (60 min para diclofenaco e 120 para os demais) da solução de fármacos individualmente. ${ }^{a}$

\begin{tabular}{ccccc}
\hline Fármacos $^{\mathbf{b}}$ & $\mathbf{t}_{\text {inicial }}$ & $\mathbf{t}_{\text {final }}$ & $\mathbf{t}_{\text {inicial }}$ & $\mathbf{t}_{\text {final }}$ \\
\cline { 2 - 5 } & $5 \mathrm{mg} \mathrm{L}^{-1} / 75 \mathrm{~W}$ & $20 \mathrm{mg} \mathrm{L}^{-1} / 75 \mathrm{~W}$ \\
\hline Acetaminofeno (ACT) & 8,9 & 5,7 & 5,6 & 6,4 \\
Atenolol (ATL) & 3,4 & 3,9 & 2,0 & 4,1 \\
Bezafibrato (BZF) & 3,0 & 2,7 & 4,2 & 2,3 \\
Diclofenaco (DIC) & 5,6 & 11,2 & 8,0 & 16,4 \\
Ibuprofeno (IBU) & 3,0 & 2,9 & 3,6 & 3,6
\end{tabular}

${ }^{a}$ Os valores indicam a \% da amostra que exerce efeito deletério a $50 \%$ dos organismo-teste. ${ }^{b}$ A concentração refere-se à concentração inicial nominal de cada fármaco na solução. 


\subsubsection{Investigação da fotólise}

Foram realizados experimentos de fotólise na ausência de oxigênio dissolvido, na presença de supressor de oxigênio singlete e na presença de supressor de radicais hidroxila, a fim de investigar os mecanismos de degradação que ocorrem na fotólise dos fármacos. Para avaliar o efeito do oxigênio dissolvido na solução aquosa durante a fotólise, foram realizados experimentos com borbulhamento de nitrogênio na solução. Para avaliar a possibilidade de participação de oxigênio singlete durante a fotólise foram realizados experimentos com azida de sódio $\left(\mathrm{NaN}_{3}\right)$ em solução, que age como supressor de oxigênio singlete, ${ }^{1} \mathrm{O}_{2}$ (Ribeiro et al., 2007). O oxigênio singlete pode ser formado por transferência de energia para o oxigênio molecular dissolvido a partir de possíveis estados triplete dos fármacos gerados a partir da absorção de fótons em 254 nm (PARSONS, 2004). A escolha da concentração de azida de sódio é importante, uma vez que esta substância também absorve radiação UV em 254 nm, podendo competir com os fármacos e inibir sua fotólise. Dessa forma, o cálculo para a concentração de azida de sódio foi realizado de modo que $90 \%$ da radiação incidente fossem absorvidos pelo fármaco, conforme mostra a Equação 25:

$$
\frac{C i . \varepsilon i}{C i . \varepsilon i+C a z . \varepsilon a z}=0,9
$$

Em que $C_{\mathrm{i}}=$ concentração do fármaco, $\varepsilon_{\mathrm{i}}=$ coeficiente de absorção molar do fármaco em $254 \mathrm{~nm} ; C_{\mathrm{az}}=$ concentração da azida de sódio e $\varepsilon_{\mathrm{az}}=510 \mathrm{~L} \mathrm{~mol}^{-1} \mathrm{~cm}^{-1}$ coeficiente de absorção molar da azida de sódio em 254 nm (PEIXOTO, 2013).

Conferindo a possibilidade de reações com radicais hidroxila $\left({ }^{\circ} \mathrm{OH}\right)$ formados durante o processo de fotólise, foram realizados experimentos na presença de isopropanol. O isopropanol tem a função de suprimir os radicais ${ }^{\circ} \mathrm{OH}$. Foi empregada concentração molar de isopropanol 10 vezes maior que a dos fármacos em estudo.

As curvas de degradação dos fármacos obtidas nesses experimentos estão apresentadas na Figura 32. Nota-se que praticamente não houve mudança importante no comportamento da concentração dos fármacos em função do tempo de fotólise com supressão de oxigênio dissolvido, oxigênio singlete e radicais hidroxila, com exceção 
do diclofenaco (DIC). Para este, houve queda na taxa de degradação na presença de supressor de radicais hidroxila, o que sugere o envolvimento importante desses radicais livres na degradação do fármaco. Espécies ativas de oxigênio, como os radicais ${ }^{\bullet} \mathrm{OH}$, podem ser formadas a partir de reações a partir de espécies geradas por transferência de elétrons envolvendo estados excitados de compostos orgânicos (BRAUN et al., 1991). Nos demais caso, a degradação deve ocorrer principalmente por quebra de ligações a partir de estados excitados das moléculas (fotólise direta).
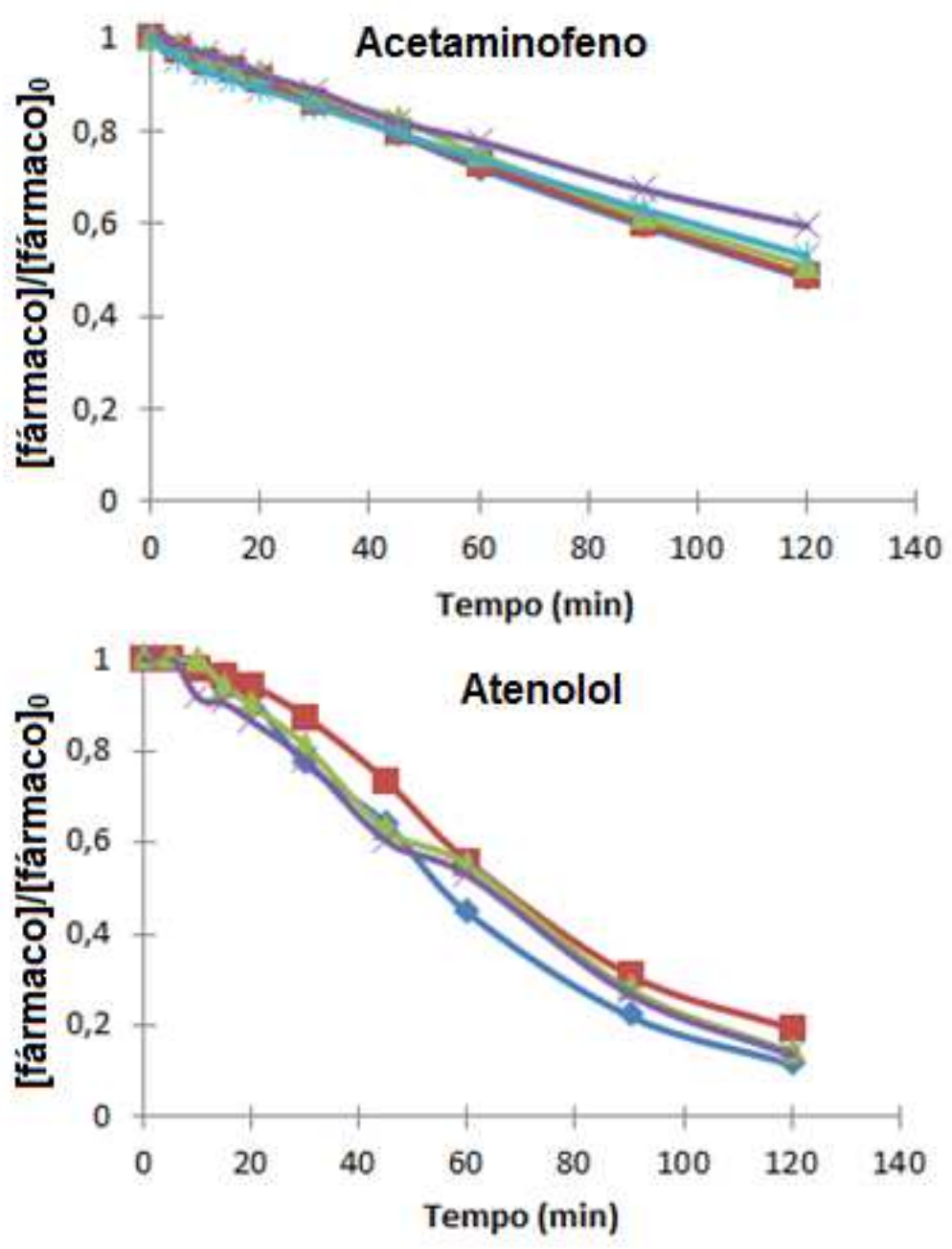

Figura 32 - Resultados dos experimentos de fotólise, fotólise com supressão de oxigênio dissolvido, fotólise com supressor de oxigênio singlete e supressor de radicais hidroxila para experimentos realizados com os fármacos individualmente com concentração nominal inicial de $20 \mathrm{mg} \mathrm{L}^{-1}$ e $75 \mathrm{~W}$ em $\mathrm{pH} 2$ e $25^{\circ} \mathrm{C}$. A concentração indicada refere-se à c oncentração inicial nominal de cada fármaco na solução aquosa. $\quad(\rightarrow-$ Fotólise na presença de oxigênio dissolvido $\rightarrow$ Supressão de oxigênio singlete $*$ Condições anóxicas - - Supressão de radicais hidroxila) 

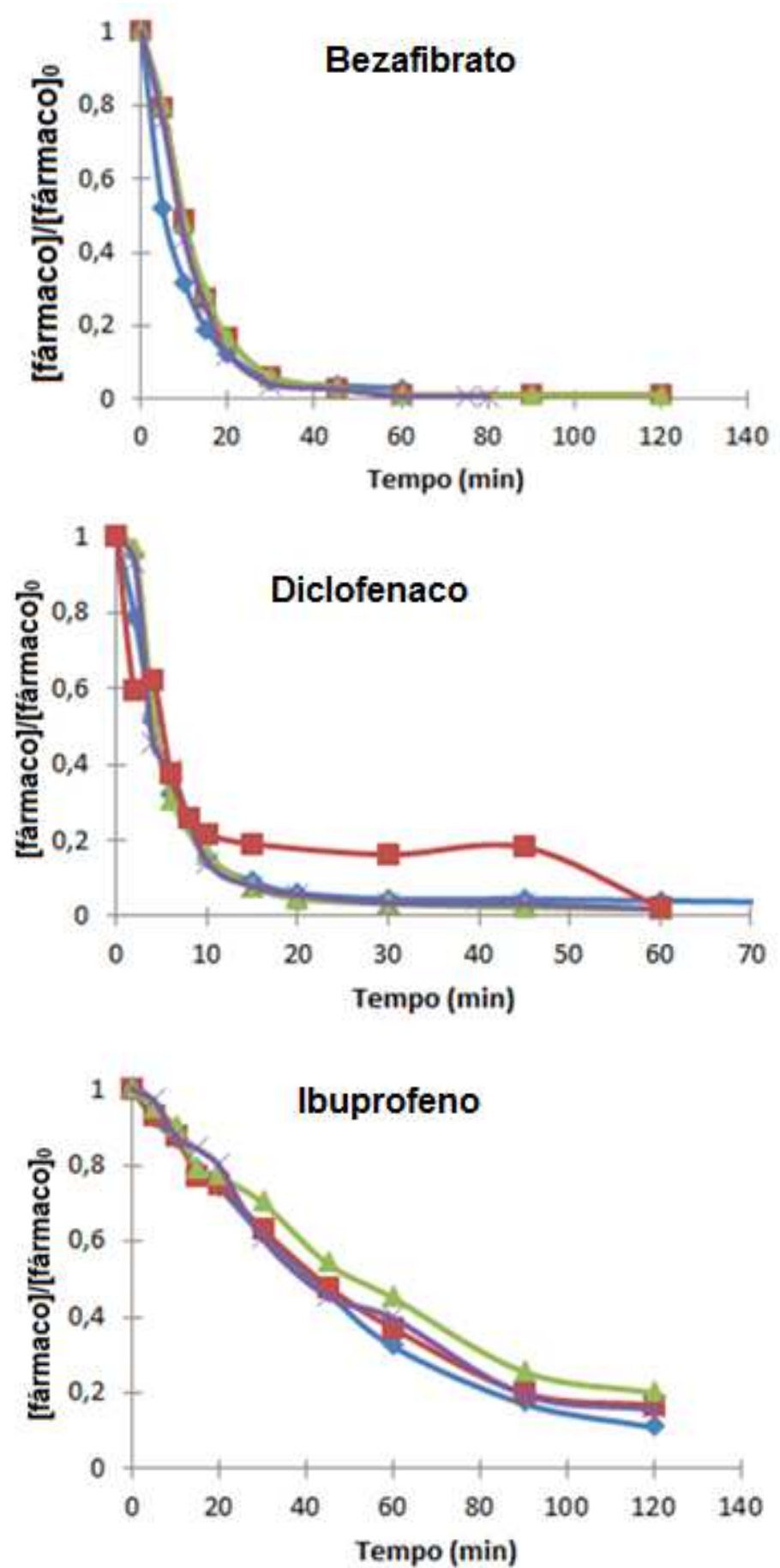

Figura 32 (cont.) - Resultados dos experimentos de fotólise, fotólise com supressão de oxigênio dissolvido, fotólise com supressor de oxigênio singlete e supressor de radicais hidroxila para experimentos realizados com os fármacos individualmente com concentração nominal inicial de $20 \mathrm{mg} \mathrm{L}$ '

e $75 \mathrm{~W}$ em pH 2 e $25^{\circ} \mathrm{C}$. A concentração indicada re fere-se à concentração inicial nominal de cada fármaco na solução aquosa. ( $\multimap$ Fotólise na presença de oxigênio dissolvido - Supressão de oxigênio singlete $\nsucc$ Condições anóxicas $\leftarrow$ - Supressão de radicais hidroxila) 


\subsection{ESTUDO DA DEGRADAÇÃO DOS FÁRMACOS POR UV/ $\mathrm{H}_{2} \mathrm{O}_{2}$}

Os históricos de concentração normalizada em função do tempo nos experimentos de peroxidação fotoassistida $\left(\mathrm{UV} / \mathrm{H}_{2} \mathrm{O}_{2}\right)$ sob radiação UV $(254 \mathrm{~nm})$ são apresentadas na Figura 33, para mistura dos fármacos com concentração de inicial nominal de $5 \mathrm{mg} \mathrm{L}^{-1}$ de cada composto e concentração inicial de $\mathrm{H}_{2} \mathrm{O}_{2}$ de $3,6 \mathrm{mmol} \mathrm{L}^{-1}$ (experimento I) e na Figura 34, para mistura dos fármacos com concentração inicial nominal de $20 \mathrm{mg} \mathrm{L}^{-1}$ cada composto e concentração inicial de $\mathrm{H}_{2} \mathrm{O}_{2}$ de $14,45 \mathrm{mmol} \mathrm{L}^{-1}$, (experimento II).

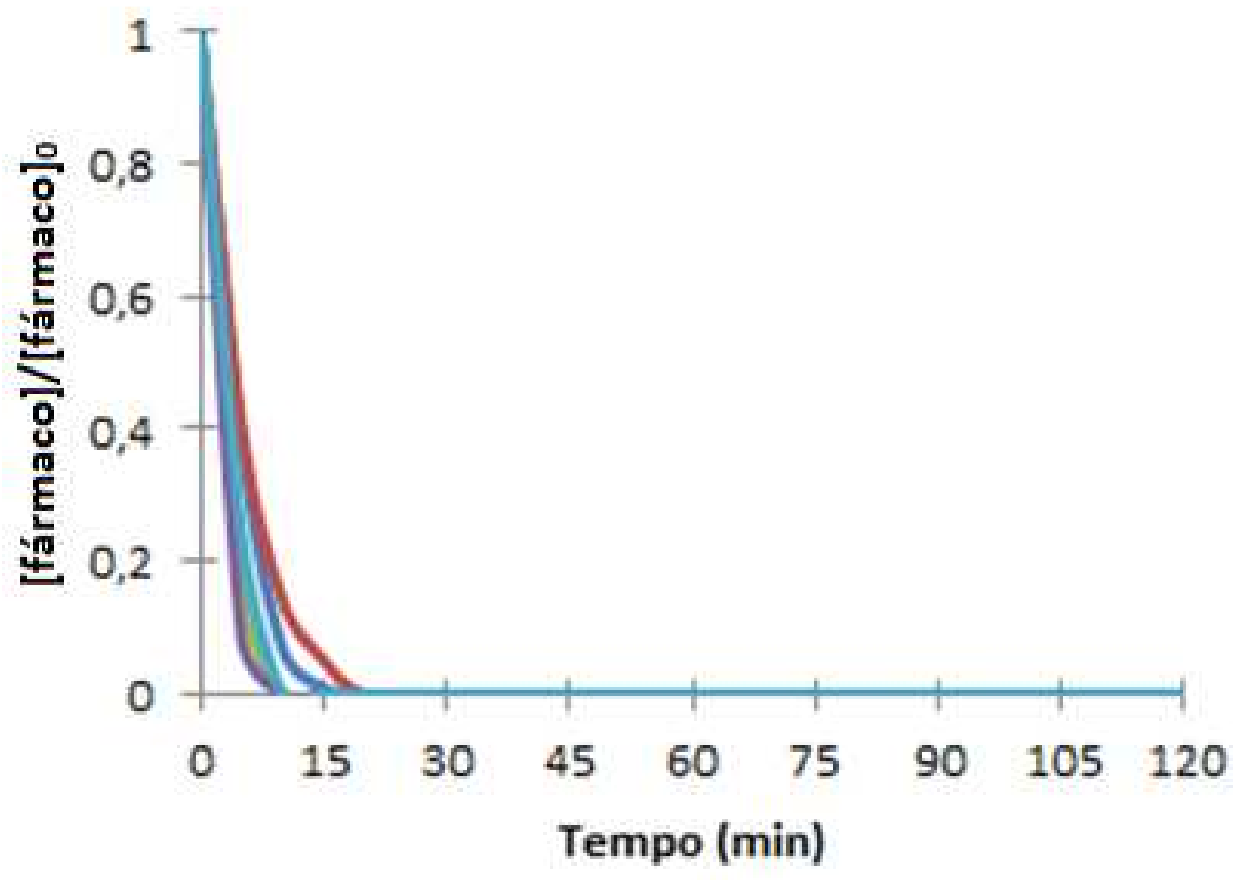

Figura 33 - Resultado do experimento $\mathrm{UV} / \mathrm{H}_{2} \mathrm{O}_{2}$ realizados com a mistura dos fármacos com concentração inicial nominal de $5 \mathrm{mg} \mathrm{L}^{-1}$ e $75 \mathrm{~W}$ em pH 2, $25{ }^{\circ} \mathrm{C}$ e concentração inicial de $\mathrm{H}_{2} \mathrm{O}_{2}$ de 3,6 $\mathrm{mmol} \mathrm{L}^{-1}$. $(-\mathrm{ATL}-\mathrm{ACT}-\mathrm{BZF}-\mathrm{DIC}-\mathrm{IBU})$ 


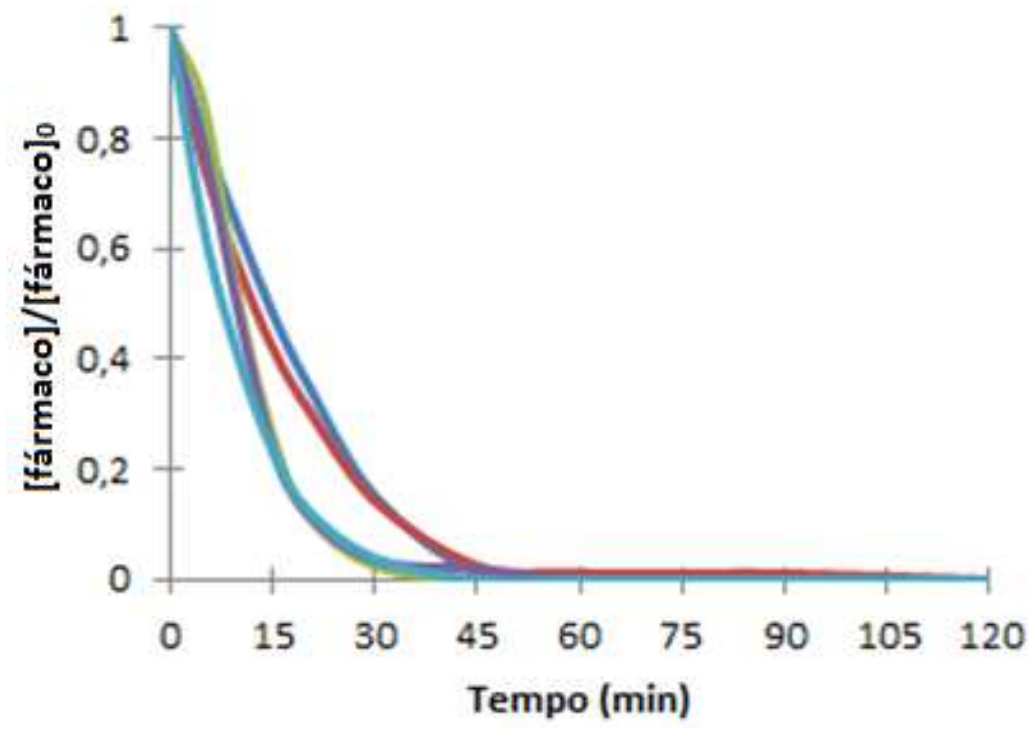

Figura 34 - Resultado do experimento $\mathrm{UV} / \mathrm{H}_{2} \mathrm{O}_{2}$ realizados com a mistura dos fármacos com concentração inicial nominal de $20 \mathrm{mg} \mathrm{L}^{-1}$ e $75 \mathrm{~W}$ em pH 2, $25^{\circ} \mathrm{C}$ e concentração inicial de $\mathrm{H}_{2} \mathrm{O}_{2}$ de $14,45 \mathrm{mmol} \mathrm{L}^{-1} . \quad(-\mathrm{ATL}-\mathrm{ACT}-\mathrm{BZF}-\mathrm{DIC}-\mathrm{IBU})$

Como esperado, a presença de $\mathrm{H}_{2} \mathrm{O}_{2}$ resultou em aumento da velocidade de degradação dos fármacos em relação ao processo de fotólise apenas. As concentrações dos fármacos em estudo estavam abaixo do limite de detecção após 20 min para todos os fármacos no experimento I e após 50 min no experimento II, indicando que, quanto menor a concentração dos fármacos, mais rápida ocorre sua degradação por radicais hidroxila gerados a partir da fotólise do $\mathrm{H}_{2} \mathrm{O}_{2}$. Esse mesmo resultado foi obtido por Rivas et al. (2011) para experimentos realizados com misturas de fármacos, entre eles o ACT. Nesse caso, a adição de peróxido de hidrogênio aumentou significativamente a fotodegradação de compostos que mostram valores baixos de degradação por fotólise. No estudo de ROSARIO-ORTIZ et al. (2010) obtiveram-se resultados de remoções que superaram $99 \%$ pelo processo $\mathrm{UV} / \mathrm{H}_{2} \mathrm{O}_{2}$ para os fármacos: meprobamato, carbamazepina, dilantina, ATL, primidona e trimetoprimem. YUAN et al. (2012) investigaram a degradação do bezafibrato (BZF) pelo processo $\mathrm{UV} / \mathrm{H}_{2} \mathrm{O}_{2}$ com concentrações iniciais de $100 \mu \mathrm{g} \mathrm{L}^{-1}$, em água deionizada, observando que foram removidos mais de 99,8\% após 16 minutos de exposição à radiação, empregando $0,1 \mathrm{mg} \mathrm{L}^{-1}$ de $\mathrm{H}_{2} \mathrm{O}_{2}$ e $\mathrm{pH}$ neutro. BAEZA et al. (2011) observaram que com concentração de $10 \mathrm{mg} \mathrm{L}^{-1} \mathrm{H}_{2} \mathrm{O}_{2}$, a remoção do DIC foi de aproximadamente $90 \%$. 


\subsubsection{Análise de Peróxido de Hidrogênio Residual}

Os resultados do comportamento da concentração de peróxido de hidrogênio residual em função do tempo, nos experimentos $\mathrm{UV} / \mathrm{H}_{2} \mathrm{O}_{2}$, são apresentados na Figura 35. $\mathrm{O}$ monitoramento da concentração de $\mathrm{H}_{2} \mathrm{O}_{2}$ indicou praticamente seu total consumo no experimento I, enquanto no experimento II não foi alcançado o total consumo de $\mathrm{H}_{2} \mathrm{O}_{2}$, porém obteve-se redução da concentração de aproximadamente $81,4 \%$ após 120 minutos.

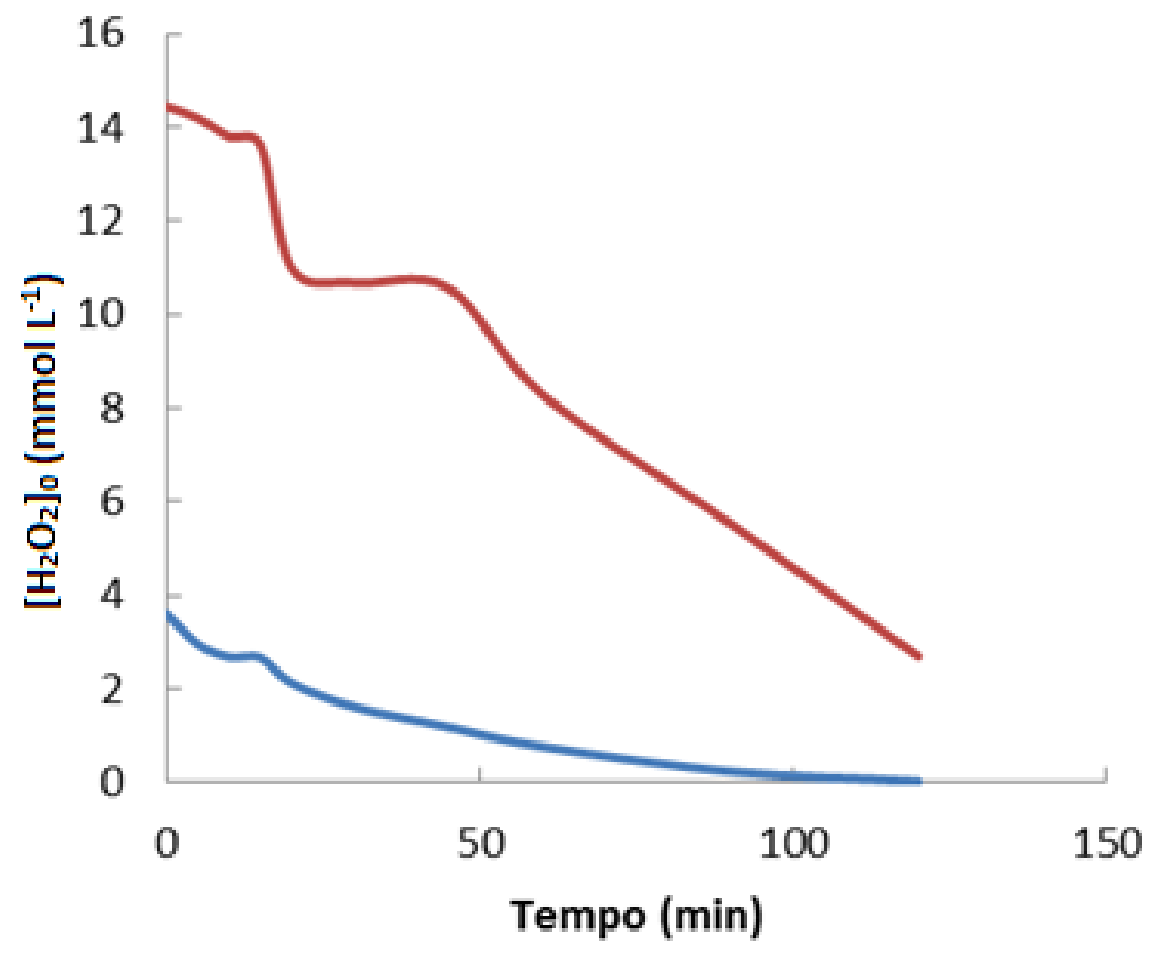

Figura 35 - Consumo de peróxido de hidrogênio durante a irradiação nos experimentos UV/ $\mathrm{H}_{2} \mathrm{O}_{2}$. Experimento I - experimentos $\mathrm{UV} / \mathrm{H}_{2} \mathrm{O}_{2}$ realizados com a mistura dos fármacos com concentração inicial nominal de $5 \mathrm{mg} \mathrm{L}^{-1}$ e $75 \mathrm{~W}$ e concentração inicial de $\mathrm{H}_{2} \mathrm{O}_{2}$ de $3,6 \mathrm{mmol} \mathrm{L}^{-1}$. Experimento II experimentos $\mathrm{UV} / \mathrm{H}_{2} \mathrm{O}_{2}$ realizados com a mistura dos fármacos com concentração inicial nominal de 20 $\mathrm{mg} \mathrm{L}^{-1}$ e $75 \mathrm{~W}$ e concentração inicial de $\mathrm{H}_{2} \mathrm{O}_{2}$ de $14,45 \mathrm{mmol} \mathrm{L}^{-1}$. (- Experimento I - Experimento II) 


\subsection{ESTUDO DA DEGRADAÇÃO DOS FÁRMACOS EM EFLUENTE DE ESTAÇÃO DE TRATAMENTO DE ESGOTO}

A fim de avaliar o efeito da matriz aquosa quanto à degradação dos fármacos estudados, foram realizados experimentos de fotólise, com a mistura dos fármacos com concentração inicial dos fármacos de $5 \mathrm{mg} \mathrm{L}^{-1}$ e $20 \mathrm{mg} \mathrm{L}^{-1}$ cada, em duplicata. Os experimentos foram realizados com o efluente tratado de uma estação de tratamento de esgoto (ETE) (unidade piloto do campo experimental de tratamento de esgoto do Centro Tecnológico de Hidráulica (CTH), Departamento de Engenharia Hidráulica e Sanitária da Escola Politécnica da USP). O esgoto sanitário que é encaminhado para a unidade piloto é proveniente do CRUSP - Conjunto Residencial da USP, composto dos esgotos dos apartamentos e do Restaurante Universitário. As soluções dos fármacos foram preparadas empregando esse efluente como matriz.

Apenas os fármacos ATL e ACT foram possíveis de se identificar pelo método de cromatografia utilizado. As médias dos experimentos são apresentados nas Figuras 36 e 37 para o ATL, com concentrações nominais iniciais de $5 \mathrm{mg} \mathrm{L}^{-1}$ e $20 \mathrm{mg} \mathrm{L}^{-1}$, respectivamente, e as médias dos experimentos para o ACT são apresentadas nas Figuras 38 e 39 , com concentrações nominais iniciais de $5 \mathrm{mg} \mathrm{L}^{-1}$ e $20 \mathrm{mg} \mathrm{L}^{-1}$, respectivamente. Nos gráficos também estão apresentados os resultados dos experimentos de fotólise realizados em água de osmose inversa, a fim de comparar seus comportamentos.

Analisando as Figuras 36, 37, 38 e 39, observa-se que cada experimento apresentou um comportamento distinto. Contudo, observa-se que mesmo em efluente de ETE ocorre a degradação desses fármacos, sendo a eficiência de remoção dos fármacos pelo processo de fotólise neste efluente semelhante aos resultados obtidos em água de osmose inversa. 


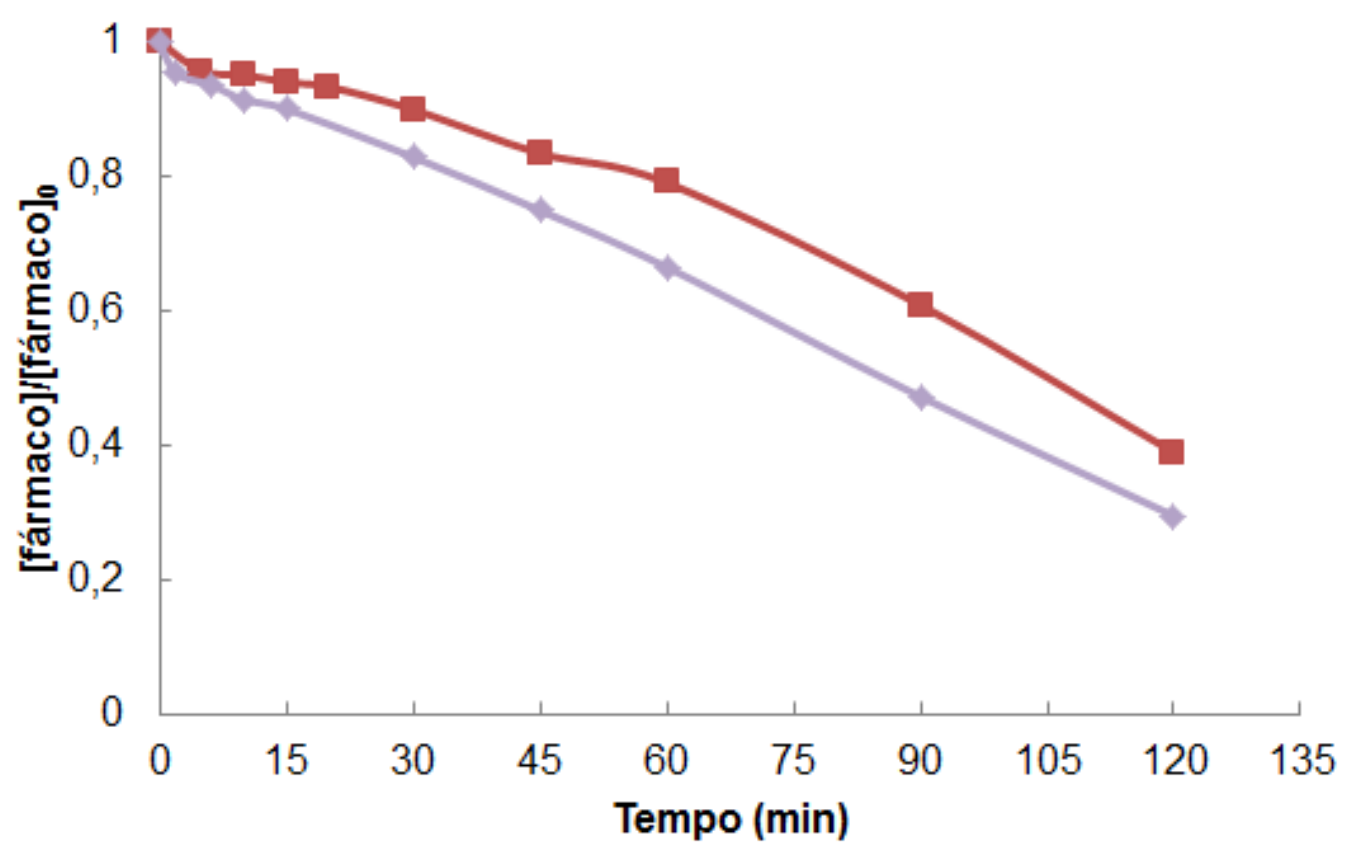

Figura 36 - Resultados para o fármaco ATL nos experimentos de fotólise realizados com água de osmose inversa e efluente de ETE, com a mistura dos fármacos com concentração nominal inicial de 5 $\mathrm{mg} \mathrm{L}^{-1}$ e $75 \mathrm{~W}$ em pH 2 e $25^{\circ} \mathrm{C}$. ( - - Água $\multimap$ efluente de ETE)

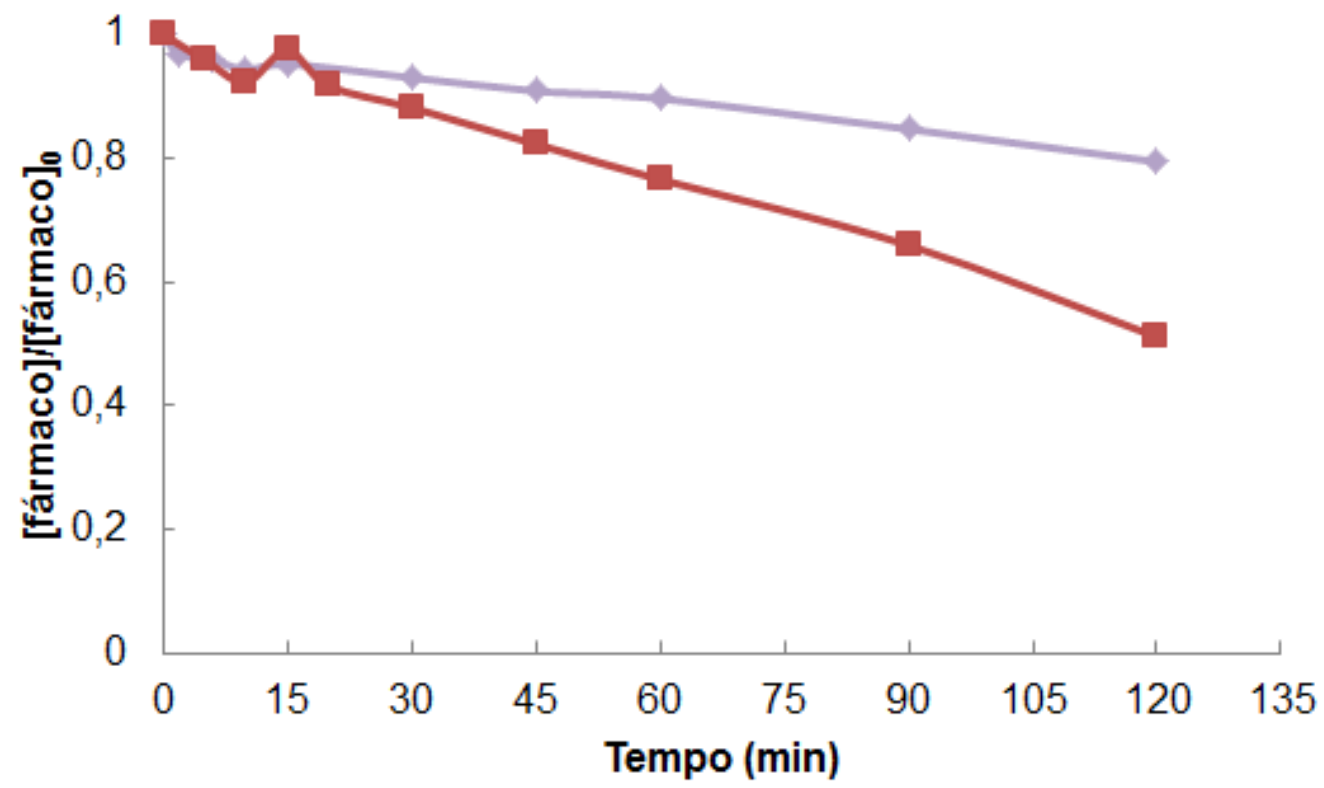

Figura 37 - Resultados para o fármaco ATL nos experimentos de fotólise realizados com água de osmose inversa e efluente de ETE, com a mistura dos fármacos com concentração nominal inicial de 20 $\mathrm{mg} \mathrm{L}^{-1}$ e $75 \mathrm{~W}$ em pH 2 e $25^{\circ} \mathrm{C} .(-$-Água $\multimap$ efluente de ETE) 


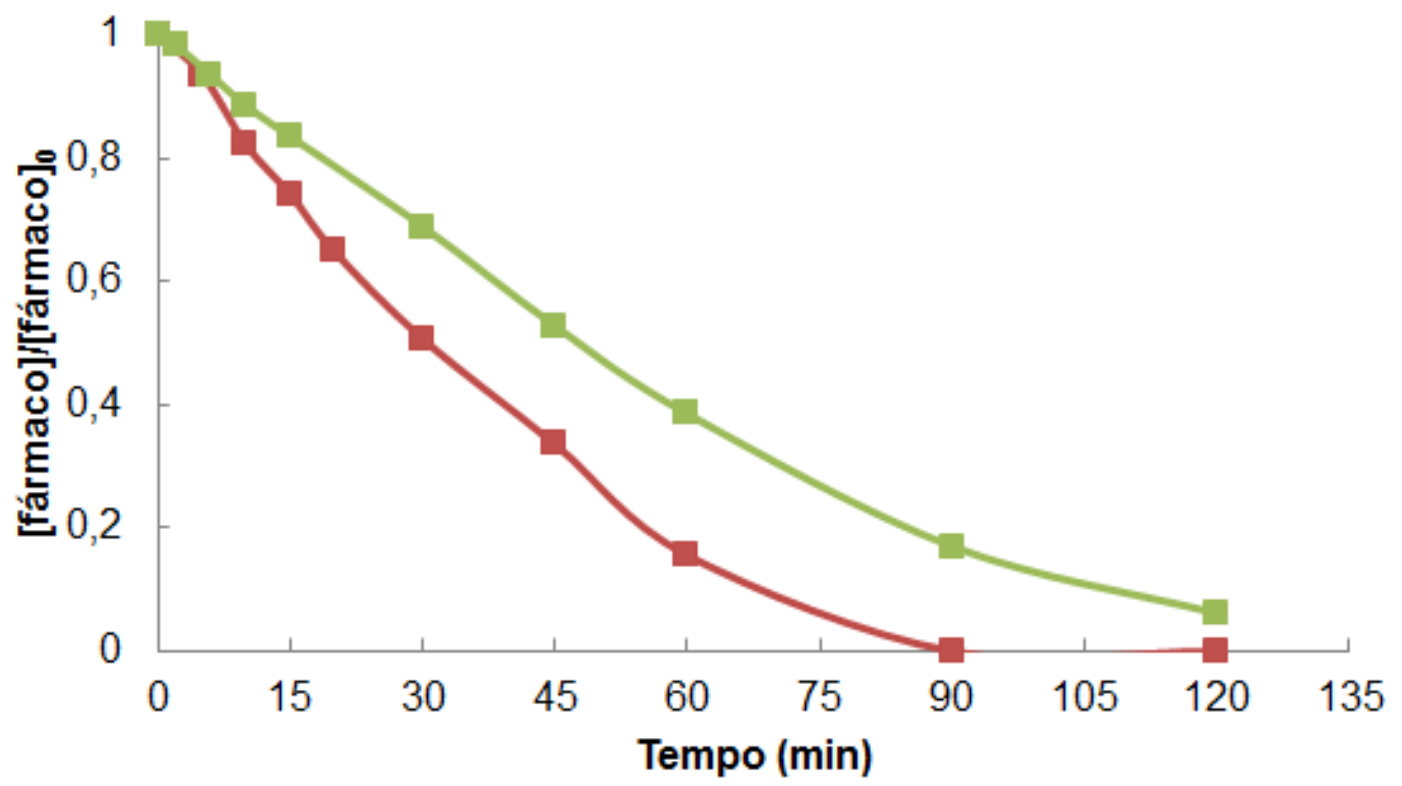

Figura 38 - Resultados para o fármaco ACT nos experimentos de fotólise realizados com água de osmose inversa e efluente de ETE, com a mistura dos fármacos com concentração nominal inicial de 5 $\mathrm{mg} \mathrm{L}^{-1}$ e $75 \mathrm{~W}$ em pH 2 e $25^{\circ} \mathrm{C}$. ( - - - Água -"- efluente de ETE)

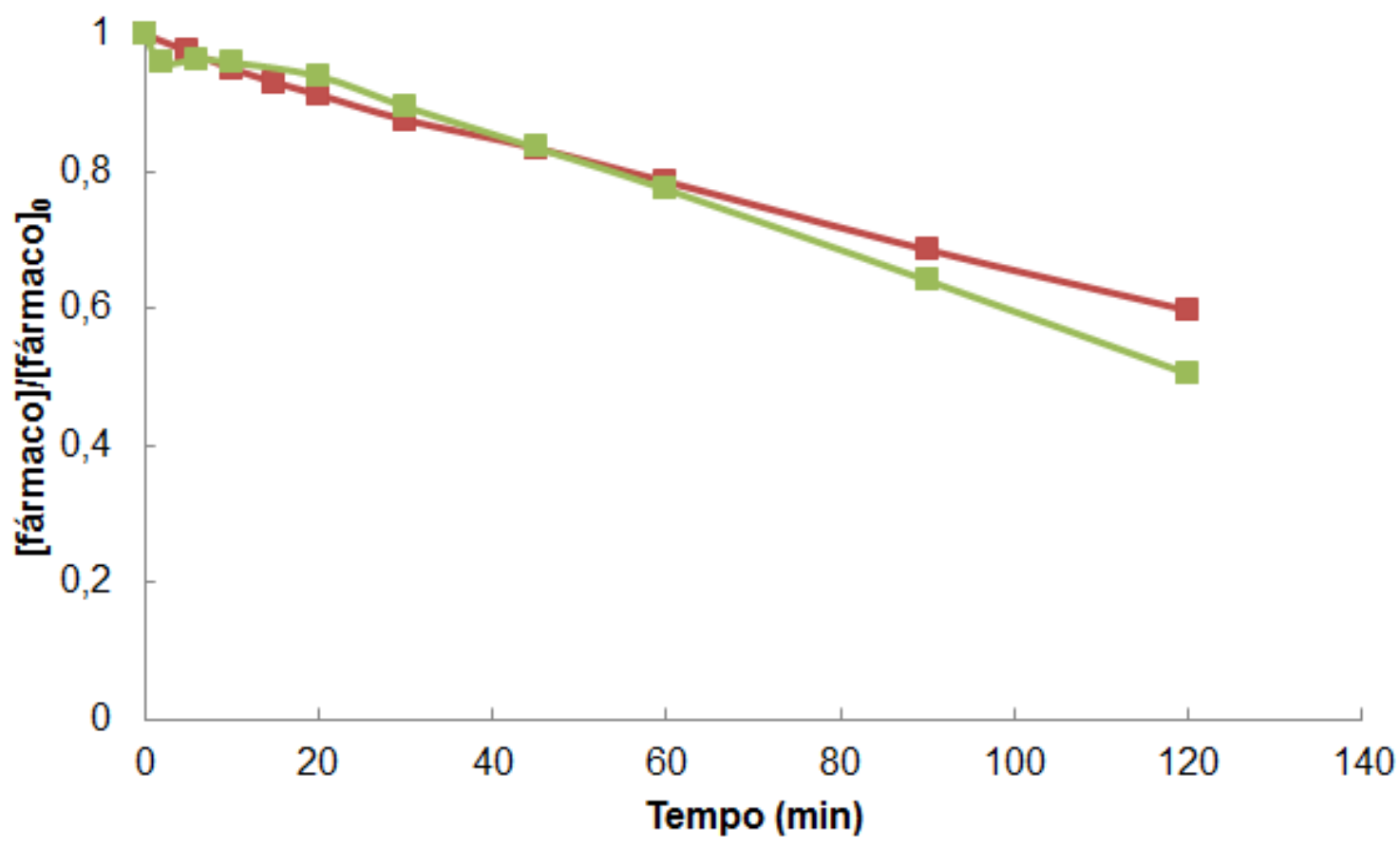

Figura 39 - Resultados para o fármaco ACT nos experimentos de fotólise realizados com água de osmose inversa e efluente de ETE, com a mistura dos fármacos com concentração nominal inicial de 20 $\mathrm{mg} \mathrm{L}^{-1}$ e $75 \mathrm{~W}$ em pH 2 e $25^{\circ} \mathrm{C}$. ( - - 
Perini (2013) estudou as degradações dos fármacos ciprofloxacino e sertralina em água destilada e em efluentes de ETE, pelos processos ferro zero e foto-Fenton. A eficiência de remoção dos fármacos com ETE foi semelhante aos resultados obtidos em água destilada independente do processo utilizado.

A aplicação da fotólise em efluentes de ETE pode permitir diminuir as contaminações ambientais causadas pelos fármacos, a fim de contribuir para a degradação destes contaminantes, melhorando a qualidade do recurso hídrico para o qual estes efluentes são direcionados após o tratamento (Perini, 2013). 


\section{CONCLUSÕES}

A partir dos experimentos realizados neste trabalho pode-se concluir que os fármacos estudados com concentrações iniciais de $5 \mathrm{mg} \mathrm{L}^{-1}$ não estão sujeitos à hidrólise após $24 \mathrm{~h}$, em diferentes $\mathrm{pH}$, em solução dos fármacos individualmente, nem na mistura, o que indica sua estabilidade na ausência de radiação UV-visível.

Os fármacos DIC e BZF são os que degradam mais rapidamente por fotólise (UV) e pelo processo de peroxidação fotoassistida $\left(\mathrm{UV} / \mathrm{H}_{2} \mathrm{O}_{2}\right)$, sendo a velocidade de degradação tão maior quanto menor a concentração inicial dos fármacos.

A degradação do ATL foi a mais lenta, provavelmente devido à baixa absorção da radiação por este fármaco, que possui o menor valor do coeficiente de absorção molar $\varepsilon$ encontrado. Por outro lado, os resultados sugerem que a fotólise do ACT ocorre com rendimento quântico muito baixo.

A fotólise dos fármacos em mistura resulta, no entanto, em produtos de degradação persistentes, com pequena remoção do TOC e aumento de toxicidade frente ao organismo-teste Vibrio fischeri, após 120 minutos de tratamento, o que indica a necessidade de empregar um oxidante auxiliar (p.e., $\mathrm{H}_{2} \mathrm{O}_{2}, \mathrm{O}_{3}$ ).

No caso das soluções dos fármacos individuais, para o atenolol (ATL) e o diclofenaco (DIC) houve aumento dos valores de $\mathrm{CE}_{50}$ após o processo de fotólise, ou seja, houve formação de subprodutos menos tóxicos que os fármacos inicialmente, o que sugere que o processo de fotólise para esses fármacos, isoladamente, seja mais eficiente que no caso em que se os fármacos encontram misturados em solução.

A presença de $\mathrm{H}_{2} \mathrm{O}_{2}$ mostra efeito muito positivo quanto ao aumento da velocidade de degradação dos fármacos em relação ao processo de fotólise apenas, com praticamente consumo total de $\mathrm{H}_{2} \mathrm{O}_{2}$.

Conclui-se também que mesmo em efluente de ETE ocorre à degradação dos fármacos ATL e ACT, sendo a eficiência de remoção dos contaminantes pelo processo de fotólise nesta matriz semelhante à obtida em água de osmose inversa. Dessa forma, a aplicação da fotólise em efluentes de ETE pode permitir diminuir as contaminações ambientais causadas pelos fármacos. 
As principais vantagens do processo $\mathrm{UV} / \mathrm{H}_{2} \mathrm{O}_{2}$ relação ao processo UV é o aumento da velocidade de degradação, o que pode vir a implicar em menor consumo de energia devido ao menor tempo de exposição à radiação UV.

Os resultados deste trabalho indicam que é possível utilizar a técnica de fotólise para tratamento de águas e efluentes contaminados com a mistura de fármacos, deixando claro que não se tratariam águas subterrâneas e superficiais, mas sim efluentes provenientes de ETE, indústrias farmacêuticas e hospitalares, fontes pontuais responsáveis pela contaminação ambiental da água, pois tratamentos convencionais em muitos casos não eliminam poluentes emergentes desses efluentes. Porém para a aplicação dos processos de fotólise e peroxidação fotoassistida $\left(U V / \mathrm{H}_{2} \mathrm{O}_{2}\right)$ requer-se o estudo de outros fatores, como por exemplo, considerar a presença de mais fármacos nesses efluentes; avaliar a toxicidade dos produtos de degradação por processo $\mathrm{UV} / \mathrm{H}_{2} \mathrm{O}_{2}$; estudar a influência da matéria orgânica dissolvida em água contendo resíduos desses e de outros fármacos; realizar estudos com menores concentrações; avaliar economicamente diferentes processos etc. Os processos de fotólise UV ou a peroxidação fotoassistida $\mathrm{UV} / \mathrm{H}_{2} \mathrm{O}_{2}$ podem ser aplicados como tratamentos terciários de ETE, permitindo a eliminação de poluentes emergentes residuais que não são totalmente removidos por tratamentos convencionais. 


\section{REFERÊNCIAS}

ACHILLEOS, A.; HAPESHI, E.; XEKOUKOULOTAKIS, N. P.; MANTZAVINOS, D., FATTA-KASSINOS, D. UV-A and solar photodegradation of ibuprofen and carbamazepine catalyzed by $\mathrm{TiO}_{2}$. Separation Science and Technology, v. 45, n. 11, p. 1564-570, 2010.

ALDER, A.C.; SCHAFFNER, C.; MAJEWSKY, M.; KLASMEIER, J.; FENNER K. Fate of $\beta$-blocker human pharmaceuticals in surface water: comparison of measured and simulated concentrations in the Glatt Valley Watershed. Water Research, v. 44, n. 3, p. 936-948, 2010.

ALMEIDA, G. A.; WEBER, R. R. Fármacos na Represa Billings. Revista Saúde e Ambiente, v.6, n. 2, 2005.

ANDREOZZI, R.; CAPRIO, V.; MAROTTA, R.; VOGNA, D. Paracetamol oxidation from aqueous solutions by means of ozonation and $\mathrm{H}_{2} \mathrm{O}_{2} / \mathrm{UV}$ system. Water Research, v. 37 , n. 5, p. 993-1004, 2003a.

ANDREOZZI, R.; MAROTTA, R.; PAXÉUS, N. Pharmaceuticals in STP effluents and their solar photodegradation in aquatic environment. Chemosphere, v. 50, n.10, p. 1319-1330, 2003b.

ANDRISANO, V; GOTTI, R.; CAVRINI, V.; Leoni, A. Photodegradation studies on Atenolol by liquid chromatography. Journal of Pharmaceutical And Biomedical Analysis, v.21, n.4, p. 851-857, 1999.

BAEZA, C.; KNAPPE, D. R. U. Transformation kinetics of biochemically active compounds in low-pressure UV photolysis and $\mathrm{UV} / \mathrm{H}_{2} \mathrm{O}_{2}$ advanced oxidation processes. Water Research, v. 45, n. 15, p. 4531-4543, 2011.

BARCELÓ, D. Emerging pollutants in water analysis. Trends in Analytical Chemisty, v. 22, n.10, p. 655-784, 2003.

BARBER, L. B.; BUXTON, H. T. Pharmaceuticals, hormones, and other organic wastewater contaminants in U.S. streams, 1999-2000: a national reconnaissance. Environmental Science \& Technology, v. 36, n. 6, p. 1202-212, 2002.

BASTOS, R. V. Estudo da degradação do antibiótico sulfametoxazol em solução aquosa por fotólise. 2012. 98 f. Dissertação (Mestrado) - Escola Politécnica, Universidade de São Paulo, São Paulo, 2012.

BENDZ, D.; PAXÉUS, N. A.; GINN, T. R.; LOGR, F. J. Occurrence and fate of pharmaceutically active compounds in the environment, a case study: Höje River in Sweden. Journal of Hazardous Materials, v. 122, n. 3, p. 195-204, 2005. 
BERNABEU, A.; PALACIOS, S.; VICENTE, R.; VERCHER, R. F.; MALATO,S.; ARQUES, A.; AMAT, A. M. Solar photo-Fenton at mild conditions to treat a mixture of six emerging pollutants. Chemical Engineering Journal, v. 198 - 199, p. 65-72, 2012.

BILA, D. M.; DEZOTTI, M. Fármacos no meio ambiente. Química Nova, v. 26, n. 4, p. 523-530, 2003.

BILA, D. M.; DEZOTTI, M. Presença de poluentes emergentes no meio ambiente. Revista de Ciência Tecnolologia, v. 6, n. 1, p. 57-68, 2006.

BRAUN, A. M.; MAURETTE, M. T.; OliVEROS, E. Photochemical Technology. Chischester, John Wiley, 1991.

CARBALA, M.; OMIL, F.; LEMA, J. M.; LLOMPART, M.; GARCÍA-JARES, C.; RODRÍGUEZ, I.; GÓMEZ, M.; TERNES, T.. Behavior of pharmaceuticals, cosmetics and hormones in a sewage treatment plant. Water Reseaach, v. 38, n. 12, p. 29182926, 2004.

CASTIGLIONI, S.; BAGNATI, R.; FANELLI, R.; POMATI, F.; CALAMARI, D.; ZUCCATO, E.;. Removal of pharmaceuticals in sewage treatment plants in Italy. Environmental Science \& Technology, v. 40, n. 1, p. 357-363, 2006.

CALAMARI, D.; ZUCCATO, E.; CASTIGLIONI, S.; BAGNATI, R.; FANELLI, R.. Article strategic survey of therapeutic drugs in the rivers Po and lambro in northern Italy. Environmental Science \& Technology, v. 37, n. 7, p. 1241-1248, 2003.

CERON, L. P. Contaminação de água por descarte de fármacos. Revista Tratamento de Água e efluentes, v. 1, n. 1, p. 14, 2011.

COMPANHIA DE TECNOLOGIA DE SANEAMENTO AMBIENTAL L.5.227: Teste de toxicidade com a bactéria luminescente Vibrio Fischeri (Método de Ensaio). São Paulo, 2001.

DAUGHTON, C. G.. Non-regulated water contaminants: emerging research Environmental Impact Assessment Review, v. 24, n. 7-8, p. 711- 732, 2004.

DEZOTTI, M.; RUSSO, C. Técnicas de controle ambiental em efluentes líquidos. Escola Piloto de Engenharia Química, COPPE, Rio de Janeiro, 1998.

ESCHER, B. I.; BAUMGARTNER, R.; KOLLER, M.; TRELLER, K.; LIENERT, J.; McCARDELL, C. D. Environmental toxicology and risk assessment of pharmaceuticals from hospital wastewater. Water Research, v. 45, n. 1, p. 75-92, 2012. 
FEI, X.; LIU, L.; XU, J.; ZHANG, Z.; MEI, Y. The non-steroidal anti-inflammatory drug, diclofenac, inhibits $\mathrm{Na}+$ current in rat myoblasts. Biochemical and Biophysical Research Communications, v. 346, n. 4, p. 1275-1283, 2006.

FICK, J.; SODERSTROM, H.; LINDBERG, R. H.; CHAU, P.; TYSKLIND, M.; LARSSON, J.. Contamination of surface, ground, and drinking water from pharmaceutical production. Environmental Toxicology and Chemistry,v. 28, n.12, p. 2522- 2529, 2009.

GAGNÉ, F.; BLAISE, C.; ANDRÉ, C. Occurrence of pharmaceutical products in a municipal effluent and toxicity to rainbow trout (Oncorhynchus mykiss) hepatocytes. Ecotoxicology and Environmental Safety, v. 64, n. 3, p. 329- 236, 2006.

GHISELLI, G. Avaliação da qualidade das águas destinadas ao abastecimento público na região de Campinas: ocorrência e determinação dos interferentes endócrinos (IE) e produtos farmacêuticos e de higiene pessoal (PFHP). 2006. 190 f. Tese (Doutorado em Química Analítica) - Instituto de Química, Universidade Estadual de Campinas, Campinas, 2006.

GOGATE, P. R.; PANDIT, A. B. A review of imperative technologies for wastewater treatment II: hybrid methods. Advances in Environmental Research, v. 8, n. 3-4, p. 553-597, 2004.

HALLING-S $\varnothing R E N S E N, \quad$ B.; NIELSEN, S.N., LANZKY, P.F.; INGERSLEV, F.; LÜTZHØFT, H.C.H.; JØRGENSEN, S.E. Occurrence, fate and effects of pharmaceutical substances in the environment-a review. Chemosphere, v. 36, n. 2, p. 357-394, 1998.

HIRSCH, R.; TERNES, T.; HABERER, K.; KRATZ, K.. Occurrence of antibiotics in the aquatic environment. Science of the Total Environment, v. 225, n. 1- 2, p. 109-118, 1999.

HUANG, C. P.; DONG, C.; TANG, Z. Advanced chemical oxidation: its present role and potential future in hazardous waste treatment. Waste Management, v. 13, n. 5-7, p. 361-377, 1993.

HUBER, M. M.; CANONICA, S.; PARKER, G. Y.; GUNTEN, U. V. Oxidation of pharmaceuticals during ozonation and advanced oxidation processes. Environmental Science \& Technology, v. 37, n. 5, p. 1016-1024, 2003.

ILLÉS, E.; TAKÁCS, E.; DOMBI, A.; GAJDA-SCHRANTZ, K.; RÁCZ, G.; GONTER, K.; WOJNÁROVITS, L. Hydroxyl radical induced degradation of ibuprofen. Science of the Total Environment, v. 447, p. 286-292, 2013. 
IOANNOU, L. A.; HAPESHI, E.; VASQUEZ, M. I.; MANTZAVINOS, D.; FATTAASSINOS, D. Solar $/ \mathrm{TiO}_{2}$ photocatalytic decomposition of $\beta$-blockers atenolol and propranolol in water and wastewater. Solar Energy, v. 85, n. 9, p. 1915-1926, 2011.

KAWABATA, K.; SUGIHARA, K.; SANOH, S.; KITAMURA, S.; OHTA, S. Ultravioletphotoproduct of acetaminophen: Structure determination and evaluation of ecotoxicological effect. Journal of Photochemistry and Photobiology A: Chemistry, v. 249, p. 29-35, 2012.

KEEN, O. S.; THURMAN, M. E., FERRER, I.; DOTSON, A. D.; LINDEN, K.G.. Dimer formation during UV photolysis of diclofenac. Chemosphere, v. 93, n. 9, p. 1948-1956, 2013.

KING, M.; DUAN, X.; SHEARDOWN, H. Partitioning of model toxins to hydrophobically terminated DAB Dendrimers. Biotechnology and Bioengineering, v. 86, n. 5, p. 512 529, 2004.

KOLPIN, D. W.; FURLONG, E. T.; MEYER, M. T.; THURMAN, E. M.; ZAUGG, S. D.; BARBER, L. B.; BUXTON, H. T. Pharmaceuticals, hormones, and other organic wastewater contaminants in U.S. streams, 1999-2000: a national reconnaissance. Environmental Science \& Technology,v. 36, n. 6, p. 1202-1211, 2002.

KUJAWA-ROELEVELD, K.; SCHUMAN, E.; GROTENHUIS, T.; KRAGIĆ, D.; MELS, A.; ZEEMAN, G. Biodegradability of human pharmaceutically active compounds (PhAC) in biological systems treating source separated wastewater streams. In: Third SWITCH Scientific Meeting Belo Horizonte, Brazil, 2008.

KUMMERER, K.. The presence of pharmaceuticals in the environment due to human use - present knowledge and future challenges. Journal of Environmental Management, v. 90, n. 8, p. 2354-2366, 2009.

LAMBROPOULOU, D. A.; KONSTANTINOU, I. K.; THURMAN, E. M.; FERRER, I.; HERNANDO, M. D.; FERNÁNDEZ-ALBA, A. R.; ALBANIS, T. A. Identification of photocatalytic degradation products of bezafibrate in $\mathrm{TiO}_{2}$ aqueous suspensions by liquid and gas chromatography. Journal of Chromatography A, v. 1183, n. 1- 2, p. 38 - 48, 2008.

LAPWORTH, D.J.; BARAN, N.; STUART, M.E.; WARD, R.S. Emerging organic contaminants in groundwater: A review of sources, fate and occurrence. Environmental Pollution, v. 163, p. 287-303, 2012

LINDQVIST, N.; TUHKANEN, T.; KRONBERG, L. Occurrence of acidic pharmaceuticals in raw and treated sewages and in receiving waters. Water Research, v. 39, n. 11, p. 2219- 2228, 2005. 
LORPHENSRI, O.; INTRAVIJIT, J.; SABATINI, D. A.; KIBBEY, T.C.G.; OSATHAPHAN, K.; SAIWAN. C. Sorption of acetaminophen, 17a-ethynyl estradiol, nalidixic acid, and norfloxacin to silica, alumina, and a hydrophobic medium. Water Research, v. 40, n. 7, p. 1481-1491, 2006.

MARTÍNEZ, V.; MAGUREGUI, M. I.; JIMÉNEZ, R. M.; ALONSO, R. M. Determination of the pKa values of beta-blockers by automated potentiometric titrations. Journal of Pharmaceutical and Biomedical Analysis, v. 23, n. 2-3, p. 459-468, 2000.

MELO, S. A. S.; TROVO, A. G.; BAUTITZ, I. R.; NOGUEIRA, R. F. P. Degradação de fármacos residuais por processos oxidativos avançados. Química. Nova, v. 32, n. 1, p. 188-197, 2009.

MELOUN, M.; BORDOVSKÁ, S.; GALLA, L. The thermodynamic dissociation constants of four non-steroidal anti-inflammatory drugs by the least-squares nonlinear regression of multiwavelength spectrophotometric $\mathrm{pH}$-titration data. Journal of Pharmaceutical and Biomedical Analysis, v. 45, n.4, p. 552-564, 2007.

MUIR, N.; NICHOLS, J.D.; STILLINGS, M.R.;. SYKES, J. Comparative bioavailability of aspirin and paracetamol following single dose administration of soluble and plain tablets. Current Medical Research and Opinion, v. 13, n. 9, p. 491-500,1997.

NOGUEIRA, R. F. P.; OLIVEIRA, M. C.; PATERLINI, W. C. Simple and fast spectrophotometric determination of $\mathrm{H} 2 \mathrm{O} 2$ in photo-Fenton reactions using metavanadate. Talanta, v. 66, n. 1, p. 86-91, 2005.

OLIVEIRA, E. G. L.; Processos oxidativos avançados: o papel do surfactante na aceleração da fotodegradação. 2011. 65 f. Dissertação (Mestrado) - Universidade Federal do Vale do São Francisco, Juazeiro/BA, 2011.

OPPENLÄNDER, T. Photochemical Purification of Water and Air: Advanced Oxidation Processes (AOPs): Principles, Reaction Mechanisms, Reactor Concepts, Wiley-VCH, (2003).

PARSONS, S. Advanced Oxidation Processes for Water and Wastewater Treatment, IWA Publishing, 2005.

PEIXOTO, A. Comunicação pessoal. 2013.

PÉREZ-ESTRADA, L. A.; MALATO, S.; GERNJAK, W.; AGÜERA, A.; THURMAN, M.; FERRER, I.; FERNÁNDEZ-ALBA, A. R. Photo-Fenton degradation of diclofenac: identification of main intermediates and degradation pathway. Environmental Science \& Technology, v. 39, n.21, p. 8300-8306, 2005. 
PERINI, J.A. L.. Degradação dos fármacos ciprofloxacino e sertralina pelos processos ferro zero e foto-fenton - aplicação em amostras de efluentes de estação de tratamento de esgoto. 2013. 181 f. Tese (Doutorado) - Curso de Química, Departamento de Instituto de Química., Universidade Estadual Paulista, Araraquara, 2013.

PINTO, L.K. A.. Estudo da degradação do diclofenaco em meio aquoso: fotólise vs fotocatálise heterogênea ( $\mathrm{TiO}_{2} / \mathrm{UV}$ ). 2013. 105 f. Dissertação (Mestrado) - Curso de Química Analítica e Inorgânica, Departamento de Instituto de Química de São Carlos, Universidade de São Paulo, São Carlos, 2013.

POMATI, F.; CASTIGLIONI, S.; ZUCCATO, E.; FANELLI, R.; VIGETTI, D.; ROSSETTI, C.; CALAMARI, D. Effects of a complex mixture of therapeutic drugs at environmental levels on human embryonic cells. Environmental Science \& Technology, v. 40, n. 7, p. 2442-2447, 2006.

POZDNYAKOV, I. P.; ZHANG, X. ; MAKSIMOVA, T. A.; VADIM V. Y.; FENG W.; VJACHESLAV P. G. ; ,VICTOR F. P.. Wavelength-dependent photochemistry of acetaminophen in aqueous solutions. Journal Of Photochemistry And Photobiology A: Chemistry, v. 274, p. 117-123, 2014.

RADJENOVIĆA, J.; SIRTORI, C.; PETROVIĆ, M.; BARCELÓ, D.; MALATO, S. Solar photocatalytic degradation of persistent pharmaceuticals at pilot-scale: kinetics and characterization of major intermediate products. Applied Catalysis B: Environmental, v. 89, n. 1-2, p. 255-264, 2009.

RAVINA, M.; CAMPANELLA, L.; KIWI, J. Accelerated mineralization of the drug diclofenac via Fenton reactions in a concentric photo-reactor. Water Research,v. 36, n. 14, p. 3553-3560, 2002.

RESERVATÓRIO BILLINGS. Disponível em: $<$ (http://www.emae.sp.gov.br/chromo/reservatorios/billings.htm>. Acesso em $10 \mathrm{de}$ agosto de 2013.

RIBEIRO, J. N.; JORGE, R. A.; SILVA, A. R.; FlORES, A. V.; RONCHI, L. M.; TEDESCO, A. C. Avaliação da atividade fotodinâmica de porfirinas para uso em terapia fotodinâmica através da fotoxidação de triptofano. Eclética Química, v. 32, n.1, p. 714, 2007.

RIVAS, J.; GIMENO,O.; BORRALHO,T.; SAGASTI, J. UV-C and UV-C/peroxide elimination of selected pharmaceuticals in secondary effluents. Desalination, v. 279, n. $1-3$, p. $115-120,2011$

RIVERA-UTRILLA, J.; SÁNCHEZ-POLO, M.; FERRO-GARCÍA, M. A.; PRADOS-JOYA, G.; OCAMPO-PÉREZ, R.. Pharmaceuticals as emerging contaminants and their removal from water. A review. Chemosphere,v. 93, n. 7, p. 1268-1287, 2013. 
ROBERTS, P. H.; THOMAS, K. V. The occurrence of selected pharmaceuticals in wastewater effluent and surface waters of the lower Tyne catchment. Science of the Total Environment, v. 356, n. 1-3, p. 143-153, 2006.

RODRIGUES, C.R.B. Aspectos legais e ambientais do descarte de residuos de fármacos. 2009. Dissertação (Mestrado) - Universidade Tecnológica Federal do Paraná, Ponta Grossa.

ROSARIO-ORTIZ, F. L.; WERT, E. C.; SNYDER, S. A. Evaluation of UV/ $\mathrm{H}_{2} \mathrm{O}_{2}$ treatment for the oxidation of pharmaceuticals in wastewater. Water Research, v. 44, n. 5, p. 1440-1448, 2010.

SALGADO, R.; PEREIRA, V. J.; CARVALHO, G.; SOEIRO, R.; GAFFNEY, V.; ALMEIDA, C.; CARDOSO, V.; FERREIRA, E.; BENOLIEL, M. J.; TERNES, T. A.; OEHMEN, A.; REIS, M. A. M.; NORONHA, J. P. Photodegradation kinetics and transformation products of ketoprofen, diclofenac and atenolol in pure water and treated wastewater. Journal of Hazardous Materials, v. 244-245, p. 516-527, 2013.

SANTOS, J. L.; APARICIO, I.; ALONSO, E.; CALLEJÓN, M.. Simultaneous determination of pharmaceutically active compounds in wastewater samples by solid phase extraction and high-performance liquid chromatography with diode array and fluorescence detectors. Analytica Chimica Acta, v. 550, n. 1, p. 116-122, 2005.

SCHWAIGER, J.; FERLING, H.; MALLOW, U.; WINTERMAYR, H.; NEGELE, R. D. Toxic effects of the non-steroidal anti-inflammatory drug diclofenac : Part I: histopathological alterations and bioaccumulation in rainbow trout. Aquatic Toxicology, v. 68, n. 2 , p. $141-150,2004$.

SERRANO, D.; SUÁREZ, S.; LEMA, J. M.; OMIL, F. Removal of persistent pharmaceutical micropollutants from sewage by addition of PAC in a sequential membrane bioreactor. Water Research, v. 45, n. 16, p. 5323-5333, 2011.

SILVA, C. G. A.; COLLINS, C. H. Aplicações de cromatografia líquida de alta eficiência para o estudo de poluentes orgânicos emergentes. Química Nova, v. 34, n. 4, p. 665676, 2011.

SIRÉS, I.; CENTELLAS, F.; GARRIGO, J. A.; RODRIGUEZ, R. M.; ARIAS, C.; CABOT, P.; BRILLAS, E. Mineralization of clofibric acid by electrochemical advanced oxidation processes using a boron-doped diamond anode and $\mathrm{Fe}^{2+}$ and UV a light as catalysts. Applied Catalysis B: Environmental, v. 72, n. 3-4, p. 373-281, 2006.

SIRÉS, I.; BRILLAS, E..Remediation of water pollution caused by pharmaceutical residues based on electrochemical separation and degradation technologies: a review. Environment International,v. 40, p. 212-229, 2012. 
STACKELBERG, P. E.; FURLONG E. T.; MEYER, M. T.; ZAUGG, S. D.; HENDERSON, A. K.; REISSMAN, A. B. Persistence of pharmaceutical compounds and other organic wastewater contaminants in a conventional drinking-water-treatment plant. Science of the Total Environment, v. 329, n. 1-3, p. 99-113, 2004.

STUMPF, M.; TERNES, T. A.; WILKEN, R. D.; RODRIGUES, S. V.; BAUMANN, W. Polar drug residues in sewage and natural waters in the state of Rio de Janeiro, Brazil. Science of the Total Environment, v. 225, n. 1-2, p. 135-141, 1999.

SOUZA, N. C. Avaliação de micropoluentes emergentes em esgotos e águas superficiais. 2011. 183 f. Tese (Doutorado) - Curso de Engenharia Civil, Departamento de Departamento de Engenharia Hidráulica e Ambiental, Universidade Federal do Ceará, Fortaleza, 2011.

SU, C.; BELLOTINDOS, L. M.; CHANG, A.; LU, M. Degradation of acetaminophen in an aerated Fenton reactor. Journal of the Taiwan Institute of Chemical Engineers, v. 44, n. 2, p. 310-216, 2013.

SZABÓ, R.K.; MEGYERI, C.; ILLÉS, E.; GAJDA-SCHRANTZ, K.; MAZELLIER, P.; DOMBI, A.. Phototransformation of ibuprofen and ketoprofen in aqueous solutions. Chemosphere, v. 84, n. 11, p. 1658-1663, 2011.

TAMBOSI, J. L. Remoção de fármacos e avaliação de seus produtos de degradação através de tecnologias avançadas de tratamento. 2008. 139 f. Tese (Doutorado em Engenharia Química) - Centro Tecnológico da Universidade Federal de Santa Catarina. 2008.

TAMBOSI, J. L.; YAMANAKA, L. Y.; MOREIRA, R. F. P. M.; JOSÉ, H. J.; SCHRÖDER, $H$. F. R. Recent research data on the removal of pharmaceuticals from sewage treatment plants (STP). Química Nova, v. 33, n. 2, p. 411-420, 2010.

TARR, M. A. Chemical degradation methods for wastes and pollutants - environmental and industrial applications. New York: Marcel Dekker, 2003.

TERNES, T. A. Occurrence of drugs in German sewage treatment plants and rivers. Water Research, v. 32, n. 11, p. 3245-3260, 1998.

TONKES, M.; GRAAF, P. J. F.; GRAANSMA, J. Assessment of complex industrial effluents in the Netherlands using a whole effluent toxicity (or wet) approach. Water Science and Technology, v. 39, n. 10-11, p. 55-61, 1999.

TROVÓ, A.G.; NOGUEIRA, R. F. P; AGUERA, A.; FERNANDEZ-ALBA, A. R.; SIRTORI, C.; MALATO, S. Degration of sulfamethoxazole in water by solar photophenton. Chemical and toxicological evaluantion. Water Research, v. 43, n. 16, p. 3922-3931, 2009. 
VOGNA, D.; MAROTTA, R.; NAPOLITANO, A.; ANDREOZZI, R.; D'ISCHIA, M. Advanced oxidation of the pharmaceutical drug diclofenac with $U \mathrm{UV} / \mathrm{H}_{2} \mathrm{O}_{2}$ and ozone. Water Research, v. 38, n. 2, p. 414-422, 2004.

WANGA, L.; XUA, H.; COOPERA, W. J.; SONG, W. Photochemical fate of betablockers in NOM enriched waters. Science Science of the Total Environment, v. 426, p. 289-295, 2012.

WRIGHT, H. B.; CAIRNS, W. L. Ultraviolet Light. In: Regional symposium on water quality: effective disinfection. Lima, CEPIS/OPS, 1998.

XAVIER, H. T. Farmacologia do fibratos. Arquivos Brasileiros de Cardiologia, v. 85, p. 15-16, 2013.

YAMAMOTO, H.; NAKAMURA. Y.; MORIGUCHI, S.; NAKAMURA, Y.; HONDA, Y.; TAMURA, I.; HIRATA, Y.; HAYASHI, A.; SEKIZAWA, J. Persistence and partitioning of eight selected pharmaceuticals in the aquatic environment: Laboratory photolysis, biodegradation, and sorption experiments. Water Research,v. 43, n. 2, p. 351-362, 2009.

YU, T.; LIN, A. Y.; PANCHANGAM, S. C.; HONG, P. A.; YI, P. Y.; LIN, C. Biodegradation and bio-sorption of antibiotics and non-steroidal anti-inflammatory drugs using immobilized cell process. Chemosphere, v. 84, n. 9, p. 1216-1222, 2011.

YUAN, F.; HU, C.; XUEXIANG, H.; QU, J.; YANG, M. Degradation of selected pharmaceuticals in aqueous solution with UV and $\mathrm{UV} / \mathrm{H}_{2} \mathrm{O}_{2}$. Water Research,v. 43, n. 6, p. 1766-1774, 2009.

YUAN, $\mathrm{H}$.; ZHANG, Y.; ZHOU, X. Degradation of Bezafibrate with $\mathrm{UV} / \mathrm{H}_{2} \mathrm{O}_{2}$ in surface water and wastewater treatment plant effluent. CLEAN - Soil, Air, Water, v. 40, n. 3, p. 239-245, 2012.

ZENG, C.; JI, Y.; ZHOU, L.; ZHANG, Y.; YANG, X. The role of dissolved organic matters in the aquatic photodegradation of atenolol. Journal of Hazardous Materials, v. 239-240, p. 340-347, 2012.

ZHANG, Y.; GEISSEN, S.; GAL, C. Carbamazepine and diclofenac: Removal in wastewater treatment plants and occurrence in water bodies. Chemosphere, v. 73, n. 8, p. 1151-1161, 2008.

ZHANG, Y.; LEI, Z.; CHAO, Z.; QI, W.; ZUNYAO, W.; SHIXIANG, G.; JI, Y.; YANG, X. Photoreactivity of hydroxylated multi-walled carbon nanotubes and its effects on the photodegradation of atenolol in water. Chemosphere, v. 93, n. 9, p. 1747-1754, 2013. 